\title{
Fundamentals and Scopes of Doped Carbon Nanotubes Towards Energy and Biosensing Applications
}

\author{
Alexandru Muhulet ${ }^{1}$, Florin Miculescu ${ }^{1 *}$, Stefan Ioan Voicu ${ }^{2 *}$, Fabian Schütt, ${ }^{3}$ Vijay Kumar \\ Thakur $^{4 *}$ Yogendra Kumar Mishra ${ }^{3 *}$
}

${ }^{1}$ Faculty of Materials Science, University Politehnica of Bucharest, Splaiul Independentei 313, 011061

Bucharest, Romania

${ }^{2}$ Faculty of Applied Chemistry and Materials Science, University Politehnica of Bucharest, Gheorghe Polizu 1-

7, 011061 Bucharest, Romania

${ }^{3}$ Functional Nanomaterials, Institute for Materials Science, Kiel University, Kaiserstr. 2, D-24143, Kiel, Germany

${ }^{4}$ Enhanced Composites and Structures Center, School of Aerospace, Transport and Manufacturing, Cranfield

University, College Road, Cranfield MK43 OAL, UK

${ }^{*}$ Corresponding authors:

E-mail: f miculescu@yahoo.com, florin.miculescu@upb.ro (Florin Miculescu)

E-mail: svoicu@gmail.com, stefan.voicu@upb.ro (Stefan Ioan Voicu)

E-mail: Vijay.Kumar@cranfield.ac.uk (Vijay Kumar Thakur)

E-mail: ykm@tf.uni-kiel.de (Yogendra Kumar Mishra) 


\begin{abstract}
Since their first allusion, carbon nanotubes have attracted significant research interest, especially with respect to composite manufacturing as a filler material for enhancing their mechanical and electrical properties. Several methods have been developed for modifying the electrical properties of carbon nanotubes such as CNTs wall's carbon atoms substitution with other appropriate atoms including engineering of their outer surfaces by covalent and noncovalent molecules, such as CNTs channel filling and nano-chemical reactions therein. CNTs with tailored electrical conduction open large perspectives for their applicabilities in advanced technologies. Taking into consideration the innovative advantages of pure and hybrid CNTs, in this article we have comprehensively reviewed the latest state-of-art research developments in the direction of different synthesis strategies, structure-property relationships, and advanced applications towards energy storage, supercapacitors, electrodes, catalytic supports, as well as biosensing.
\end{abstract}

Keywords: doped carbon nanotubes; energy storage; catalytic support; supercapacitor electrodes. 


\section{Introduction}

Since the discovery by Iijima[1-4], carbon nanomaterials and especially nanotubes (CNTs) have attracted very significant research attention in a number of applications, especially in composites manufacturing as a result of enhanced mechanical, thermal, and electrical properties[5-26]. The extraordinary physical properties of carbon nanotubes and their different variants, such single-walled carbon nanotubes (SWCNT), double-walled carbon nanotubes (DWCNT), multi-walled carbon nanotubes (MWCNT), etc. are attributed to their inherent morphological alignments and structural characteristics[27-32]. Doping in carbon nanotubes offers inclusion of further functionalities which extend their utilizations in further advanced technological applications, such as in water purification[33], drug delivery[34,35], gene transfer[36], biological imaging[37-39], adsorption[40], transparent conducting films[41], advanced field electronic field (FET) devices,[42] and in many others.

Besides their materials reinforcing advantages, further research has explored conductive properties of doped carbon nanotubes[43-50] Recently, several strategies have been developed for modifying the electronic properties of CNT's by substituting carbon atoms at the walls with other appropriate atoms including the outer entire nanotube surface modification by covalent and noncovalent molecules, or CNT channel filling and nano-chemical reactions inside the CNTs[51-56]. In order to improve the electrical properties of nanotubes, the most common used doping elements are nitrogen[57-59] and boron[60-62]. Figures 1 and 2 demosntrate the single $\mathrm{N}$ atom doped SWNT structures with the Bader charge transfers[58] and B-N co-doping $(5,0)$ and $(4,0)$ SWCNTs[60].

X-ray photoelectron spectroscopy (XPS) has been mainly followed to study the changes in nitrogen atoms chemical state in the structure of $\mathrm{N}$-doped multiwall carbon nanotubes $(\mathrm{CNx}-$ MWCNTs) that result from the impact of the pulsed ion beam at numerous parameters of the beam. The earlier study has indicated that a single pulse ion beam irradiation with energy densities of $0.5,1$, and $1.5 \mathrm{Jcm}^{-2}$ leads to a restructuring of the nitrogen from the pyridinic and pyrrolic configuration to the graphitic state. Maximum changes in nitrogen atoms chemical state in CNx-MWCNTs structure were observed for ten pulses at $1.5 \mathrm{Jcm}^{-2}$. Following this irradiation strategy, controlled removal of nitrogen embedded in the structure of the walls of CNx-MWCNTs can be achieved to obtain variety of carbon nanostructures (e.g., pyridinic, pyrrolic, graphitic) with controlled doping levels. The results showed that the use of the pulsed ion beam is an effective tool for the modification of $\mathrm{N}$ defects in the structure of $\mathrm{CNx}$ - 
MWCNTs[63]. Other studies were focused on the synthesis of N-doped carbon nanotubes using natural hydrocarbons (camphor, turpentine oil, eucalyptus oil, neemoil, and sesame oil, etc.) as the starting precursors that are easily available on the market and have a much lower costs than conventional fossil hydrocarbons based precursors[64]. Using these natural precursor, high-yield synthesis of aligned-stacked branched nitrogen-doped carbon nanotubes has been successfully realized. Synthesis of higly aligned doped CNTs was confirmed by the SEM image of nanostructures as shown in Figure 3. The SEM morphologies clearly demostrate that the newly synthesized material are composed of aligned-stacked bN-CNTs that were directly grown without any additional substrate inside the inner wall of the CVD quartz tube. High-resolution TEM (HR-TEM) was used to analyse individual N-CNTs and bN-CNTs (Figure 4) which succesfully revealed the shape and position of the Fe catalyst nanoparticle, internal morphology, branching structure, etc., of the synthesized dpoed CNTs. The XPS spectroscopy was further used to study the structure of N-CNTs particulalry to identify the amount of nitrogen as well as the bonding environment in aligned-stacked bN-CNTs (Figure 5). The XPS studies confirmed the presence of elemental C $1 \mathrm{~s}, \mathrm{~N} 1 \mathrm{~s}, \mathrm{Fe} 2 \mathrm{p}$ and $\mathrm{O} 1 \mathrm{~s}$, with corresponding energies values at 284.5, 400.9, 707.2 and $529 \mathrm{eV}$, respectively[64]. The growth mechanism for the synthesis and formation of aligned-stacked bN-CNTs has been presented and briefly discussed (Figure 6)[64].

The doping processes of carbon nanotubes were improved over time, accompanied by molecular modelling calculations and simulations[61,65-68]. Figure 7 shows the strcuture of Si-doped $(n, n) n=3-5$ carbon nanotubes along with full geometrical optimization obtained through first-principle simulations on silicon-doped armchair single-walled carbon nanotubes of various diameters[68]. Other studies have focused on the usage of different electron acceptor dopants, such as fullerenes[69] and $\mathrm{Si}[70]$ or electron donors, such as $\mathrm{Pt}[71,72]$. In this review article we present a brief overview of the latest investigations in the direction of applications of doped carbon nanotubes, such as energy storage, electrodes, catalytic support, supercapacitors and biosensing applications.

\section{Applications of doped carbon nanotubes}

\subsection{Doped CNTs for electrochemical energy storage}

Based on their electrochemical properties, transition metals-based compounds and carbon nanomaterials have been extensively studied since their first reporting, and they have demonstrated the potentials for electrode materials with relevant efficiencies to be used in 
lithium-ion batteries (LIBs). Also, because of their effective processing costs, outstanding electronic characteristics, high structural stability and compact pulverizing problems, the transitional metals nitrides (TMNs) have been widely used as anode materials for LIBs. Thus the transition metal doped carbon nanomaterials have opened a lot of scope towards electrochemical energy storage materials in advanced batteries. Abbas et al., have reported about MoN-decorated nitrogen doped-carbon nanotubes anode and their performances for lithium-based energy storage devices. MoN nanoparticles with average diameter around $25 \mathrm{~nm}$ were dispersed onto the surface of nitrogen doped carbon nanotubes to achieve a high performance anodic MoN/N-CNT material[73]. The fabricated hybrid composite materials were found to exhibit the high reversible capacity anode with long life cycle and excellent rate performance. A reversible capacity of $1232 \mathrm{mAhg}^{-1}$ was maintained after 200 cycles at a current density of $100 \mathrm{~mA} \mathrm{~g}^{-1}$. The electrode testing at higher current densities of $1000 \mathrm{mAg}^{-1}$, $1250 \mathrm{mAg}^{-1}$ and $1500 \mathrm{~mA} \mathrm{~g}^{-1}$ (for 20 cycles each) revealed that the electrode still holds high specific capacity of $1184.7 \mathrm{mAhg}^{-1}, 1096.5 \mathrm{mAhg}^{-1}$ and $989.5 \mathrm{mAhg}^{-1}$ respectively. The electrochemical performance of this newly fabricated composite material has been found to be much superior in comparison to pristine $\mathrm{MoN}, \mathrm{N}-\mathrm{CNT}, \mathrm{MoO}_{2}$ and $\mathrm{MoO}_{2}$ / functionalized-CNT anode materials which opens large scope towards utilization of such composites in electrochemical energy storage[73].

Recently, transition metals oxides have gained significant attraction as anodic materials in lithium-ion batteries (LIBs) due to their high theoretical capacities, low costs and eco-friendly usage. They have been found to act as a hierarchical hollow backbone, buffer, and conductive additive as well. Due to their enhanced reactivity and electrical conductivity, N-doped carbon nanotubes (N-CNTs) are now-a-days rather more preferred in contrast to pure CNTs[74]. Yue et al., have studied in detail about the properties of coaxial manganese dioxide@N-doped carbon nanotubes for applications in lithium ion batteries as anode material. The addition of $\mathrm{MnO}_{2}$ nanoparticles resulted in a superior composite anodic material in form of $\mathrm{MnO}_{2}-\mathrm{N}-\mathrm{CNT}$ which demonstrated a specific capacity of $1415 \mathrm{mAhg}^{-1}$ after 100 cycles at the current density of $100 \mathrm{mAg}^{-1}$, which is found to be superior than the commercial $\mathrm{MnO}_{2}-\mathrm{CNT}$ s or pristine $\mathrm{MnO}_{2}$ anodes as depicted in Figure 8[74]. Figure 9 shows the schematic for the facile synthesis of the $\mathrm{MnO}_{2} @ \mathrm{~N}-\mathrm{CNT}$ nanocomposites. Figure 10 cumulatively overviews the morphological and structural (SEM and TEM images) evolutions of the synthesized N-CNT and $\mathrm{MnO}_{2} @ \mathrm{~N}-$ CNT which confirmed the successful formation of $\mathrm{MnO}_{2}$ nanosheets which are uniformly coated with N-CNT. X-ray photoelectron spectroscopy (XPS) was used to further investigate 
the contents of $\mathrm{N}$ and $\mathrm{C}$ in the $\mathrm{MnO}_{2} @ \mathrm{~N}-\mathrm{CNT}$ (Figure 11) which also confirmed the existence of $\mathrm{Mn}, \mathrm{O}, \mathrm{N}$ and $\mathrm{C}$ elements in the hybrid material.

Although significant progress has been made in the field of anodic materials but still challenge is open for researchers to improve the performance of long-life anodic active materials for lithium ion batteries (LIBs) because of multiple issues that result from the volumetric expansion of electrode materials during lithiation-delithiation process. Li et al., have studied about nitrogen doped carbon nanotubes encapsulated $\mathrm{MnO}$ nanoparticles derived from metal coordination polymer as novel compound material for high performance LIB[75]. The MnO/NCNTs hybrid materials were synthesised by $\mathrm{MnO}$ nanoparticles (20-50 $\mathrm{nm}$ ) encapsulation process that enables necessary separation between nanoparticles (prohibiting their close agglomerations). Using this strategy, they could easily overcome with several common issues, such as disintegration, volumetric expansion during lithium ions insertion-extraction processes, $\mathrm{MnO}$ dissolution, aggregation as well as with allowance of more volume expansion capabilities[75]. Figure 12 shows the schematic representation of the synthesis of $\mathrm{MnO} / \mathrm{N}-$ CNT. From SEM images it was found that the $\mathrm{MnO} / \mathrm{N}-\mathrm{CNT}$ morphology was very well retained after the heat treatment process. On the other hand, the TEM results demonstrated that a significant amount of MnO NPs were randomly dispersed in the CNTs with a peapod-like morphological arrangement (Figure 13). X-ray photoelectron spectroscopy (XPS) measurements were carried out to study the composition and surface chemical state of the $\mathrm{MnO} / \mathrm{N}-\mathrm{CNT}$ (in Figure 14) confirming the presence of all (Mn, N, C and O) elements in the composite. It was found that the content of nitrogen in the synthesized composites was around $2.5 \%$, while the molar ratio between $\mathrm{Mn}$ and $\mathrm{O}$ was almost close to 1 in the $\mathrm{MnO} / \mathrm{N}-\mathrm{CNT}$ nanocomposite specimen. The electrochemical performance of $\mathrm{MnO} / \mathrm{N}-\mathrm{CNT}$ was investigated as electrode material for lithium-ion batteries. The measurements revealed that the $\mathrm{MnO} / \mathrm{N}$ CNTs based composite exhibits discharge and charge capacities of 1,557.5 $\mathrm{mAhg}^{-1}$ and 1,171.0 $\mathrm{mAhg}^{-1}$ in the initial cycle at $100 \mathrm{mAg}^{-1}$, respectively (Figure 15). A reversible capacity of $450.2 \mathrm{mAhg}^{-1}$ was even maintained after increasing the current density to $5 \mathrm{Ag}^{-1}$. The capacity was steadily maintained at $804 \mathrm{mAhg}^{-1}$ even after 100 charge-discharge cycles at $1 \mathrm{Ag}^{-1}[75]$. Sharifi et al., have investigated the hierarchical self-assembled structures based on nitrogendoped carbon nanotubes as advanced negative electrodes for LIBs and three dimensional (3D) microbatteries[76]. In their work, the hierarchical structures based on carbon paper with attached multiwalled nitrogen-doped carbon nanotubes were successfully synthesized. These structures were decorated with hematite nanorods in order to get the innovative 3D 
architectures as negative electrodes for the lithium-ion batteries. Figure $\mathbf{1 6}$ shows the schematic representation of the adopted synthesis route for preparing the hierarchical HR/NCNTs/CP structures (a-f) and the corresponding SEM morphologies of the resulting NCNTs/CP (g) and HR/NCNTs/CP (h) electrodes. Here, the carbon paper works as a metal free 3D current collector, that ensures a good electrical contact between active material and the carbon fiber network. Using only N-doped carbon nanotubes onto the carbon paper, a high footprint area capacity of $2.1 \mathrm{mAhcm}^{-2}$ at $0.1 \mathrm{mAcm}^{-2}$ was successfully obtained. Hematite nanorods incorporation was found to increase the footprint area capacity to $\sim 2.25 \mathrm{mAhcm}^{-2}$ at $0.1 \mathrm{mAcm}^{-2}$. However, the repeated conversion/deconversion of $\mathrm{Fe}_{2} \mathrm{O}_{3}$ limited the energy efficiency of these hybrid electrodes, but still a footprint area capacity enhancement up to 1.95 $\mathrm{mAhcm}{ }^{-2}$ after 60 cycles at $0.3 \mathrm{mAcm}^{-2}$ was effectively obtained[76].

\subsection{Doped CNTs for fuel cells}

Fuel cells are getting popular day-by-day for energy storage applications but the electrochemical performances of the polymer electrolyte membranes for fuel cells are limited usually by the oxygen reduction reaction (ORR) process. The platinum-based catalysts are generally used as efficient electro-catalysts for ORR, but their high production cost and poor durabilities are the strong disadvantages and the doped carbon nanomaterials could offer better opportunities in this direction. The synergetic effect of simultaneous $\mathrm{N}$ and $\mathrm{S}$ doping of CNT ( $\mathrm{S}, \mathrm{N}-\mathrm{CNTs}$ ) was investigated in order to enhance the ORR activity in both the acidic and the alkaline media and was compared to that of just N-CNTs as reference. The introduction of S in $\mathrm{N}$-CNTs changes the state of the N species, creating an asymmetrical spin and charge density. This leads to a synergetic effect of $\mathrm{N}$ and $\mathrm{S}$, which facilitates the electron transfer in the ORR. Moreover, the S, N-CNTs exhibit excellent durability and remarkable tolerance ability to methanol crossover effects in acidic and alkaline solutions, which predicts a promising foreground instead of Pt-based catalyst for the commercial application in fuel cells[77]. Several methods for the synthesis of S, N-CNTs have been reported in literature. For example, Wei et al., reported that the transformation from FeS/Fe3C@S, N-C nanotubes to FeS/Fe3C@S, N-C $\mathrm{g}(50)$ nanosheets under a glucose protective pyrolysis strategy could yield an improved oxygen reduction performance. Using this facile strategy, the walls of FeS/Fe3C@S, N-C nanotubes are unrolled to obtain $\mathrm{FeS} / \mathrm{Fe} 3 \mathrm{C}$ nanoparticles coupled to $\mathrm{S}, \mathrm{N}$ dual doped carbon nanosheets (FeS/Fe3C@S, N-C g(50)) with relatively large surface area and high doping level. FeS/Fe3C@S, N-C g(50) exhibited an onset potential of $0.938 \mathrm{~V}$, together with low peroxide 
yield, good selectivity and durability. S, N dual doped carbon nanosheets and $\mathrm{FeS} / \mathrm{Fe} 3 \mathrm{C}$ nanoparticles contributed to an enhanced oxygen reduction activity[78]. The preliminary studies performed on porous carbon network like materials showed a significant improvement related to ORR activity at $\mathrm{S}, \mathrm{N}$ simultaneous doping using commercially available monomers (acrylonitrile and methyl methacrylate) and the traditional radical polymerization method. The as-prepared S, N doped porous carbons exhibited high specific areas of up to $681 \mathrm{~m}^{2} \mathrm{~g}^{-1}$ and high $\mathrm{N}$ and $\mathrm{S}$ contents of up to $4.9 \%$ and $0.9 \%$, respectively. As electrocatalysts in alkaline media, these porous carbons demonstrated high ORR activity with half wave potential of up to $0.825 \mathrm{~V}$ vs. RHE, electron transfer number of 3.9 and good tolerance to methanol. As an air cathode for $\mathrm{Zn}$-air batteries, these porous 3D carbons showed peak power density of 10.7 $\mathrm{mWcm}^{-2}$ at $17.4 \mathrm{mAcm}^{-2}[79]$. The obtained results are relatively superior to earlier reports on $\mathrm{N}$ doped[80-84] or S doped carbon materials[85-87]. The synergistic effects between $\mathrm{N}, \mathrm{S}$ and B were also thoroughly studied towards their influence on the ORR. For example, a N/S/Bdoped graphitized carbon encased Fe composite (Fe-N/S/B-C) was successfully synthesized by facile pyrolyzing a mixture of thiourea, boric acid and $\mathrm{FeCl}_{3} \cdot 6 \mathrm{H}_{2} \mathrm{O}$, followed by subsequent etching with sulfuric acid. Following this simple and effective strategy, the Fe-N/S/B-C catalyst exhibits a hierarchical porous structure, which is highly beneficial for the favorable mass transfer and a high doping-level for N, S and B for high the efficient ORR active sites. The Fe-N/S/B-C material exhibits an impressive ORR activity for its half-wave potential of $0.1 \mathrm{~V}$, which is $36 \mathrm{mV}$ or $19 \mathrm{mV}$ higher than that of the corresponding single or dual doped counterparts (Fe-N-C or Fe-N/S-C) and $31 \mathrm{mV}$ higher than that of $\mathrm{Pt} / \mathrm{C}$ catalyst, respectively[88]. In another study, the onion-derived N, S self-doped nanoporous carbon spheres (NSC) were synthesized via a simple hydrothermal and subsequent pyrolysis process, forming an efficient metal-free electrocatalyst. The typical NSC with a high BET specific surface area of $1558 \mathrm{~m}^{2} \mathrm{~g}^{-1}$, contains 6.23 at.\% $\mathrm{N}$ and 0.36 at.\% $\mathrm{S}$, and possesses high concentrations of pyridinic and graphitic nitrogen species. The resulting $\mathrm{N}$ and $\mathrm{S}$ co-doped nanoporous carbon showed excellent electrocatalytic activity, and long durability when they were employed as metal-free catalyst for ORR in alkaline media due to a 4-electron mechanism with an onset potential of $0.88 \mathrm{~V}$ (vs. RHE), and a superior stability comparable to commercial $\mathrm{Pt} / \mathrm{C}$ catalyst. The high electrocatalytic activity is attributed to not only the synergistic effect of $\mathrm{N}$ and $\mathrm{S}$ dual doping in carbon and the sufficient active sites, but also its high BET specific surface area and suitable microporous architecture[89]. 
Furthermore, the metal alloy nanoparticles encapsulated in nitrogen and sulfur-codoped peapod-like carbon nanotubes with a diameter within the range of ca. $15 \mathrm{~nm}$ to $100 \mathrm{~nm}$ were prepared by direct pyrolysis of the $\mathrm{Fe}_{3}\left[\mathrm{Co}(\mathrm{CN})_{6}\right]_{2} / \mathrm{TCA}$ precursor. Electrochemical measurements showed that sulfur co-doping with nitrogen dramatically enhances the catalytic activity towards oxygen reduction reaction compared with that of FeCo alloy encapsulated in $\mathrm{N}$-doped only carbon nanotubes. The specimen prepared at a pyrolysis temperature of $800{ }^{\circ} \mathrm{C}$ delivered the best performance among the entire series, exhibiting a more positive half-wave potential of $+0.838 \mathrm{~V}$, nearly $100 \%$ enhancement in kinetic current, a higher operation stability and stronger immunity to the negative impacts of fuel crossover than the commercial $\mathrm{Pt} / \mathrm{C}$ catalysts. The remarkable improvement of catalytic activity was understood in terms of the increase of charge transfer from encapsulated FeCo alloy nanoparticles to the thin walls of CNTs upon the additional sulfur doping besides nitrogen[90]. From another synthesis strategy, N, S co-doped carbon based quantum dots (NSCDs) were initially synthesized[91], which were then self-assembled on exfoliated multiwalled carbon nanotubes in order to prepare N- and Sco-doped multiwalled carbon nanotubes $(\mathrm{NSCD} / \mathrm{C})$ in the final step. Morphological studies revealed the existence of surface defects on the CNT sidewalls, which was again confirmed by Raman spectroscopy analysis. The electrochemical studies confirmed that upon optimization of the NSCD/C catalyst, the ORR kinetics could be drastically improved with $\mathrm{E}_{\text {onset }}$ of $0.87 \mathrm{~V}$ vs RHE and $\mathrm{J}_{\mathrm{L}}$ of $5.0 \mathrm{~mA} \mathrm{~cm}{ }^{-2}$ in alkaline condition. Additionally, the catalyst shows a single step, nearly 4-electron transfer pathway, indicating first order kinetics similar to that of $\mathrm{Pt} / \mathrm{C}$ based catalysts[92]. Moreover, the incorporation of $\mathrm{N}$ and $\mathrm{S}$ into defects of CNTs generated by different ball milling periods was investigated. When the graphitic structure of CNTs collapses, the amount of $\mathrm{N}$ actually incorporated into the $\mathrm{C}-\mathrm{C}$ network can be increased by co-doping with S. The ORR activity of the N/CNT increases with increasing content of $\mathrm{N}$ in the catalysts, both, in the acid and the alkaline media. As a consequence, the co-doping with $\mathrm{S}$ results in more active catalysts for the ORR in acid media as the introduced $\mathrm{S}$ promotes the incorporation of surface $\mathrm{N}[93]$. With respect to lithium sulfur batteries, it has been shown that the performance can be greatly improved by the use of nitrogen doped carbon nanotubes (N-CNTs) based cathode. By manipulating the number of defects in its structure, the usage of N-CNTs results in a better dispersion of sulfur particles on the N-CNTs surfaces and thus a higher electrical conductivity compared with their non-doped counterparts. This directly explains, why the N-CNTs/S composites show an improved performance for the storage of sulfur. The specific discharge capacity was maintained at $625 \mathrm{mAh} \mathrm{g}^{-1}$ and $513 \mathrm{mAh} \mathrm{g}^{-1}$ after 100 cycles at $0.2 \mathrm{C}$ and $0.5 \mathrm{C}$, respectively, which was about 2 times as high as that of the pure CNTs. 
This method is proved to be a promising way to develop cathode materials for lithium sulfur batteries[94]. The co-doped S, N-CNTs were also prepared via a simple solution method and studied as a cathode material for lithium/sulfur batteries. By taking advantage of the selfweaving behavior of CNTs and hence N-CNTs in present work, the binders and the current collectors are rendered unnecessary in the cathode, thereby simplifying its manufacturing and increasing the sulfur weight ratio in the electrode. As a core in the composite, the N-CNTs provide a highly conductive and mechanically flexible framework, thereby enhancing the electronic conductivity and consequently the high rate capability of the material[95]. Besides the improvement related to ORR and lithium sulfur batteries, the presence of sulfur was also found to enhance the nitrogen doping, as well as the magnetic properties of $\mathrm{CNTs}[96]$.

Hydrogen production, by employing the water electrolysis process, using renewable electricity has often been proposed as an ecological route for energy storage/ harvesting. However, starting these premises, the kinetics of oxygen evolution reaction (OER), the anodic reaction in water electrolysis, still remains a big challenge with respect to electrode development for ensuring successful applications. Xie et al., have reported about promoting the effect of nitrogen doping on carbon nanotube-supported $\mathrm{RuO}_{2}$ nanoparticles, which were applied in the electrocatalytic OER[97]. In this work, the $\mathrm{RuO}_{2}$ nanoparticles onto oxygen or nitrogen functionalized carbon nanotubes (O-CNTs or N-CNTs) were synthesized and used for enhancing OER performances in alkaline media $(0.1 \mathrm{M} \mathrm{KOH})$. An organic metal chemical vapour deposition (CVD) process was used to synthesize the catalysts by using ruthenium carbonyl $\left(\mathrm{Ru}_{3}(\mathrm{CO})_{12}\right)$ as ruthenium precursor. The obtained $\mathrm{RuO}_{2} / \mathrm{O}-\mathrm{CNTs}$ and $\mathrm{RuO}_{2} / \mathrm{N}-\mathrm{CNTs}$ nanocomposites were characterized using different techniques in order to confirm the structureactivity correlations. Cyclic voltammetry, sweep voltammetry, and chronopotentiometry characterization were used to demonstrate that the OER activity which revealed that the stability was higher with the incorporation of nitrogen-containing functional groups on CNTs than without. It was also observed that the presence of $\mathrm{RuO}_{2}$ nanoparticles significantly reduces the carbon corrosion[97].

For the fuel cells, the $\mathrm{H}_{2}$ oxidation kinetics is quite simple requiring just a small quantity of catalyst at the anode, however, the slow oxygen reduction reaction (ORR) on the cathode is very complex. Indeed, it is one of the most imperative step, that limits the energy conversion efficiency of a fuel cell and as a result requires a high amount of catalyst (e.g. Pt). In their work, González et al., have reported about the $\mathrm{O}_{2}$ reduction on electrodes modified with nitrogen 
doped CNTs synthesized with different metal catalysts [98]. In this work, the electroreduction of $\mathrm{O}_{2}$ was studied using several nanomaterials, including $\mathrm{N}$-doped CNTs which were synthesized using a CVD technique. The $\mathrm{Fe}_{2} \mathrm{O}_{3}$ nanoparticles, $\mathrm{Co}$ nanoparticles and $\mathrm{MoO}_{3}$ were supported on a sol-gel polymer and were subsequently employed as seed-catalyst for the growth of N-CNTs. The catalyst and ethylenediamine percentage was studied in N-CNTs synthesis and their influences on the oxygen reduction reaction (ORR) in alkaline medium. Raman spectroscopy and X-ray photoelectron spectroscopy (XPS) were used to confirm the results and they successfully indicated that N-CNTs were catalysed by $\mathrm{MoO}_{3}$ and presented the highest amount of pyridinic-type nitrogen $(\sim 39 \%)$. The electrocatalytic activity of N-CNTs for the ORR was evaluated by rotating disk electrode (RDE) analysis. The electrochemical results showed that $\mathrm{N}-\mathrm{CNT}$ s catalysed with $0.2 \mathrm{wt} . \% \mathrm{MoO}_{3}$ and synthesized with $19.5 \mathrm{wt} . \%$ of ethylenediamine exhibited higher activity for ORR than N-CNTs catalysed with Co nanoparticles or $\mathrm{Fe}_{2} \mathrm{O}_{3}$ nanoparticles[98].

Liu et al., have reported their study on arsenic (As)-doped, As and N-co-doped carbon nanotubes as highly active and durable electrocatalysts for $\mathrm{O}_{2}$ reduction in alkaline medium in order to develop more efficient metal free electrocatalyst cathodes for fuel cells[99]. In this paper, the As-containing carbon nanotubes were found to exhibit considerably enhanced activity and long-term durability for the ORR, indicating that the doping of As or co-doping As- $\mathrm{N}$ into carbon nanotubes matrix could significantly improve the ORR activity of carbon materials due to the synergetic effects between As and $\mathrm{N}$ atoms. Moreover it was noted that As-containing carbon nanotubes displayed much better methanol tolerance, demonstrating a very high potential for application in future methanol fuel cells MFCs[99].

Sharifi et al., have reported about maghemite nanorods (MR) anchored on a 3D nitrogen-doped CNTs foam/sponge as a scalable direct electrode for water oxidation[100]. In this work, a hybrid catalyst 3D electrode composed of needle shaped maghemite nanorods firmly anchored to nitrogen doped carbon nanotubes N-CNTs was used for electrochemical water oxidation. The N-CNTs were grown on a conducting carbon paper (CP), which simultaneously acts as an imperative current collector. Figure 17 shows the schematic for the synthesis route of the hierarchical MR@NCNTs/CP structures (a-f). Raman spectroscopy, XPS spectrum and TEM studies were also performed to confirm the successful synthesis of the MR@NCNTs/CP (Figure 18). A $0.1 \mathrm{M} \mathrm{KOH}$ solution was used to investigate the electrocatalytic OER activity of MR@NCNTs/CP in a standard three electrode system. Different types of reference samples 
were analysed in detail and compared to the final results. Figure 19 shows the different results including the Raman spectrum and SEM image of MR@NCNTs/CP (after being used in the stability test for $300 \mathrm{~min}$ ). In $0.1 \mathrm{M} \mathrm{KOH}$ alkaline media, the hybrid electrode was found to reach a current density of $1 \mathrm{mAcm}^{-2}$ (geometric surface) at an over potential of $362 \mathrm{mV}$ performing also a high chronoamperometric stability. These electrochemical results indicated the proficient catalytic processes at the surface of the maghemite nanorods, and demonstrate the existence of a very high surface area due to the 3D electrode design[100].

Simultaneous doping of multiwall carbon nanotubes with $\mathrm{S}$ and $\mathrm{N}$ atoms was also found to improve various effects and also enhance catalytic performances for ORR reaction in acid or alkaline media[93]. The studied CNTs in this work had defects in graphic structures and the N and $\mathrm{S}$ heteroatoms were included in the defects areas leading to active catalyst structures for ORR reaction. Usage of precursors containing both $\mathrm{N}$ and $\mathrm{S}$ atoms in their chemical structure, like thiourea, leads to enhanced incorporation of $\mathrm{N}$ atoms comparing to precursors containing only $\mathrm{N}$ atoms. As a consequence of this noted aspect, the ORR activity for S, N-MWCNTs composites were found to be higher compared to the one for N-MWCNTs. This activation effect inducted by the presence of $\mathrm{S}$ atoms was observed to be more like impregnated in the alkaline media than in acid media[93].

Protons exchange membranes fuel cells (PEMFCs) development has been found to face crucial issues in using expensive materials like Pt and its alloys in the structure of calalysts both for ORR cathode reaction or hydrogen oxidation reaction (HOR) reaction at the anode[101]. Therefore, an important challenge in this research area is the development of low cost catalyst with catalytic activities comparable to Pt and long life performances in the extreme cathode media of PEMFCs fuell cells. Carbon nanotubes doped with nitrogen (N-CNTs), synthesized by chemical vapours deposition CVD in the pressence of Fe (II) fthalocyanine (acting as the metalic catalyst for nanotubes) were proposed to be an important candidate for noble metal catalysts as replacement for the ORR reaction[101]. The synthesis was found to be possible in a single step reaction using a tube furnace starting from different precusrsors (aniline, diethylamine, ethylenediamine) as nitrogen sources. Vertical aligned N-CNTs were found to have the highest $\mathrm{N}$ content 4.33-6.58wt.\%. N-CNTs obtained from ethylenediamine proved to be the most electrochemically active species for the ORR reduction reaction in acid media. This very active type of catalyst possess unique properties due to the corrugated nanotubs 
structure with sufficient surface defects in combination with high procent of N-pyridinic and $\mathrm{N}$-pyridinic oxides[101].

The different effects of catalyst aging on the growth morphology and oxygen reduction activity of nitrogen-doped carbon nanotubes were also studied[102]. It was reported that the Fe/ $\mathrm{MgO}$ used in the N-CNTs synthesis could significantly influence their activity in ORR reaction at the fuel cells cathode. Also, it was observed that samples with maximum N-pyridinic/pyrrolic contents were the most active ones in the ORR reaction. The results suggested a direct relation with the surface composition function. The presence of a small amount of Fe and lack of $\mathrm{N}$ did not lead to an increased electroactivity for the ORR, while the presence of both Fe and $\mathrm{N}$ atoms lead to an improved catalytic activity for ORR. Also, decreasing the N-pyridinic/pyrrolic content was found to result in a lower catalytic activity suggesting that the presence and nature of $\mathrm{N}$-containing surface groups was more important in enhancing the ORR activity than the presence of metallic impurities[102].

Zhong et al., have reported their studies on the usage of nitrogen doped carbon nanotubes with encapsulated ferric carbide as an excellent electrocatalyst for oxygen reduction reaction in acid and alkaline media[103]. CNTs doped with $\mathrm{N}$ and Fe3C nanoparticles incapsulated inside the nanotubes were synthesised by direct pyrolysis of melamine and feric chloride. Figure 20 shows the schematic for (a) the synthesis route and (b) growth mechanism of Fe3C@NCNTs. SEM images of the samples prepared at (c) $600{ }^{\circ} \mathrm{C}$, (d) $680{ }^{\circ} \mathrm{C}$, (e) $700{ }^{\circ} \mathrm{C}$ and (f) $800{ }^{\circ} \mathrm{C}$. In this study, the TEM, HRTEM analysis and elemental-mapping were further used to characterize the nanoparticle-filled CNTs (Figure 21). The nanocomposite catalyst $\mathrm{Fe}_{3} \mathrm{C} @ \mathrm{~N}-$ CNTs were found to exhibit superior activity in ORR reaction in the PEMFC cathode. Also, the methanol tollerance and long term stability in alkaline and acid media were excellent. The $\mathrm{N}$ species distributed outside the N-CNTs surface were found to represent the active centers for $\mathrm{ORR}$, and the $\mathrm{Fe}_{3} \mathrm{C}$ ring with $\mathrm{C}$ species in exterior acts as a synergetic center. Figure 22 (a-c) shows three possible catalytic active sites presented in $\mathrm{FeNx} / \mathrm{C}$ and $\mathrm{NxC}$ catalysts while Figure 22 (d) shows the linear sweep voltametry (LSV) curves and electron transfer values.

Next to N-doped or S-doped CNTs, B-doped multiwalled carbon nanotubes (B-MWCNTs) have been synthesized by thermal treatment of MWCNTs in the presence of boric acid to be used as catalysts for ORR and OER in alkaline media[104]. TEM and XRD investigations showed that MWCNTs structures were not damaged during the doping process, and XPS 
spectrometry proved that B atoms were successfully doped in the MWCNTs structures. BMWCNTs materials with $2.37 \mathrm{wt} . \%$ boron content had superior catalytic activity both for ORR and OER in alkaline media[104]. Different types of supporting materials play a significant role in reducing the metal catalysts costs for ORR in alkaline media in fuel cells[105]. Cheng et al., have reported their studies on the usage of Ag nanoparticles on boron doped MWCNTs as a synergistic catalyst for the ORR in alkaline media. In this work, new support materials based on MWCNTs doped with boron and silver at different silver loadings (20/30/50wt.\%) were synthesized, using a very simple chemical method. Electrochemical results showed that all three materials had a catalytic influence on the ORR in alkaline media. Despite of all, the 20wt.\% silver containing material had the highest mass catalytic activity $\left(-1544.13 \mathrm{mAcm}^{-2} \mathrm{mg}^{-}\right.$ ${ }^{1} \mathrm{Ag}$ ) due to synergetic effect of Ag-B-MWCNTs and good Ag nanoparticles dispersion[105].

Song et al., have reported their studies on the development of new materials based on polypyrrole functionalized carbon nanotubes and phosphorus doped P-NCNTs as an alternative for non-metal electrocatalyst for enhancing ORR activity in alkaline media[106]. In their work, the P-NCNTs were very simply obtained by polypyrrole PPy and triphenilphosphane TPP pyrolisis in $\mathrm{N}_{2}$ current. N-pyridinic content was found to increase after $\mathrm{P}$ doping and improved the ORR activity. 1.1wt.\% phosphorus doped CNTs showed intense catalytic activity and longtime stability for ORR in alkaline media and also better methanol resistance comparing to simple N-CNTs and commercial Pt/C catalyst[106].

In order to decrease the costs for cathode electrocatalysts based on platinum materials used in fuel cells, a series of Si doped CNTs were synthesized from trimethylphenilsilane and toluene by thermal decomposition[107]. Electrochemical results demonstrated that the electrochemical activity of Si-CNTs was much higher in comparison to pure CNTs. The electrochemical activity was found to increase with the increase in Si content, but after a certain level of Si doping, the electrochemical activity dropped[107]. Sulphur-doped carbon nanotubes as catalysts for the oxygen reduction reaction in alkaline medium were also developed[108]. The electrocatalysts were synthesized by simultaneous annealing oxidized carbon nanotubes and pbenzenedithiol in nitrogen. The catalytic activity of S-CNTs in ORR reaction in alkaline media was evaluated using rotated ring disk electrode voltammetry. S-CNTs 900, the sample annealed at $900{ }^{\circ} \mathrm{C}$ showed excellent electrochemical performance for ORR with an onset potential of $0.082 \mathrm{~V}$, a high current density of $34.6 \mathrm{mAcm}^{-2}$ at $-0.35 \mathrm{~V}$, a dominant 4 electrons transfer mechanism as well as an excellent methanol tolerance and long-life performances. The 
obtained results were found to be very significant towards the development of S-CNTs catalysts in alkaline fuel cells[108].

Liu et al., have reported their study on the development of a new electro-Fenton gas diffusion cathode based on N-doped graphene@CNT composite materials[109]. The nitrogen doped graphene/carbon nanotubes composites (N-G/CNTs) showed high very activity and stability too. The results indicate that such nanoocmposites are a very valuable candidate for cathode materials in electro-Fenton processes with respect to wastewater treatment. On the investigating of the ORR reaction and using dimethylphtalate (DMP) degradation in aqueous media, it was observed that the activity of syntheiszed N-G/CNTs composite material was quite high as compared to C/CNTs. It was also found that for the lowest known cathodic DMP potential $(-0.2 \mathrm{~V})$, the degradation on the GDE (gas difusion electrode) for N-G/CNTs was 14, 19 and respectively, which is 54 times more efficient as compared to pristine graphite-GDE, graphene-GDE and CNTs-GDE. The energetic consumption was also highly reduced with: NG/CNTs $\left(2.56 \mathrm{Jmg}^{-1}\right)<$ graphite $\left(10.61 \mathrm{Jmg}^{-1}\right)<$ graphene $\left(12.23 \mathrm{Jmg}^{-1}\right)<$ CNTs $\left(38.35 \mathrm{Jmg}^{-}\right.$ ${ }^{1}$ )[109]. Modi et al., have reported their studies on the in situ nitrogen-doping of nickel nanoparticle-dispersed carbon nanofiber-based electrodes and its positive effects on the performance of a microbial fuel cell[110]. The in-situ nickel nanoparticles mediated nitrogen doping and dispersing processes in carbon nanofibers growth on active carbon fibers as substrate by using chemical vapours deposition CVD method, created a new nanocomposite $\mathrm{N}-\mathrm{Ni}-\mathrm{CNF}$ /CFs which were succesfully used as electrode material in microbial fuel cells (MFCs) for bioelectricity production. The MFCs performances were considerably improved when using $\mathrm{N}$-doped material. The maximum power density was found to be almost double in the case of N-Ni-CNFs/CNFs $\left(1850 \pm 20 \mathrm{mWm}^{-2}\right)$ when compared to the pure material (Ni$\mathrm{CNFs} / \mathrm{CNFs}$ ). $\mathrm{N}$ atoms doping was also found to improve the electrocathalitic activity for ORR at the cathode[110]. Hiltrop et al., reported their studies on Palladium deposited on functionalized CNTs for the electrooxidation of ethanol in alkaline media[111]. It was reported that the palladium deposition on nitrogen doped or oxygen functionalized carbon nanotubes structures can successfully be used as anodic catalyst material for ethanol oxidation reaction. Due to the intense interactions between Pd nanoparticles and N-CNTs, the Pd/N-CNTs anode material $\left(0,85 \%\right.$ wt.\% Pd NPs loading) showed a higher current density of $517 \mathrm{AgPd}^{-1}$ compared to Pd/O-CNTs (0,85\% wt.\% Pd NPs loading), which was $421 \mathrm{AgPd}^{-1}$. However, unfortunately the electrocatalytic performances were found to be gradually deteriorating in an 80 hours interval[111]. 
Direct methanol fuel cells (DMFCs) are also a scientific intensive investigations subject because they could become promising power sources for portable devices due to their simplicity, easy operability, low operation temperatures and high energetic densities[112]. Until now, platinum is the most used anodic material and that is the reason for numerous challenges for lowing production costs for this type of catalyst. A new $\mathrm{Pt}-\mathrm{RuO}_{2}$ catalyst was obtained using 1.4-diaminoantrachinone (DAAQ) functionalized multiwall carbon nanotubes DAAQ-MWCNTs as support. Different characterization technique such as Raman and FTIR were used to confirm the immobilization of DAAQ molecule on the surface of MWCNTs. Figure 23 shows the FT-IR spectra of (a) DAAQ and (b) DAAQ-MWCNTs. The Pt-RuO nanoparticles were obtained in different morphologies via involving polyols and microwaves assisted irradiation (Figure 24). Highly crystalline face centred cubic (FCC) structures of platinum and low crystalline $\mathrm{RuO}_{2}$ nanoparticles were deposited on DAAQ functionalized MWCNTs. The thus obtained electrocatalyst showed a high active surface $\left(79.8 \mathrm{~m}^{2} \mathrm{~g}^{-1}\right)$ and electrocatalytic activity for methanol oxidation reaction (MOR) of $29.4 \mathrm{mAcm}^{-2}$ [112].

\subsection{Doped CNTs for catalytic applications}

The effect of Manganese doping on performances and structures evolution for NiMgO catalysts used in MWCNTs synthesis from methane was investigated in detail[113]. Mn addition to $\mathrm{NiMgO}$ catalyst was found to improve the efficiency to $2244 \%$ for $\mathrm{Mn}_{0.2} \mathrm{NiMgO}$ structure that was two times higher than just $\mathrm{NiMgO}$ catalyst. It was observed that the solid solution structure $\mathrm{NiMgO}_{2}$ formed inside $\mathrm{NiMgO}$ catalysts is partially disturbed by $\mathrm{Mn}$ addition and a new solid solution structure $\mathrm{MnMg}_{6} \mathrm{O}_{9}$ have been obtained. Figure 25 shows the the morphologies of $\mathrm{NiMgO}, \mathrm{Mn}_{0.2} \mathrm{Ni}_{0.8} \mathrm{MgO}$ and $\mathrm{Mn}_{0.3} \mathrm{Ni}_{0.7} \mathrm{MgO}$ catalysts characterized by TEM. From the TEM morphologies, the average Ni particle size of NiMgO catalyst was found to be $\sim 15.3 \mathrm{~nm}$ and $\sim 19.9 \mathrm{~nm}$ for $\mathrm{Mn}_{0.2} \mathrm{Ni}_{0.8} \mathrm{MgO}$ and $\mathrm{Mn}_{0.3} \mathrm{Ni}_{0.7} \mathrm{MgO}$ catalysts respectively. $\mathrm{NiO}$ species were reduced to $\mathrm{Ni}$ at the catalyst surface and the $\mathrm{Ni}$ nanoparticles dimensions increased from 15.2 $\mathrm{nm}(\mathrm{NiMgO})$ to $19.9 \mathrm{~nm}\left(\mathrm{Mn}_{0.2} \mathrm{Ni}_{0.8} \mathrm{MgO}\right)$ and respectivelly $29.6 \mathrm{~nm}\left(\mathrm{Mn}_{0.3} \mathrm{Ni}_{0.8} \mathrm{MgO}\right)$. Also, exterior diameter for synthesized MWCNTs was directly proportional to increase in the Ni nanoparticles dimensions[113]. Ombaka et al., have developed a facile approach towards increasing the nitrogen-content in nitrogen-doped carbon nanotubes via halogenated catalysts[114]. N-doped carbon nanotubes were synthesized by CVD method at $850{ }^{\circ} \mathrm{C}$, using p-substituted ferocenyl derivate ( $\mathrm{p}-\mathrm{CN}, \mathrm{p}-\mathrm{CF}_{3}$ și $\left.\mathrm{p}-\mathrm{Cl}\right)$ as catalysts and pyridine and acetonitrile as common source for $\mathrm{N}$ and $\mathrm{C}$. Figure 26 and Figure 27 show the different TEM images of 
the synthesized samples. From the TEM analysis, it was demonstrated that the nanotubes exhibit bamboo kind of compartments.

In case of $\mathrm{p}-\mathrm{CN}$ substituted derivate, N-CNTs were obtained as main products and carbon spheres CS (for pyridine) or carbon nanofibers CNF (for acetonitrile) as secondary products. The most efficient in N-CNTs synthesis with a high percentage of $\mathrm{N}$ (both starting pyridine and acetonitrile) was the $\mathrm{p}^{-\mathrm{CF}_{3}}$ substituted ferocenil derivate. Morphology and surfaces chemistry in case of using pyridine and p-halogenated substitute derivate was significantly changed and the structure looks helical. Halogenated catalysts in acetonitrile resulted in the activation of Fe incorporation inside N-CNTs and this lead to decrease in N-CNTs diameter d, as well as limited secondary products CNF quantities[114]. A novel approach was initiated for enhancing Fe based catalysts properties in Fischer-Tropsch synthesis[115]. Using this new technique, the desired $\mathrm{N}$-doped CNTs were obtained by post-doping procedure at $700-900{ }^{\circ} \mathrm{C}$. Figure 28 shows the illustration for the preparation of nitrogen-doped carbon nanotubes by a post-doping method.

The synthesis efficiency of the N-CNTs and N content increased almost linearly with postdoping temperatures increasing, while the N-CNTs surface decreased with increase in temperature because of cavities contractions and deposition of carbon nanospheres. Both mild media acid functionalized CNTs and N-CNTs $(1.75 \mathrm{wt} . \% \mathrm{~N})$ supports were used for $\mathrm{Fe}$ catalysts in order to study the influences for Fischer-Tropsch synthesis. In order to understand the types of the nitrogen-containing species as well as the chemical bonding configurations of $\mathrm{N}$ in the synthesized materials, the detailed XPS studies have been performed. Figure 29 shows the $\mathrm{N}_{1 \mathrm{~s}}$ XPS spectra of (a) N-CNT-750 and (b) the types of nitrogen species on the nitrogendoped carbon nanotubes prepared by post-doping method. TEM analysis of the N-CNTs prepared via the post-doping method was also carried out to study the effect of different temperatures (Figure 30). It was observed from the study that the nitrogen incorporation did not have a significant impact on the morphology and structure of the CNTs up to about $800{ }^{\circ} \mathrm{C}$. $\mathrm{Fe} / \mathrm{N}-\mathrm{CNTs}$ catalysts showed superior performances compared to Fe/CNTs catalysts, unconcerned by the used acid pre-treatment conditions $(55.3 \% / 70 \% \mathrm{CO}$ conversion yield for $\mathrm{mild} /$ rough acid pre-treatment conditions in case of Fe/N-CNTs catalysts and 29\% / 44\% CO conversion yield for mild/rough acid pre-treatment conditions in case of Fe/CNTs catalysts)[115]. 
Volatile organic compounds (VOC) catalytic oxidation for industrial gases emission control is considered to be one of the most promising environment technologies. Noble metals Pt, Pd, Au were studied for these processes but high costs, low thermal stability and catalyst poisoning tendency has turned out attention towards other alternatives from transition metals oxides category. In this direction, Jiang et al have reported on effect of doping the nitrogen into carbon nanotubes on the activity of $\mathrm{NiO}$ catalysts for the oxidation removal of toluene[116]. For toluene catalytic oxidation, $\mathrm{N}$-doped nanotubes consisted catalyst support for $\mathrm{NiO}$ and it was found that catalytic results depend a lot on the graphitic nitrogen doped $\mathrm{N}_{\mathrm{G}}$ content. Optimized catalyst composition $\mathrm{NiO} / \mathrm{N}-\mathrm{CNTs}\left(6.22 \mathrm{wt}\right.$. \% $\mathrm{N}_{\mathrm{G}}$ doped content) was found to achieve complete toluene oxidative conversion at $248^{\circ} \mathrm{C}[116]$. Selective oxidation of glycerol over NCNTs supported platinum catalyst in base-free solution was also reported[117]. N-doped multiwall carbon nanotubes (N-MWCNTs) on platinum $1.8 \mathrm{~nm}$ nanoparticles support (NPt) were prepared by microwaves irradiation. Figure 31 shows the schematic for synthesis of $\mathrm{Pt} / \mathrm{N}$ MWCNTs. The obtained catalysts were successfully tested for selective glycerol oxidation processes, in aquatic media and no alkaline solution addition was required during the process. XPS and TEM investigations confirmed that N-MWCNTs enhanced NPts dispersion by strong interactions metal-support using electronic transfer (Figure 32, Figure 33).

CVD obtained N-doped carbon nanotubes N-CNTs were used as catalyst for benzylic alcohol selective oxidation with molecular oxygen as terminal oxidant agent in mild conditions[118]. The research results obtained from this study showed that N-CNTs demonstrate the enhanced catalytic activity in comparison to the pristine CNTs. Moreover, the N-CNTs demonstrated the excellent stability without losing activity or benzylic alcohol selectivity even after 8 reaction cycles and these results revealed positive argument for the development of new carbon based selective catalysts for liquid phase oxidation of benzylic alcohol[118]. Systematically studies have been also undertaken in order to analyse interactions between platinum nanoparticles NPt and N-doped/ oxidizing functionalized N-doped CNTs[119]. In this study, the N-CNTs/ONCNTs and their catalytic consistency against glycerol aerobic oxidation and CO electrooxidation was investigated in detail. TEM, XPS, Raman, XRD investigations proved that advanced NPt nanoparticles dispersion was enhanced on the usage of N-CNTs. Strong NPt-NCNTs interactions were observed and graphitic nitrogen form $\mathrm{N}_{\mathrm{G}}$ strongly interacted with $\mathrm{NPt}$ as well as act like a massive electron donor. Donor-acceptor interactions were found to be weaker in case of oxidizing functionalized N-doped carbon nanotubes ON-NCTs but this impediment could be easily overcome by increasing N doped content. Superior catalytic 
activities were noticed for both samples in comparison to the simple Pt on CNTs support catalyst. Furthermore the intrinsic activity was found to be more dependent on the electrons enriching NPt surface and maximized the interactions between platinum nanoparticles and $\mathrm{N}_{\mathrm{G}}$ active centres[119].

\subsection{Supercapacitors based on doped CNTs}

Supercapacitors, known also as electrochemical capacitors have become a promising device for energy storage due to their unique properties particularly: high power density, long life cycles and rapid charging/discharging rates. Three major types of electrode materials are generally used for electrochemical capacitors manufacturing: carbon-based materials, metal oxides/hydroxides and conductive polymers. Porous carbon derived from biomass are geting greater attension from reserchers both from the academi and industry for the manufacturing of supercapacitors. Lu et al., have reportd their study on the development of new nanocomposite materials containing porous carbon derived from kenaf stem $/ \mathrm{N}$-doped carbon nanotubes/polianiline KSC/N-CNT/PANI[120]. Firstly, the tri-dimensional nanocomposites KSC/N-CNTs were synthesized using CVD process. The N-CNTs had a dense distribution along inside KSC channels walls that enlarged the active surface. Secondly, the polyaniline (PANI) was deposited onto KSC/N-CNTs composites by chemical in-situ oxidative chemical oxidation. Figure 34 shows the morphology of KSC/NCNTs/PANI nanocomposites. It was confirmed from the images that a layer of PANI film was grown on the channel walls. The synthesized nanocomposites were used for electrode material in supercapacitors because of the combined advantages faciliated by PANI (high electroactivity, high pseudocapacitance, unusual doping/undoping chemistry) and the KSC/N-CNTs (high specific area, high porosity, good electrical conductivity) materials. Figure 35 shows the CVs of KSC/NCNTs/PANI (curve a), KSC/PANI (curve b), PANI (curve c), KSC/NCNTs (curve d), and KSC (curve e) in $2 \mathrm{M} \mathrm{H}_{2} \mathrm{SO}_{4}$ at scan rate of $5 \mathrm{mVs}^{-1}$, respectively. With increase in the scan rate, all thee peak currents were found to be increased and were proportional to the square root of the scan rate, suggesting that the electron transfer reaction involved a diffusion-controlled process. Furthermore, among the studied three kinds of electrode materials, the KSC/NCNTs/PANI electrode demonstrated an excellent rate capability. At a current density of $0.1 \mathrm{Ag}^{-1}$, nanocomposite KSC/N-CNTs/PANI showed a specific capacitance of $1090 \mathrm{Fg}^{-1}$ and a specific energetic density of $97 \mathrm{Whkg}^{-1}$. Moreover, specific capacitance stayed at $96.9 \%$ even after 1000 charging/decharging cycles, at a current density of $0.1 \mathrm{Ag}^{-1}$ (Figure 36)[120]. 
A new ternary composite, cobalt oxide nanoparticles/N-doped graphene/carbon nanotubes $\mathrm{Co}_{3} \mathrm{O}_{4} / \mathrm{NG} / \mathrm{CNTs}$ was synthesyzed by using a facile hydrothermal method[121]. Figure 37 shows various images from the synthesized $\mathrm{Co}_{3} \mathrm{O}_{4} / \mathrm{NG} / \mathrm{CNTs}$ materials. It images (Figure 37) clearly revealed that $\mathrm{Co}_{3} \mathrm{O}_{4}$ nanoparticles were well dispersed on the $\mathrm{NG}$ sheet with minimum aggregation. Due to synergetic effects of cobalt oxide nanoparticles, N-doped graphene and carbon nanotubes, this ternary nanocomposite material was found to exhibit superior electrochemical performances compared to dual composites $\mathrm{Co}_{3} \mathrm{O}_{4} / \mathrm{NG}$ and $\mathrm{Co}_{3} \mathrm{O}_{4} / \mathrm{G}$. It showed a specific capacitance of $456 \mathrm{Fg}^{-1}$, at a current density of $1 \mathrm{Ag}^{-1}$. Additionaly, capacitance increseased by 23.2\% after 100 usage cycles (Figure 37)[121]. The outstanding properties obtained here were attributed to the synergetic effects caused by various components in the ternary composites (Figure 38).

Lin et al., have reported their study on porous nitrogen-doped graphene/carbon nanotubes (PNGC) composite that were found to demonstrate an enhanced supercapacitor performance[122]. N-doped porous graphene/carbon nanotubes (N-PG/CNTs) based nanocomposite material were synthesized using pyrolysis. Figure $\mathbf{4 0}$ shows the schematic representation for synthesis of PNGC. The porous structure of the resulting materials was controlled with combined action of urea and lignosulphonate[122]. Measured specific capacitance was found to be $246.6 \mathrm{Fg}^{-1}$ at a current density $0.5 \mathrm{Ag}^{-1}$, and $96.5 \%$ capacitance stability after 2000 cycles at $100 \mathrm{mVs}^{-1}$. Figure 40 shows the galvanostatic charge-discharge tests as well as specific capacitance of PNGC. These results successfully reveal that the PNGC exhibit an excellent performance and have potential for supercapacitors possibilities.

One of the most real challenges in supercapacitor field is to find an appropriate electrostatic capacitive material for pseudo capacitors integration and obtain high energetic densities. A new model of asymmetric capacitor was studied that was fabricated using polypyrrole nanotubes as positive electrode and $\mathrm{N}$-doped carbon nanotubes as negative electrode[123]. This PPy-NT/NCNTs combination proved to have a high operation voltage $(1.4 \mathrm{~V})$, high energetic density $28.95 \mathrm{WhKg}^{-1}$ and a power density of $7.75 \mathrm{kWKg}^{-1}$. Cyclic stability was high $8998 \%$ maintained also after 2000 cycles[123]. Yang et al., have carried out their studies on Bamboolike carbon nanotubes containing sulphur for high performance supercapacitors[124]. In this work, the sulphur doped bamboo like carbon nanotubes structures (S-BCNTs) were synthesized using carbonisation and sulphonated polymer activation in $\mathrm{CO}_{2}$. Figure shows the syntheis of BCNTs. The obtained S-BCNTs showed high specific capacitance $259 \mathrm{Fg}^{-1}$ at a 
current density of $1 \mathrm{Ag}^{-1}$. Furthermore $97.7 \%$ of initial capacitance was maintained after 1000 cycles at a current denisty of $5 \mathrm{Ag}^{-1}$. By contrast, amorphous carbon without sulphur doping specific capacitance was found to be $129 \mathrm{Fg}^{-1}$ at a current density of $1 \mathrm{Ag}^{-1}$. As principle, the low content sulphur doping (1.66 wt.\%) induced an increment in specific capacitance of carbon nanotubes. The high specific capacitance and excellent cyclic stability for S-CNTs has been attributed to the high specific surface area and tubular bamboo like morphology[124]. Montgomery et al., have reported their study on spray doping method to create a low-profile high-density carbon nanotube thermoelectric generator. The newly developed doping method through spraying allowed fine tuning of thermo-electrical properties of thin composite films $p$ polymer/carbon nanotubes like poly(vinylidene fluoride) (PVDF)/CNTs[125]. Inserting low polyethyleneimine (PEI) type $n$ - molecules through spraying process allowed film transformation to a multi-section device with alternate $p$ - and $n$ - sections. Replacing the classic solution doping methods with spray doping based strategies significantly influences the viability of thermos-electric generators (TEGs) manufacturing. It was concluded from the study that organic TEGs with an appropriate design can be closer in performance to existent inorganic based TEGs and have a huge potential for further exploration[125].

\subsection{Biosensing applications of doped-CNTs}

Doped CNTs also exhibit a very high potential for biosensing applications towards very efficient sensing devices[126]. For example, glucose biosensor is one of the most useful instrument for controlling different food products or different biotechnological processes. It is also used for diabetic person's identification and monitoring. Glucose oxidase (Gox) is generally used for oxygen glucose catalytic oxidation in order to result hydrogen peroxide and gluconic acid. Glucose can be easily identified through amperometric monitor for the hydrogen peroxide released quantity. Zhang et al., have reported their study on the usage of flexible 3D nitrogen-doped carbon nanotubes nanostructure as matrix for enzyme immobilization and biosensing[127]. In this work, an easy and scalable method for manufacturing a biosensor for detection of glucose was deevloped by glucose oxidase GOx immobilisation onto 3D N-doped CNTs support, based on electrospun carbon nanofibers film. N-CNTs@CNFs composite was droped on electrode surface with high load of glucose oxidase GOx $\left(3.2 \times 10^{-9} \mathrm{molcm}^{-2}\right)$ and it resulted in a highly glucose selective biosensor $\left(24.8 \mathrm{mAM}^{-1} \mathrm{~cm}^{-2}\right)$ with low glucose detection limit ( $6 \mu \mathrm{M}$ for a signal/noise rapport of 3 ). The biosensor has been found to exhibit very high reproducibility, good stability for enzime storage, anti-interferences high ability and high aplicability in real tests. Relatively simple preparation method as well as atractive analitical 
performances promotes this robust electrode for high performance electrochemical sensors development[127].

Ultrasensitive non-enzymatic immunosensor for carcino-embryonic antigen based on palladium hybrid vanadium pentoxide/multiwalled carbon nanotubes was also reported[128]. This newly developed sandwich electrochemical sensitive sensor was successfully used for monitoring of carcinoembryonic antigen (CEA) which is one of the most known and used tumour markers. Figure $\mathbf{4 3}$ demonstrates the fabrication process for the development of the electrochemical immunosensor. The nanocomposite based on tin oxide/reduced graphene oxide was used as support material for enlarging specific surface area and conductivity of glass carbon electrode (GCE). Also, gold nanoparticles were added to this first layer with the role of bonding primary antigen $\mathrm{Ab}_{1}$ and to increase and accelerate electrons transfers in this system. At the same time, nanocomposite of paladium nanoparticles and vanadium oxide on MWCNTs support was used to fix secondary antigen $\mathrm{Ab}_{2}$. This nanocomposite presented excellent catalytic activity towards $\mathrm{H}_{2} \mathrm{O}_{2}$ reduction and facilitated increment in signal amplitude and improved the sensibility as well as low detection limit $\left(0.17 \mathrm{pgmL}^{-1}\right)$ with a linear behavior on the interval $0.5 \mathrm{pgmL}^{-1}-0.25 \mathrm{ngmL}^{-1}$. The obtained immunosensor was further practically tested on serum samples and the results clearly indicated possibility for using the sensor in quantitative detection of CEA antigen in diagnose clinics[128].

Electrochemiluminescence sensor for melamine based on a $\mathrm{Ru}(\mathrm{bpy}) 3^{2+}$-doped silica nanoparticles/carboxylic acid functionalized MWCNTs /Nafion composite film modified electrode was also reported[129]. Electrochemiluminescence (ECL) is a light emitting process from stimulated states of a luminophore that is generally engendered on electrode surface via an electrochemical redox reaction[129]. As a result of the good electrochemical stability, high efficiency and vast linear answer domain, $\mathrm{Ru}(\mathrm{bpy}) 3^{2+}$ based ECL systems has become one of the most imperative analysis instrument. Unfortunately, the high cost as well as the consumption of the $\mathrm{Ru}$ (bpy) $3^{2+}$ during detection, significantly limits its applicability. So, the $\mathrm{Ru}$ (bpy) $3^{2+}$ encapsulation into spherical and homogeneous silica nanoparticles (RUDS) via a revert micro emulsion method was carried out to prevent $\mathrm{Ru}$ (bpy) $3^{2+}$ loss from the modified glass carbon electrode RUDS/CMWCNTs/Nafion/GCE. For enhancing the electroconductivity of the film and promote electrons transfer rate onto electrode surface, carboxylic functionalized multiwall carbon nanotubes (CMWCNTs) were used. ECL signal was found to be highly improved and proportional to melamine MEL logarithmic concentration detectable in interval 
$5 \times 10^{-13} \mathrm{molL}^{-1}-1 \times 10^{-7} \mathrm{molL}^{-1}$, with a detection limit of $1 \times 10^{-13} \mathrm{molL}^{-1}$. These tests were successfully and practically applied for detecting the presence of milk melamine[129].

Sensitive and selective determination of ractopamine is also interesting for therapeutic usage monitoring and anti-doping control. A novel voltammetric sensor based on carbon nanotubes and nanoparticles of antimony tin oxide for the determination of ractopamine was developed[130]. The sensor was developed by mixing of carbon nanotubes /antimony and tin oxides nanoparticles modification of a glassy carbon electrode (GCE)[130]. Figure 44 shows the schematic illustration for the preparation of the developed electrode. On comparison with the pristine CGE electrode or with the one modified only with CNTs, ATONP/CNTs/GCE electrode showed an enhanced catalytic activity in ractopamine oxidation with an anode peak well defined at $600 \mathrm{mV}$. Current response was linear in the limits 10-240 $\mathrm{nM}$ and a detection limit of $3.3 \mathrm{nM}$. The synthesized electrode was successfully tested for selective determination of ractopamine in the presence of high concentrations of uric acid (UA); asorbic acid (AA) and dopamine(DA). It was also successfully tested to determine the presence of ractopamine feed and urine samples[130].

Guo et al., have reported highly sensitive simultaneous electrochemical detection of hydroquinone and catechol with three-dimensional N-doping carbon nanotube film electrode[131]. Hidroquinone (HQ) and catechol (CC) are two isomeric forms of phenolic compounds that are used in lots of applications and are considered as dangerous pollutants for the environment because of their high toxicity and low biodegradability. So 3D N-CNTs film were obtained by the combination of CVD methods and electrospun deposition. This process resulted in uniform and dense nanocomposites bounded to the carbon nanofiber matrix NCNTs@CNFs. Subsequqntly by directly dropping the flexible film onto the electrode surface without additional oxidant treatment, a dihydroxybenzene biosensor was easily constructed. The biosensor was then succesfully tested for simoultaneous determination of HQ and CC in real samples with satisfying results. Sensor showed linear response in interval 0.08-350 $\mu \mathrm{M} /$ detection limit $20 \mathrm{nM}$ for $\mathrm{CC}$ and $0.1-425 \mu \mathrm{M} /$ detection limit $50 \mathrm{nM}$ for HQ. Attractive electrochemicl performances as well as simple synthesis method demonstrated that this new sensosr type as an excelent candidate for precision dihydroxibenzene detection sensors[131].

\subsection{Other applications for doped carbon nanotubes}


Doped CNTs also find applications in several other fields such as for dye-sensitized solar cells (DSSCs). The bamboo like structure N-doped carbon nanotubes (N-CNTs) were synthesized by direct pyrolysis of analogue nanostructures with PB (Prussia blue metal hexacyanoferate) using nickel hexacyanoferrate ( $\mathrm{NiHCF}$ ); [copper hexacyanoferrate, $\left.\mathrm{KCuFe}(\mathrm{CN})_{6}\right]$ and $\mathrm{FeHCF}$ [ferric hexacyanoferrate, $\mathrm{KFeFe}(\mathrm{CN})_{6}$ ] as the starting precursors at temperatures above $700{ }^{\circ} \mathrm{C}$. The use of lower temperatures, $500{ }^{\circ} \mathrm{C}$ in the synthesis was found to result in N-doped carbon nanospheres (N-CNSs). After acid treatment, active BET surface reached $261 \mathrm{~m}^{2} \mathrm{~g}^{-1}$ for bamboo like structure N-CNTs, compared to $105 \mathrm{~m}^{2} \mathrm{~g}^{-1}$ in case of N-CNSs. Electrical conductivity was also higher in case of N-CNTs, pointing the potential of the synthesized NCNTs material in electrocatalytic applications. The N-CNTs electrode were found to exhibit superior activity in couple redox reactions $\mathrm{I}^{-} / \mathrm{I}_{3}{ }^{-}$. The cyclic voltammetry result indicates that good electrocatalytic performances could be attributed to the high current densities corresponding to lower resistance to charge and mass transfers. Solar cells using photosensitive pigment DSC showed a higher photovoltaic conversion efficiency $(\sim 7.48 \%)$ in case of using bamboo like structure N-CNTs electrode in comparison to the classic Pt electrode $(7.12 \%)$ or nanospheres electrode N-CNSs (5.53\%)[132]. Multiwall carbon nanotubes (MWCNTs) and acylamino-copper phtalocyanine AM-CuPc containing hybrid thin films were also prepared using oxygenated plasma treatment[133]. In these films, the doping level was found to influence the photoelectric properties of thin films and these properties have been investigated and discussed in detail. The prepared functional composites were found to exhibit excellent dispersion properties as covalent bonding was formed among the Am-CuPc and MWCNTs. Band gap was also affected by the doping level and minimum $1.63 \mathrm{eV}$ was obtained at a $40 \mathrm{wt}$. $\%$ MWCNTs loading. The used technique in this work was proposed to lead to a new way of developing innovative materials for solar energy producing[133].

Energetic system based on hydrogen is also expected to replace in the nearest future, the conventional ones based on fossil combustible because hydrogen is cleaner, sustainable and renewable. The high surface area and big pores volumes has attracted researchers to use carbon nanotubes and its variants for hydrogen storage as the porous carbon is well known as a good adsorbing material. Mixed doping of carbon nanotubes with nitrogen and transition metals leads to the formation of new kinds of functional composite materials that can have high potential to be useful in hydrogen storage. Density functional theory (DFT) was used to study the hydrogen adsorption of novel n-doped carbon nanotubes functionalized with scandium[134]. It was formulated from the study that $\mathrm{N}$ and $\mathrm{Sc}$ doped carbon nanotubes were 
the most efficient as each Sc atom can fix up to 5 hydrogen molecules[134]. DFT calculations combined with general gradient aproximation (GGA) were also used in a systematic study for the electronic structure and morphological characteristisation of simple CNTs and of those exohydrogenated doped with cobalt, used for hydrogen adsorbtion and storage[135]. In case of exterior Co doped structures, the $\mathrm{Co}[136]$ atoms worked as additional adsorbers for hydrogen, and storage capacity for hydrogen had been proved to be significantly higher. For internal doping of Co atoms, the nature of exo-hydrogenation was found to change from chemical to physical and depends on the nanotubes chirality[135]. Silicon carbide nanotubes had been synthesized by reaction between silica vapours and carbon nanotubes[137]. Purified nanotubes were doped with $\mathrm{K}$ and Ti. Hydrogen adsorption was gravimetrically measured with a magnetic suspension microbalance. Silicon carbide nanotubes doped with $\mathrm{K}$ demonstrated the promising properties for hydrogen adsorption and storage capacity was found to be 3 times higher compared to classic CNTs[137]. Li et al., have reported their study on the First-principle study of $\mathrm{SO}_{2}$ molecule adsorption on Ni-doped vacancy-defected single-walled $(8,0)$ CNTs[138]. The interactions between $\mathrm{SO}_{2}$ and SWCNTS doped with Ni atoms were studied using DFT calculations for exploring the detection of dangerous gases such as like $\mathrm{SO}_{2}$. The study showed a better ability for adsorbing $\mathrm{SO}_{2}$ molecules in case of Ni/SWCNTs composite in comparison to simple SWCNTs. Thus the Ni-doped CNTs were found to exhibit a very high potential in sensor development for detection of $\mathrm{SO}_{2}$ gas molecules[138]. There has been very limited study on the simulation of membranes applications for gas separation. These studies are limited as a result of correlation between gas selectivity and membrane permeability. Zhou et al., have provided an insights into the ultrahigh gas separation efficiency of lithium doped CNT membrane using carrier-facilitated transport mechanism[139]. Using molecular simulations, excellent selectivity associated with extraordinary permeability for $\mathrm{CO}_{2}$ for polymer nanocomposite membrane containing CNTs doped with Li atoms was highlighted. The magnitude order in this study was found to be almost 2 times higher in comparison to the most advanced existent membranes[139].

\section{Conclusions and future perspectives}

Insertion of doping agents inside the carbon nanotubes channels or chemical transformation of surface bonded compounds are the most promising methods for controlled modifications of the CNTs electronic properties because of high number of existing substances that can be inserted inside CNTs inner cavities by specific encapsulation procedures. Chemical reactions inside CNTs channels open new ways for fine tuning of electronic properties with appropriate starting 
precursors and reaction conditions. Electronic properties of CNTs can be easily modified and improved for specific applications such as energy storage, electrodes, catalytic support, supercapacitors and biosensing applications.

Future perspectives in this direction can involve the use of composite materials based on carbon nanotubes, the entire material being selective for certain analytes from complex mixtures for example the use of polymeric membranes. In this way, the entire device can specifically separate the interested chemical species from analytical matrix with a high efficiency of analysis of one component from many. More than that, the use of polymeric membranes for sensors or supercapacitors preparation gives the advantage of a more reproducible doping reaction if the membrane acts as a reactor. The principle method consists in the access of reagents to reaction centres through membrane pores, while the transport being facilitated by diffusion[140]. The recently developed new form of 3D carbon nanomaterials could play rather better roles towards different technological applications after doping.[141-150]

Acknowledgement: This work was supported by a grant of the Romanian National Authority for Scientific Research and Innovation, CNCS_-UEFISCDI, project number PN-II-RU-TE2014-4-0292 - nanostructured membrane reactors for derivatization and doping of carbon nanotubes and graphenes. 


\section{References}

[1] S. Iijima, Helical microtubules of graphitic carbon, Nature. 354 (1991) 56-58. doi:10.1038/354056a0.

[2] S. Iijima, T. Ichihashi, Single-shell carbon nanotubes of 1-nm diameter, Nature. 363 (1993) 603-605. doi:10.1038/363603a0.

[3] S. Iijima, P.M. Ajayan, T. Ichihashi, Growth model for carbon nanotubes, Phys. Rev. Lett. 69 (1992) 3100-3103. doi:10.1103/PhysRevLett.69.3100.

[4] S. Iijima, C. Brabec, A. Maiti, J. Bernholc, Structural flexibility of carbon nanotubes, J. Chem. Phys. 104 (1998) 2089. doi:10.1063/1.470966.

[5] J. Tersoff, R.S. Ruoff, Structural properties of a carbon-nanotube crystal, Phys. Rev. Lett. 73 (1994) 676-679. doi:10.1103/PhysRevLett.73.676.

[6] V.K. Thakur, S.I. Voicu, Recent advances in cellulose and chitosan based membranes for water purification: A concise review, Carbohydr. Polym. 146 (2016) 148-165. doi:10.1016/j.carbpol.2016.03.030.

[7] M. Miculescu, V.K. Thakur, F. Miculescu, S.I. Voicu, Graphene-based polymer nanocomposite membranes: a review, Polym. Adv. Technol. 27 (2016) 844-859. doi:10.1002/pat.3751.

[8] M.C. Corobea, O. Muhulet, F. Miculescu, I.V. Antoniac, Z. Vuluga, D. Florea, D.M. Vuluga, M. Butnaru, D. Ivanov, S.I. Voicu, Novel nanocomposite membranes from cellulose acetate and clay-silica nanowires, Polym. Adv. Technol. 27 (2016) 15861595 .

[9] A. Bhati, A. Singh, M. Tripathi, S. Kumar, Sunlight induced photochemical degradation of methylene blue by water- soluble carbon nano-rods, Int. J. Photoenergy. 2016 (2016) 2583821.

[10] S.I. Voicu, M.A. Pandele, E. Vasile, R. Rughinis, L. Crica, L. Pilan, M. Ionita, The Impact of Sonication Time Through Polysulfone-Graphene Oxide Composite Film Properties, Dig. J. Nanomater. Biostructures. 8 (2013) 1389-1394. http://www.chalcogen.ro/1389_Voicu.pdf (accessed March 8, 2018).

[11] I. Kholmanov, J. Kim, E. Ou, R.S. Ruoff, L. Shi, Continuous Carbon NanotubeUltrathin Graphite Hybrid Foams for Increased Thermal Conductivity and Suppressed Subcooling in Composite Phase Change Materials, ACS Nano. 9 (2015) 11699-11707. doi:10.1021/acsnano.5b02917.

[12] I.N. Kholmanov, C.W. Magnuson, R. Piner, J.-Y. Kim, A.E. Aliev, C. Tan, T.Y. Kim, A.A. Zakhidov, G. Sberveglieri, R.H. Baughman, R.S. Ruoff, Optical, Electrical, and Electromechanical Properties of Hybrid Graphene/Carbon Nanotube Films, Adv. Mater. 27 (2015) 3053-3059. doi:10.1002/adma.201500785.

[13] G. Yamamoto, K. Shirasu, T. Hashida, T. Takagi, J.W. Suk, J. An, R.D. Piner, R.S. Ruoff, Nanotube fracture during the failure of carbon nanotube/alumina composites, Carbon N. Y. 49 (2011) 3709-3716. doi:10.1016/J.CARBON.2011.04.022.

[14] D.H. Lee, J.E. Kim, T.H. Han, J.W. Hwang, S. Jeon, S.-Y. Choi, S.H. Hong, W.J. Lee, R.S. Ruoff, S.O. Kim, Versatile Carbon Hybrid Films Composed of Vertical Carbon Nanotubes Grown on Mechanically Compliant Graphene Films, Adv. Mater. 22 (2010) 
1247-1252. doi:10.1002/adma.200903063.

[15] M. Ionita, E. Vasile, L.E. Crica, S.I. Voicu, A.M. Pandele, S. Dinescu, L. Predoiu, B. Galateanu, A. Hermenean, M. Costache, Synthesis, characterization and in vitro studies of polysulfone/graphene oxide composite membranes, Compos. Part B Eng. 72 (2015) 108-115. doi:10.1016/j.compositesb.2014.11.040.

[16] M. Ionita, L.E. Crica, S.I. Voicu, A.M. Pandele, H. Iovu, Fabrication of cellulose triacetate/graphene oxide porous membrane, Polym. Adv. Technol. 27 (2016) 350357. doi:10.1002/pat.3646.

[17] S.I. Voicu, A. Dobrica, S. Sava, A. Ivan, L. Naftanaila, Cationic surfactants-controlled geometry and dimensions of polymeric membrane pores, J. Optoelectron. Adv. Mater. 14 (2012) 923-928.

[18] W. Ding, L. Calabri, K.M. Kohlhaas, X. Chen, D.A. Dikin, R.S. Ruoff, Modulus, Fracture Strength, and Brittle vs. Plastic Response of the Outer Shell of Arc-grown Multi-walled Carbon Nanotubes, Exp. Mech. 47 (2007) 25-36. doi:10.1007/s11340006-9344-6.

[19] R.S. Ruoff, Time, temperature, and load: the flaws of carbon nanotubes., Proc. Natl. Acad. Sci. U. S. A. 103 (2006) 6779-80. doi:10.1073/pnas.0601753103.

[20] C. Li, R.S. Ruoff, T.-W. Chou, Modeling of carbon nanotube clamping in tensile tests, Compos. Sci. Technol. 65 (2005) 2407-2415. doi:10.1016/J.COMPSCITECH.2005.06.019.

[21] S. Zhang, S.L. Mielke, R. Khare, D. Troya, R.S. Ruoff, G.C. Schatz, T. Belytschko, Mechanics of defects in carbon nanotubes: Atomistic and multiscale simulations, Phys. Rev. B. 71 (2005) 115403. doi:10.1103/PhysRevB.71.115403.

[22] S. Zhang, W.K. Liu, R.S. Ruoff, Atomistic Simulations of Double-Walled Carbon Nanotubes (DWCNTs) as Rotational Bearings, Nano Lett. 4 (2004) 293-297. doi:10.1021/n10350276.

[23] M.-F. Yu, B.S. Files, S. Arepalli, R.S. Ruoff, Tensile Loading of Ropes of Single Wall Carbon Nanotubes and their Mechanical Properties, Phys. Rev. Lett. 84 (2000) 55525555. doi:10.1103/PhysRevLett.84.5552.

[24] M.F. Yu, O. Lourie, M.J. Dyer, K. Moloni, T.F. Kelly, R.S. Ruoff, Strength and breaking mechanism of multiwalled carbon nanotubes under tensile load, Science (80-. ). 287 (2000) 637-640. doi:10.1126/science.287.5453.637.

[25] I. Anastopoulos, V.A. Anagnostopoulos, A. Bhatnagar, A.C. Mitropoulos, G.Z. Kyzas, A review for chromium removal by carbon nanotubes, Chem. Ecol. 33 (2017) 572588. doi:10.1080/02757540.2017.1328503.

[26] A. Das, K.W. Stöckelhuber, R. Jurk, M. Saphiannikova, J. Fritzsche, H. Lorenz, M. Klüppel, G. Heinrich, Modified and unmodified multiwalled carbon nanotubes in high performance solution-styrene-butadiene and butadiene rubber blends, Polymer (Guildf). 49 (2008) 5276-5283. doi:10.1016/J.POLYMER.2008.09.031.

[27] L. Yu, C. Shearer, J. Shapter, Recent Development of Carbon Nanotube Transparent Conductive Films, Chem. Rev. 116 (2016) 13413-13453.

doi:10.1021/acs.chemrev.6b00179. 
[28] S.L. Mielke, S. Zhang, R. Khare, R.S. Ruoff, T. Belytschko, G.C. Schatz, The effects of extensive pitting on the mechanical properties of carbon nanotubes, Chem. Phys. Lett. 446 (2007) 128-132. doi:10.1016/J.CPLETT.2007.08.033.

[29] W. Ding, A. Eitan, F.T. Fisher, X. Chen, D.A. Dikin, R. Andrews, L.C. Brinson, L.S. Schadler, R.S. Ruoff, Direct Observation of Polymer Sheathing in Carbon NanotubePolycarbonate Composites, Nano Lett. 3 (2003) 1593-1597. doi:10.1021/n10345973.

[30] J. Gerard Lavin, S. Subramoney, R.S. Ruoff, S. Berber, D. Tománek, Scrolls and nested tubes in multiwall carbon nanotubes, Carbon N. Y. 40 (2002) 1123-1130. doi:10.1016/S0008-6223(02)00050-7.

[31] M.-F. Yu, M. Dyer, J. Chen, D. Qian, W. Liu, R. Ruoff, Locked twist in multiwalled carbon-nanotube ribbons, Phys. Rev. B. 64 (2001) 241403.

doi:10.1103/PhysRevB.64.241403.

[32] A. Das, G.R. Kasaliwal, R. Jurk, R. Boldt, D. Fischer, K.W. Stöckelhuber, G. Heinrich, Rubber composites based on graphene nanoplatelets, expanded graphite, carbon nanotubes and their combination: A comparative study, Compos. Sci. Technol. 72 (2012) 1961-1967. doi:10.1016/J.COMPSCITECH.2012.09.005.

[33] M. Adamska, U. Narkiewicz, Fluorination of Carbon Nanotubes - A Review, J. Fluor. Chem. 200 (2017) 179-189. doi:10.1016/j.jfluchem.2017.06.018.

[34] A.R. Chowdhuri, T. Singh, S.K. Ghosh, S.K. Sahu, Carbon Dots Embedded Magnetic Nanoparticles@Chitosan@Metal Organic Framework as a Nanoprobe for pH Sensitive Targeted Anticancer Drug Delivery, ACS Appl. Mater. Interfaces. 8 (2016) 16573-16583. doi:10.1021/acsami.6b03988.

[35] M. Tuerhong, Y. XU, X.-B. YIN, Review on Carbon Dots and Their Applications, Chinese J. Anal. Chem. 45 (2017) 139-150. doi:10.1016/S1872-2040(16)60990-8.

[36] C. Liu, P. Zhang, X. Zhai, F. Tian, W. Li, J. Yang, Y. Liu, H. Wang, W. Wang, W. Liu, Nano-carrier for gene delivery and bioimaging based on carbon dots with PEIpassivation enhanced fluorescence, Biomaterials. 33 (2012) 3604-3613. doi:10.1016/J.BIOMATERIALS.2012.01.052.

[37] S. Zhu, J. Zhang, C. Qiao, S. Tang, Y. Li, W. Yuan, B. Li, L. Tian, F. Liu, R. Hu, H. Gao, H. Wei, H. Zhang, H. Sun, B. Yang, Strongly green-photoluminescent graphene quantum dots for bioimaging applications, Chem. Commun. 47 (2011) 6858. doi:10.1039/c1cc11122a.

[38] S.K. Bhunia, A. Saha, A.R. Maity, S.C. Ray, N.R. Jana, Carbon Nanoparticle-based Fluorescent Bioimaging Probes, Sci. Rep. 3 (2013) 1473. doi:10.1038/srep01473.

[39] H. Ali, S.K. Bhunia, C. Dalal, N.R. Jana, Red Fluorescent Carbon Nanoparticle-Based Cell Imaging Probe, ACS Appl. Mater. Interfaces. 8 (2016) 9305-9313. doi:10.1021/acsami.5b11318.

[40] J. Lahaye, G. Nansé, A. Bagreev, V. Strelko, Porous structure and surface chemistry of nitrogen containing carbons from polymers, Carbon N. Y. 37 (1999) 585-590. doi:10.1016/S0008-6223(98)00225-5.

[41] J.O. Hwang, J.S. Park, D.S. Choi, J.Y. Kim, S.H. Lee, K.E. Lee, Y.-H. Kim, M.H. Song, S. Yoo, S.O. Kim, Workfunction-Tunable, N-Doped Reduced Graphene Transparent Electrodes for High-Performance Polymer Light-Emitting Diodes, ACS 
Nano. 6 (2012) 159-167. doi:10.1021/nn203176u.

[42] X. Wang, X. Li, L. Zhang, Y. Yoon, P.K. Weber, H. Wang, J. Guo, H. Dai, N-doping of graphene through electrothermal reactions with ammonia., Science. 324 (2009) 768-71. doi:10.1126/science.1170335.

[43] F. Xu, Z. Yu, Z. Gong, H. Jin, First-principles study on the electronic and transport properties of periodically nitrogen-doped graphene and carbon nanotube superlattices, Front. Phys. 12 (2017) 127306. doi:10.1007/s11467-017-0650-5.

[44] M. Eising, C.E. Cava, R.V. Salvatierra, A.J. Gorgatti Zarbin, L.S. Roman, Doping effect on self-assembled films of polyaniline and carbon nanotube applied as ammonia gas sensor, Sensors and Actuators B-Chemical. 245 (2017) 25-33. doi:10.1016/j.snb.2017.01.132.

[45] O. Stephan, P.M. Ajayan, C. Colliex, P. Redlich, J.M. Lambert, P. Bernier, P. Lefin, Doping Graphitic and Carbon Nanotube Structures with Boron and Nitrogen, Science (80-. ). 266 (1994) 1683-1685. doi:10.1126/science.266.5191.1683.

[46] $*, \dagger$ R. Czerw, $\$, \S$ M. Terrones, $\|$ J.-C. Charlier, $\perp$ X. Blase, $\dagger, \#$ B. Foley, $\ddagger$ R. Kamalakaran, ๆ N. Grobert, § H. Terrones, † D. Tekleab, @ P. M. Ajayan, \# W. Blau, $\$$ and M. Rühle, D.L. Carroll †, Identification of Electron Donor States in N-Doped Carbon Nanotubes, (2001). doi:10.1021/NL015549Q.

[47] Y. Ganesan, C. Peng, Y. Lu, L. Ci, A. Srivastava, P.M. Ajayan, J. Lou, Effect of Nitrogen Doping on the Mechanical Properties of Carbon Nanotubes, ACS Nano. 4 (2010) 7637-7643. doi:10.1021/nn102372w.

[48] J. Wu, R.M. Yadav, M. Liu, P.P. Sharma, C.S. Tiwary, L. Ma, X. Zou, X.-D. Zhou, B.I. Yakobson, J. Lou, P.M. Ajayan, Achieving Highly Efficient, Selective, and Stable $\mathrm{CO}_{2}$ Reduction on Nitrogen-Doped Carbon Nanotubes, ACS Nano. 9 (2015) 53645371. doi:10.1021/acsnano.5b01079.

[49] P.P. Sharma, J. Wu, R.M. Yadav, M. Liu, C.J. Wright, C.S. Tiwary, B.I. Yakobson, J. Lou, P.M. Ajayan, X.D. Zhou, Nitrogen-Doped Carbon Nanotube Arrays for HighEfficiency Electrochemical Reduction of CO2: On the Understanding of Defects, Defect Density, and Selectivity, Angew. Chemie - Int. Ed. 54 (2015) 13701-13705. doi:10.1002/anie.201506062.

[50] M.H.G. Wichmann, S.T. Buschhorn, L. Böger, R. Adelung, K. Schulte, Direction sensitive bending sensors based on multi-wall carbon nanotube/epoxy nanocomposites, Nanotechnology. 19 (2008) 475503. doi:10.1088/0957-4484/19/47/475503.

[51] Y. Zhang, J. Zhang, D.S. Su, Substitutional Doping of Carbon Nanotubes with Heteroatoms and Their Chemical Applications, ChemSusChem. 7 (2014) 1240-1250. doi:10.1002/cssc.201301166.

[52] W.J. Lee, U.N. Maiti, J.M. Lee, J. Lim, T.H. Han, S.O. Kim, Nitrogen-doped carbon nanotubes and graphene composite structures for energy and catalytic applications, Chem. Commun. 50 (2014) 6818-6830. doi:10.1039/c4cc00146j.

[53] K. Gong, F. Du, Z. Xia, M. Durstock, L. Dai, Nitrogen-doped carbon nanotube arrays with high electrocatalytic activity for oxygen reduction., Sci. . 323 (2009) 760-764. doi:10.1126/science.1168049.

[54] L. Yang, S. Jiang, Y. Zhao, L. Zhu, S. Chen, X. Wang, Q. Wu, J. Ma, Y. Ma, Z. Hu, 
Boron-doped carbon nanotubes as metal-free electrocatalysts for the oxygen reduction reaction, Angew. Chemie - Int. Ed. 50 (2011) 7132-7135.

doi:10.1002/anie.201101287.

[55] O. Lupan, F. Schütt, V. Postica, D. Smazna, Y.K. Mishra, R. Adelung, Sensing performances of pure and hybridized carbon nanotubes-ZnO nanowire networks: A detailed study, Sci. Rep. 7 (2017) 14715. doi:10.1038/s41598-017-14544-0.

[56] A. Das, A.K. Sood, A. Govindaraj, A.M. Saitta, M. Lazzeri, F. Mauri, C.N.R. Rao, Doping in carbon nanotubes probed by Raman and transport measurements, Phys. Rev. Lett. 99 (2007) 136803. doi:10.1103/PhysRevLett.99.136803.

[57] W. Yu, L. Wang, Y. Qi, L. Chen, L. Wang, H. Xie, The influence of nitrogen doping on thermal conductivity of carbon nanotubes, Thermochim. Acta. 617 (2015) 163-168. doi:10.1016/j.tca.2015.08.034.

[58] X. Shao, D. Li, J. Cai, H. Luo, C. Dong, First-principles study of structural and work function properties for nitrogen-doped single-walled carbon nanotubes, Appl. Surf. Sci. 368 (2016) 477-482. doi:10.1016/j.apsusc.2016.01.271.

[59] R.S. Lee, H.J. Kim, J.E. Fischer, A. Thess, R.E. Smalley, Conductivity enhancement in single-walled carbon nanotube bundles doped with K and Br, Nature. 388 (1997) 255257. doi: $10.1038 / 40822$.

[60] C. Shao, J. Xia, J. Zhang, Q. Shao, Effects of B-N co-doping into the ultra-small diameter zigzag single-walled carbon nanotubes: A density functional theory study, Phys. E Low-Dimensional Syst. Nanostructures. 59 (2014) 88-92.

doi:10.1016/j.physe.2013.12.023.

[61] H. Rezania, The effects of boron doping on the optical absorption of carbon nanotubes, Opt. - Int. J. Light Electron Opt. 126 (2015) 1918-1922.

doi:10.1016/j.ijleo.2015.05.041.

[62] K. Xie, F. Yang, P. Ebbinghaus, A. Erbe, M. Muhler, W. Xia, A Reevaluation of the Correlation Between the Synthesis Parameters and Structure and Properties of Nitrogen-doped Carbon Nanotubes, J. Energy Chem. 24 (2015) 407-415. doi:10.1016/j.jechem.2015.06.016.

[63] P.M. Korusenko, V. V. Bolotov, S.N. Nesov, S.N. Povoroznyuk, I.P. Khailov, Changes of the electronic structure of the atoms of nitrogen in nitrogen-doped multiwalled carbon nanotubes under the influence of pulsed ion radiation, Nucl. Instruments Methods Phys. Res. Sect. B Beam Interact. with Mater. Atoms. 358 (2015) 131-135. doi:10.1016/j.nimb.2015.06.009.

[64] R. Kumar, R.K. Singh, R.S. Tiwari, Growth analysis and high-yield synthesis of aligned-stacked branched nitrogen-doped carbon nanotubes using sesame oil as a natural botanical hydrocarbon precursor, Mater. Des. 94 (2016) 166-175. doi:10.1016/j.matdes.2016.01.025.

[65] M.M.S. Fakhrabadi, A. Allahverdizadeh, V. Norouzifard, B. Dadashzadeh, Effects of boron doping on mechanical properties and thermal conductivities of carbon nanotubes, Solid State Commun. 152 (2012) 1973-1979.

doi:10.1016/j.ssc.2012.08.003.

[66] A. Vongachariya, V. Parasuk, Stabilities and mechanical and electronic properties on 
BN doped zigzag single-wall carbon nanotubes, Solid State Commun. 223 (2015) 2831. doi:10.1016/j.ssc.2015.09.006.

[67] F.H. Monteiro, D.G. Larrude, M.E.H. Maia da Costa, F.L. Freire, Estimating the boron doping level on single wall carbon nanotubes using Raman spectroscopy, Mater. Lett. 92 (2013) 224-226. doi:10.1016/j.matlet.2012.10.073.

[68] N. Yuan, H. Bai, Y. Ma, Y. Ji, First-principle simulations on silicon-doped armchair single-walled carbon nanotubes of various diameters, Phys. E Low-Dimensional Syst. Nanostructures. 64 (2014) 195-203. doi:10.1016/j.physe.2014.07.027.

[69] M. V. Kharlamova, Advances in tailoring the electronic properties of single-walled carbon nanotubes, Prog. Mater. Sci. 77 (2016) 125-211. doi:10.1016/j.pmatsci.2015.09.001.

[70] R.S. Singh, A. Solanki, Modulation of electronic properties of silicon carbide nanotubes via sulphur-doping: An ab initio study, Phys. Lett. A. 380 (2016) 12011204. doi:10.1016/j.physleta.2016.01.029.

[71] M.D. Ganji, M.G. Ahangari, A. Khosravi, Doping of carbon nanotubes with aluminum atom to improve Pt adsorption, Appl. Surf. Sci. 290 (2014) 86-91. doi:10.1016/j.apsusc.2013.11.003.

[72] F. López-Urías, M. Terrones, H. Terrones, Beryllium doping graphene, graphenenanoribbons, C60-fullerene, and carbon nanotubes, Carbon N. Y. 84 (2015) 317-326. doi:10.1016/j.carbon.2014.11.053.

[73] S.M. Abbas, U.A. Rana, S.U.-D. Khan, Z. Iqbal, N. Ahmad, MoN-decorated nitrogen doped carbon nanotubes anode with high lithium storage performance, Electrochim. Acta. 190 (2016) 988-996. doi:10.1016/j.electacta.2015.12.147.

[74] J. Yue, X. Gu, X. Jiang, L. Chen, N. Wang, J. Yang, X. Ma, Coaxial Manganese Dioxide@N-doped Carbon Nanotubes as Superior Anodes for Lithium Ion Batteries, Electrochim. Acta. 182 (2015) 676-681. doi:10.1016/j.electacta.2015.09.150.

[75] C.C. Li, H. Yu, Q. Yan, H.H. Hng, Nitrogen doped carbon nanotubes encapsulated $\mathrm{MnO}$ nanoparticles derived from metal coordination polymer towards high performance Lithium-ion Battery Anodes, Electrochim. Acta. 187 (2016) 406-412. doi:10.1016/j.electacta.2015.11.058.

[76] T. Sharifi, M. Valvo, E. Gracia-Espino, R. Sandström, K. Edström, T. Wågberg, Hierarchical self-assembled structures based on nitrogen-doped carbon nanotubes as advanced negative electrodes for Li-ion batteries and 3D microbatteries, J. Power Sources. 279 (2015) 581-592. doi:10.1016/j.jpowsour.2015.01.036.

[77] Q. Shi, F. Peng, S. Liao, H. Wang, H. Yu, Z. Liu, B. Zhang, D. Su, Sulfur and nitrogen co-doped carbon nanotubes for enhancing electrochemical oxygen reduction activity in acidic and alkaline media, J. Mater. Chem. A. 1 (2013) 14853. doi:10.1039/c3ta12647a.

[78] C. Wei, M. Shen, K. Ai, L. Lu, Transformation from FeS/Fe3C nanoparticles encased $\mathrm{S}, \mathrm{N}$ dual doped carbon nanotubes to nanosheets for enhanced oxygen reduction performance, Carbon N. Y. 123 (2017) 135-144. doi:10.1016/J.CARBON.2017.07.051.

[79] H. Lin, D. Chen, C. Lu, C. Zhang, F. Qiu, S. Han, X. Zhuang, Rational synthesis of 
N/S-doped porous carbons as high efficient electrocatalysts for oxygen reduction reaction and Zn-Air batteries, Electrochim. Acta. 266 (2018) 17-26.

doi:10.1016/J.ELECTACTA.2018.02.017.

[80] I. Zeferino González, A.M. Valenzuela-Muñiz, C. Ben Youssef, M. Miki Yoshida, N. Brodusch, R. Gauvin, Y. Verde Gómez, Parametric study on the influence of synthesis variables in the properties of nitrogen-doped carbon nanotubes, Int. J. Hydrog. Energy. 42 (2017) 30318-30329. doi:10.1016/J.IJHYDENE.2017.10.029.

[81] A. Sharma, K. Dasgupta, A. Patwardhan, J. Joshi, Kinetic study of nitrogen doped carbon nanotubes in a fixed bed, Chem. Eng. Sci. 170 (2017) 756-766. doi:10.1016/J.CES.2017.03.017.

[82] A. Ariharan, B. Viswanathan, V. Nandhakumar, Nitrogen-incorporated carbon nanotube derived from polystyrene and polypyrrole as hydrogen storage material, Int. J. Hydrog. Energy. (2018). doi:10.1016/J.IJHYDENE.2018.01.110.

[83] J.P.F. Santos, M. Arjmand, G.H.F. Melo, K. Chizari, R.E.S. Bretas, U. Sundararaj, Electrical conductivity of electrospun nanofiber mats of polyamide 6/polyaniline coated with nitrogen-doped carbon nanotubes, Mater. Des. 141 (2018) 333-341. doi:10.1016/J.MATDES.2017.12.052.

[84] L. Huang, Q. Guan, J. Cheng, C. Li, W. Ni, Z. Wang, Y. Zhang, B. Wang, Freestanding N-doped carbon nanofibers/carbon nanotubes hybrid film for flexible, robust half and full lithium-ion batteries, Chem. Eng. J. 334 (2018) 682-690. doi:10.1016/J.CEJ.2017.10.030.

[85] D. Janas, Powerful doping of chirality-sorted carbon nanotube films, Vacuum. 149 (2018) 48-52. doi:10.1016/J.VACUUM.2017.12.013.

[86] T. Altalhi, A. Mezni, A. Aldalbahi, A. Alrooqi, Y. Attia, A. Santos, D. Losic, Fabrication and characterisation of sulfur and phosphorus $(\mathrm{S} / \mathrm{P})$ co-doped carbon nanotubes, Chem. Phys. Lett. 658 (2016) 92-96. doi:10.1016/j.cplett.2016.06.028.

[87] D. Liu, P. Du, W. Wei, H. Wang, Q. Wang, P. Liu, Flexible and Robust SandwichStructured S-Doped Reduced Graphene Oxide/Carbon Nanotubes/Polyaniline (SrGO/CNTs/PANI) Composite Membranes: Excellent Candidate as Free-Standing Electrodes for High-Performance Supercapacitors, Electrochim. Acta. 233 (2017) 201209. doi:10.1016/J.ELECTACTA.2017.03.040.

[88] G.-L. Li, G.-C. Cheng, W.-W. Chen, C.-D. Liu, L.-F. Yuan, B.-B. Yang, C. Hao, N/S/B-doped graphitized carbon encased Fe species as a highly active and durable catalyst towards oxygen reduction reaction, J. Colloid Interface Sci. 514 (2018) 108116. doi:10.1016/J.JCIS.2017.12.012.

[89] S. Yang, X. Mao, Z. Cao, Y. Yin, Z. Wang, M. Shi, H. Dong, Onion-derived N, S selfdoped carbon materials as highly efficient metal-free electrocatalysts for the oxygen reduction reaction, Appl. Surf. Sci. 427 (2018) 626-634. doi:10.1016/J.APSUSC.2017.08.222.

[90] D. Zhao, L. Li, L. Xie, N. Zhou, S. Chen, Sulfur codoping enables efficient oxygen electroreduction on FeCo alloy encapsulated in N-Doped carbon nanotubes, J. Alloy. Compd. 741 (2018) 368-376. doi:10.1016/J.JALLCOM.2018.01.144.

[91] Y. Dong, H. Pang, H. Bin Yang, C. Guo, J. Shao, Y. Chi, C.M. Li, T. Yu, Carbon- 
Based Dots Co-doped with Nitrogen and Sulfur for High Quantum Yield and Excitation-Independent Emission, Angew. Chem. Int. Ed. . 52 (2013) 7800-7804. doi:10.1002/anie.201301114.

[92] I.M. Patil, V. Reddy, M. Lokanathan, B. Kakade, Nitrogen and sulphur co-doped multiwalled carbon nanotubes as an efficient electrocatalyst for improved oxygen electroreduction, Appl. Surf. Sci. (2017). doi:10.1016/J.APSUSC.2017.12.124.

[93] C. Domínguez, F.J. Pérez-Alonso, S.A. Al-Thabaiti, S.N. Basahel, A.Y. Obaid, A.O. Alyoubi, J.L. Gómez de la Fuente, S. Rojas, Effect of N and S co-doping of multiwalled carbon nanotubes for the oxygen reduction, Electrochim. Acta. 157 (2015) 158-165. doi:10.1016/j.electacta.2015.01.031.

[94] Y. Li, R. Mi, S. Li, X. Liu, W. Ren, H. Liu, J. Mei, W.-M. Lau, Sulfur-nitrogen doped multi walled carbon nanotubes composite as a cathode material for lithium sulfur batteries, Int. J. Hydrog. Energy. 39 (2014) 16073-16080. doi:10.1016/J.IJHYDENE.2014.04.047.

[95] Y. Zhao, F. Yin, Y. Zhang, C. Zhang, A. Mentbayeva, N. Umirov, H. Xie, Z. Bakenov, A Free-Standing Sulfur/Nitrogen-Doped Carbon Nanotube Electrode for HighPerformance Lithium/Sulfur Batteries, Nanoscale Res. Lett. 10 (2015) 450. doi:10.1186/s11671-015-1152-4.

[96] T. Cui, R. Lv, Z. Huang, F. Kang, K. Wang, D. Wu, Effect of sulfur on enhancing nitrogen-doping and magnetic properties of carbon nanotubes, Nanoscale Res. Lett. 6 (2011) 77. doi:10.1186/1556-276X-6-77.

[97] K. Xie, W. Xia, J. Masa, F. Yang, P. Weide, W. Schuhmann, M. Muhler, Promoting effect of nitrogen doping on carbon nanotube-supported $\mathrm{RuO} 2$ applied in the electrocatalytic oxygen evolution reaction, J. Energy Chem. 25 (2016) 282-288. doi:10.1016/j.jechem.2016.01.023.

[98] E.A. González, M. Gulppi, M.A. Páez, J.H. Zagal, O2 reduction on electrodes modified with nitrogen doped carbon nanotubes synthesized with different metal catalysts, Diam. Relat. Mater. 64 (2016) 119-129. doi:10.1016/j.diamond.2016.02.003.

[99] Z. Liu, M. Li, F. Wang, Q.-D. Wang, Novel As-doped, As and N-codoped carbon nanotubes as highly active and durable electrocatalysts for $\mathrm{O} 2$ reduction in alkaline medium, J. Power Sources. 306 (2016) 535-540. doi:10.1016/j.jpowsour.2015.12.053.

[100] T. Sharifi, W.L. Kwong, H.-M. Berends, C. Larsen, J. Messinger, T. Wågberg, Maghemite nanorods anchored on a 3D nitrogen-doped carbon nanotubes substrate as scalable direct electrode for water oxidation, Int. J. Hydrogen Energy. 41 (2016) 6978. doi:10.1016/j.ijhydene.2015.11.165.

[101] W.Y. Wong, W.R.W. Daud, A.B. Mohamad, A.A.H. Kadhum, K.S. Loh, E.H. Majlan, Influence of nitrogen doping on carbon nanotubes towards the structure, composition and oxygen reduction reaction, Int. J. Hydrogen Energy. 38 (2013) 9421-9430. doi:10.1016/j.ijhydene.2013.01.189.

[102] R. Bresciani, S. Marzorati, A. Lascialfari, B. Sacchi, N. Santo, M. Longhi, Effects of catalyst aging on the growth morphology and oxygen reduction activity of nitrogendoped carbon nanotubes, Electrochem. Commun. 51 (2015) 27-32. doi:10.1016/j.elecom.2014.12.003. 
[103] G. Zhong, H. Wang, H. Yu, F. Peng, Nitrogen doped carbon nanotubes with encapsulated ferric carbide as excellent electrocatalyst for oxygen reduction reaction in acid and alkaline media, J. Power Sources. 286 (2015) 495-503.

doi:10.1016/j.jpowsour.2015.04.021.

[104] Y. Cheng, Y. Tian, X. Fan, J. Liu, C. Yan, Boron Doped Multi-walled Carbon Nanotubes as Catalysts for Oxygen Reduction Reaction and Oxygen Evolution Reactionin in Alkaline Media, Electrochim. Acta. 143 (2014) 291-296. doi:10.1016/j.electacta.2014.08.001.

[105] Y. Cheng, Y. Tian, S.-W. Tsang, C. Yan, Ag Nanoparticles on Boron Doped Multiwalled Carbon Nanotubes as a Synergistic Catalysts for Oxygen Reduction Reaction in Alkaline Media, Electrochim. Acta. 174 (2015) 919-924. doi:10.1016/j.electacta.2015.05.183.

[106] P. Song, X. Bo, A. Nsabimana, L. Guo, Additional doping of phosphorus into polypyrrole functionalized nitrogenous carbon nanotubes as novel metal-free oxygen reduction electrocatalyst in alkaline solution, Int. J. Hydrogen Energy. 39 (2014) 15464-15473. doi:10.1016/j.ijhydene.2014.07.126.

[107] X. Fu, Q.-D. Wang, Z. Liu, F. Peng, Si-doped carbon nanotubes as efficient metal-free electrocatalysts for O2 reduction in alkaline medium, Mater. Lett. 158 (2015) 32-35. doi:10.1016/j.matlet.2015.05.141.

[108] W. Li, D. Yang, H. Chen, Y. Gao, H. Li, Sulfur-doped carbon nanotubes as catalysts for the oxygen reduction reaction in alkaline medium, Electrochim. Acta. 165 (2015) 191-197. doi:10.1016/j.electacta.2015.03.022.

[109] T. Liu, K. Wang, S. Song, A. Brouzgou, P. Tsiakaras, Y. Wang, New Electro-Fenton Gas Diffusion Cathode based on Nitrogen-doped Graphene@Carbon Nanotube Composite Materials, Electrochim. Acta. 194 (2016) 228-238. doi:10.1016/j.electacta.2015.12.185.

[110] A. Modi, S. Singh, N. Verma, In situ nitrogen-doping of nickel nanoparticle-dispersed carbon nanofiber-based electrodes: Its positive effects on the performance of a microbial fuel cell, Electrochim. Acta. 190 (2016) 620-627. doi:10.1016/j.electacta.2015.12.191.

[111] D. Hiltrop, J. Masa, A. Maljusch, W. Xia, W. Schuhmann, M. Muhler, Pd deposited on functionalized carbon nanotubes for the electrooxidation of ethanol in alkaline media, Electrochem. Commun. 63 (2016) 30-33. doi:10.1016/j.elecom.2015.11.010.

[112] R. Liu, Z. Luo, Q. Wei, X. Zhou, Pt-RuO2 nanoparticles supported on diaminoanthraquinone-functionalized carbon nanotubes as efficient catalysts for methanol oxidation, Mater. Des. 94 (2016) 132-138.

doi:10.1016/j.matdes.2016.01.026.

[113] M. Ran, W. Chu, Y. Liu, D. Liu, C. Zhang, J. Zheng, Doping effects of manganese on the catalytic performance and structure of $\mathrm{NiMgO}$ catalysts for controllabe synthesis of multi-walled carbon nanotubes, J. Energy Chem. 23 (2014) 781-788. doi:10.1016/S2095-4956(14)60212-6.

[114] L.M. Ombaka, P.G. Ndungu, B. Omondi, J.D. McGettrick, M.L. Davies, V.O. Nyamori, A Facile Approach Towards Increasing the Nitrogen-content in Nitrogendoped Carbon Nanotubes via Halogenated Catalysts, J. Solid State Chem. 235 (2016) 
202-211. doi:10.1016/j.jssc.2016.01.007.

[115] H. Xiong, M.A. Motchelaho, M. Moyo, L.L. Jewell, N.J. Coville, Fischer-Tropsch synthesis: Iron-based catalysts supported on nitrogen-doped carbon nanotubes synthesized by post-doping, Appl. Catal. A Gen. 482 (2014) 377-386. doi:10.1016/j.apcata.2014.06.019.

[116] S. Jiang, E.S. Handberg, F. Liu, Y. Liao, H. Wang, Z. Li, S. Song, Effect of doping the nitrogen into carbon nanotubes on the activity of $\mathrm{NiO}$ catalysts for the oxidation removal of toluene, Appl. Catal. B Environ. 160-161 (2014) 716-721. doi:10.1016/j.apcatb.2014.06.026.

[117] M. Zhang, J. Shi, Y. Sun, W. Ning, Z. Hou, Selective oxidation of glycerol over nitrogen-doped carbon nanotubes supported platinum catalyst in base-free solution, Catal. Commun. 70 (2015) 72-76. doi:10.1016/j.catcom.2015.08.002.

[118] J. Luo, F. Peng, H. Wang, H. Yu, Enhancing the catalytic activity of carbon nanotubes by nitrogen doping in the selective liquid phase oxidation of benzyl alcohol, Catal. Commun. 39 (2013) 44-49. doi:10.1016/j.catcom.2013.04.030.

[119] X. Ning, H. Yu, F. Peng, H. Wang, Pt nanoparticles interacting with graphitic nitrogen of N-doped carbon nanotubes: Effect of electronic properties on activity for aerobic oxidation of glycerol and electro-oxidation of CO, J. Catal. 325 (2015) 136-144. doi:10.1016/j.jcat.2015.02.010.

[120] X. Lu, Y. Hu, L. Wang, Q. Guo, S. Chen, S. Chen, H. Hou, Y. Song, Macroporous Carbon/Nitrogen-doped Carbon Nanotubes/Polyaniline Nanocomposites and Their Application in Supercapacitors, Electrochim. Acta. 189 (2016) 158-165. doi:10.1016/j.electacta.2015.12.099.

[121] W. Bao, B. Yu, W. Li, H. Fan, J. Bai, Z. Ren, Co3O4/nitrogen-doped graphene/carbon nanotubes: An innovative ternary composite with enhanced electrochemical performance, J. Alloys Compd. 647 (2015) 873-879.

doi:10.1016/j.jallcom.2015.06.128.

[122] T.-T. Lin, W.-H. Lai, Q.-F. Lü, Y. Yu, Porous nitrogen-doped graphene/carbon nanotubes composite with an enhanced supercapacitor performance, Electrochim. Acta. 178 (2015) 517-524. doi:10.1016/j.electacta.2015.08.048.

[123] D.P. Dubal, N.R. Chodankar, Z. Caban-Huertas, F. Wolfart, M. Vidotti, R. Holze, C.D. Lokhande, P. Gomez-Romero, Synthetic approach from polypyrrole nanotubes to nitrogen doped pyrolyzed carbon nanotubes for asymmetric supercapacitors, J. Power Sources. 308 (2016) 158-165. doi:10.1016/j.jpowsour.2016.01.074.

[124] Y. Yang, L. Liu, Y. Tang, Y. Zhang, D. Jia, L. Kong, Bamboo-like carbon nanotubes containing sulfur for high performance supercapacitors, Electrochim. Acta. 191 (2016) 846-853. doi:10.1016/j.electacta.2016.01.149.

[125] D.S. Montgomery, C.A. Hewitt, R. Barbalace, T. Jones, D.L. Carroll, Spray doping method to create a low-profile high-density carbon nanotube thermoelectric generator, Carbon N. Y. 96 (2016) 778-781. doi:10.1016/j.carbon.2015.09.029.

[126] V.S. Thakare, M. Das, A.K. Jain, S. Patil, S. Jain, Carbon nanotubes in cancer theragnosis., Nanomedicine. 5 (2010) 1277-1301. doi:10.2217/nnm.10.95.

[127] M. Zhang, G. Zhou, Y. Feng, T. Xiong, H. Hou, Q. Guo, Flexible 3D nitrogen-doped 
carbon nanotubes nanostructure: A good matrix for enzyme immobilization and biosensing, Sensors Actuators B Chem. 222 (2016) 829-838.

doi:10.1016/j.snb.2015.09.030.

[128] J. Han, L. Jiang, F. Li, P. Wang, Q. Liu, Y. Dong, Y. Li, Q. Wei, Ultrasensitive nonenzymatic immunosensor for carcino-embryonic antigen based on palladium hybrid vanadium pentoxide/multiwalled carbon nanotubes, Biosens. Bioelectron. 77 (2016) 1104-1111. doi:10.1016/j.bios.2015.11.008.

[129] X. Chen, S. Lian, Y. Ma, A. Peng, X. Tian, Z. Huang, X. Chen, Electrochemiluminescence sensor for melamine based on a $\mathrm{Ru}(\mathrm{bpp})(3)(2+)$-doped silica nanoparticles/carboxylic acid functionalized multi-walled carbon nanotubes/Nafion composite film modified electrode, Talanta. 146 (2016) 844-850. doi:10.1016/j.talanta.2015.05.076.

[130] A.K. Baytak, T. Teker, S. Duzmen, M. Aslanoglu, A Novel Voltammetric Sensor based on Carbon Nanotubes and Nanoparticles of Antimony Tin Oxide for the Determination of Ractopamine, Mater. Sci. Eng. C. 59 (2016) 368-374. doi:10.1016/j.msec.2015.10.030.

[131] Q. Guo, M. Zhang, G. Zhou, L. Zhu, Y. Feng, H. Wang, B. Zhong, H. Hou, Highly sensitive simultaneous electrochemical detection of hydroquinone and catechol with three-dimensional N-doping carbon nanotube film electrode, J. Electroanal. Chem. 760 (2016) 15-23. doi:10.1016/j.jelechem.2015.11.034.

[132] M.-S. Wu, Z.-Z. Ceng, Bamboo-like nitrogen-doped carbon nanotubes formed by direct pyrolysis of Prussian blue analogue as a counter electrode material for dyesensitized solar cells, Electrochim. Acta. 191 (2016) 895-901. doi:10.1016/j.electacta.2016.01.123.

[133] L. Yu, R. Wang, L. Xu, Preparation of acylamino copper Phthalocyanine modified multiwalled carbon nanotubes thin films with oxygen plasma treatment, Mater. Lett. 164 (2016) 282-285. doi:10.1016/j.matlet.2015.09.078.

[134] M. Mananghaya, Hydrogen adsorption of novel N-doped carbon nanotubes functionalized with Scandium, Int. J. Hydrogen Energy. 40 (2015) 9352-9358. doi:10.1016/j.ijhydene.2015.05.087.

[135] M. Mohammadi, B. Khoshnevisan, Doping effects of Co on exo-hydrogenated narrow single-walled carbon nanotubes, Int. J. Hydrogen Energy. 39 (2014) 2087-2092. doi:10.1016/j.ijhydene.2013.11.036.

[136] Y.K. Mishra, R. Adelung, C. Röhl, D. Shukla, F. Spors, V. Tiwari, Virostatic Potential of Micro-nano Filopodia-like ZnO Structures Against Herpes Simplex Virus-1, Antivir. Res. 92 (2011) 305-312.

[137] S.H. Barghi, T.T. Tsotsis, M. Sahimi, Experimental investigation of hydrogen adsorption in doped silicon-carbide nanotubes, Int. J. Hydrogen Energy. 41 (2016) 369-374. doi:10.1016/j.ijhydene.2015.10.091.

[138] W. Li, X.M. Lu, G.Q. Li, J.J. Ma, P.Y. Zeng, J.F. Chen, Z.L. Pan, Q.Y. He, Firstprinciple study of SO2molecule adsorption on Ni-doped vacancy-defected singlewalled $(8,0)$ carbon nanotubes, Appl. Surf. Sci. 364 (2016) 560-566.

doi:10.1016/j.apsusc.2015.12.177. 
[139] H. Zhou, J. Xie, S. Ban, Insights into the ultrahigh gas separation efficiency of Lithium doped carbon nanotube membrane using carrier-facilitated transport mechanism, J. Memb. Sci. 493 (2015) 599-604. doi:10.1016/j.memsci.2015.07.029.

[140] M. Ioniţă, G.M. Vlăsceanu, A.A. Watzlawek, S.I. Voicu, J.S. Burns, H. Iovu, Graphene and functionalized graphene: Extraordinary prospects for nanobiocomposite materials, Compos. Part B Eng. (n.d.). doi:10.1016/j.compositesb.2017.03.031.

[141] M. Mecklenburg, A. Schuchardt, Y.K. Mishra, S. Kaps, R. Adelung, A. Lotnyk, L. Kienle, K. Schulte, Aerographite: ultra lightweight, flexible nanowall, carbon microtube material with outstanding mechanical performance, Adv. Mater. 24 (2012) 3486-3490.

[142] O. Parlak, Y.K. Mishra, A. Grigoriev, M. Mecklenburg, W. Luo, S. Keene, A. Salleo, K. Schulte, R. Ahuja, R. Adelung, Hierarchical Aerographite Nano-Microtubular Tetrapodal Networks based Electrodes as Lightweight Supercapacitor, Nano Energy. 34 (2017) 570-577.

[143] E.L. Silva, Y.K. Mishra, A.J.S. Fernandes, R.F. Silva, J. Strobel, L. Kienle, R. Adelung, F.J. Oliveira, M.L. Zheludkevich, Direct Synthesis of Electrowettable Carbon Nanowall-Diamond Hybrid Materials from Sacrificial Ceramic Templates Using HFCVD, Adv. Mater. Interfaces. 4 (2017) 1700019. doi:10.1002/admi.201700019.

[144] K.M. Tripathi, T.S. Tran, Y.J. Kim, T. Kim, Green fluorescent onion-Like carbon nanoparticles from flaxseed oil for visible light induced photocatalytic applications and label-free detection of Al(III) ions, ACS Sustain. Chem. Eng. 5 (2017) 3982-3992. doi:10.1021/acssuschemeng.6b03182.

[145] S. Garlof, T. Fukuda, M. Mecklenburg, D. Smazna, Y.K. Mishra, R. Adelung, K. Schulte, B. Fiedler, Electro-mechanical Piezoresistive Properties of Three Dimensionally Interconnected Carbon Aerogel (Aerographite)-epoxy Composites, Compos. Sci. Technol. 134 (2016) 226-233. doi:10.1016/j.compscitech.2016.08.019.

[146] S. Garlof, M. Mecklenburg, D. Smazna, Y.K. Mishra, R. Adelung, K. Schulte, B. Fiedler, 3D Carbon Networks and Their Polymer Composites: Fabrication and Electromechanical Investigations of Neat Aerographite and Aerographite-based PNCs Under Compressive Load, Carbon N. Y. 111 (2017) 103-112. doi:10.1016/j.carbon.2016.09.046.

[147] H. Ji, L. Zhang, M.T. Pettes, H. Li, S. Chen, L. Shi, R. Piner, R.S. Ruoff, Ultrathin graphite foam: a three-dimensional conductive network for battery electrodes, Nano Lett. 12 (2012) 2446-2451.

[148] F. Schütt, S. Signetti, H. Krüger, S. Röder, D. Smazna, S. Kaps, S.N. Gorb, Y.K. Mishra, N.M. Pugno, R. Adelung, Hierarchical self-entangled carbon nanotube tube networks, Nat. Commun. 8 (2017) 1215. doi:10.1038/s41467-017-01324-7.

[149] Y.K. Mishra, R. Adelung, ZnO tetrapod materials for functional applications, Mater. Today. (2018) (10.1016/j.mattod.2017.11.003). doi:10.1016/j.mattod.2017.11.003.

[150] D. Smazna, J. Rodrigues, S. Shree, V. Postica, G. Neubüser, A.F. Martins, N. Ben Sedrine, N.K. Jena, L. Siebert, F. Schütt, O. Lupan, R. Ahuja, M.R.P. Correia, T. Monteiro, L. Kienle, Y. Yang, R. Adelung, Y.K. Mishra, Buckminsterfullerene Hybridized Zinc Oxide Tetrapods: Defects and Charge Transfer Induced Optical and 
Electrical Response, Nanoscale. (2018) (DOI:10.1039/C8NR01504J). doi:10.1039/C8NR01504J. 
(a)

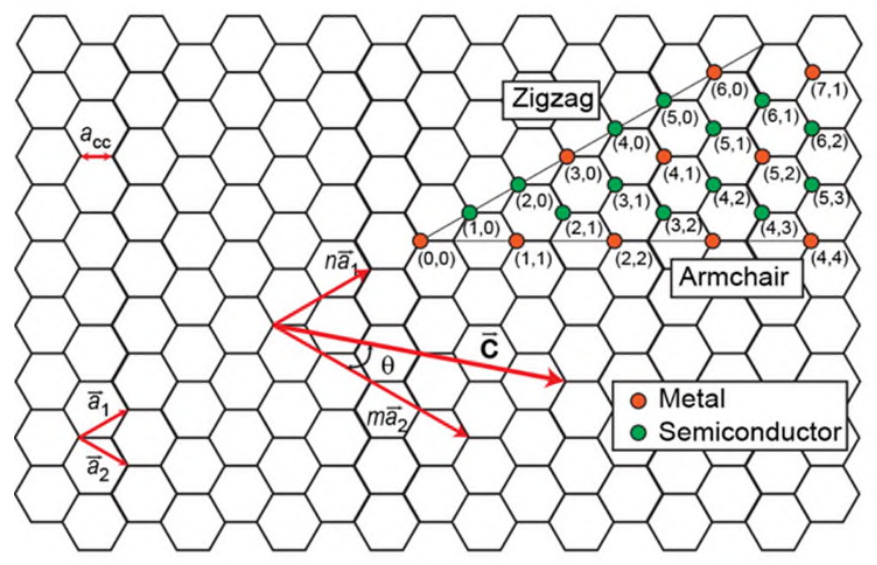

(b)

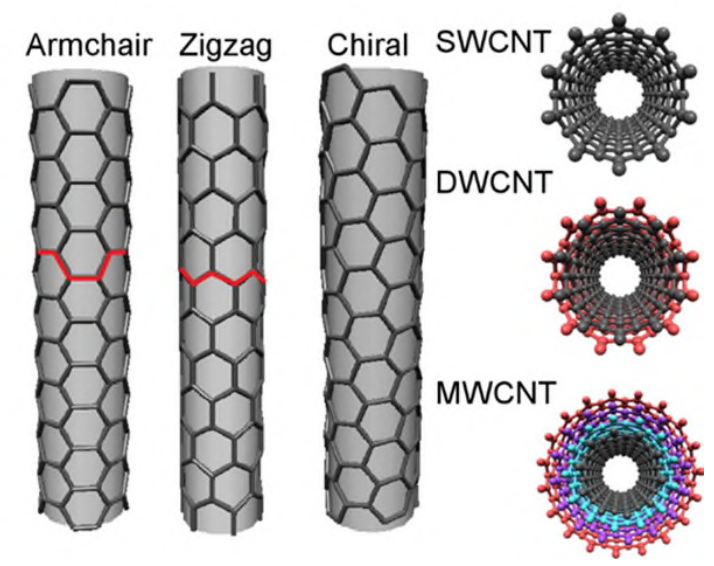

Scheme 1. (a) Unrolled SWCNT showing chiral vector $C$ and how different values of the integers $\mathrm{n}$ and $\mathrm{m}$ affect the electrical property of the SWCNT; (b) The direction of the chiral vector affects the appearance of the nanotube. Examples of CNTs are shown: $(4,4)$ armchair shape, $(6,0)$ zigzag shape, and $(5,3)$ chiral shape; and (c) "Ball and stick" Representation of single-walled CNT (SWCNT), double-walled CNT (DWCNT), and multi-walled CNT (MWCNT) [27]. Reprinted with permission. [27] Copyright 2016 American Chemical Society. 


\section{FIGURE 1}

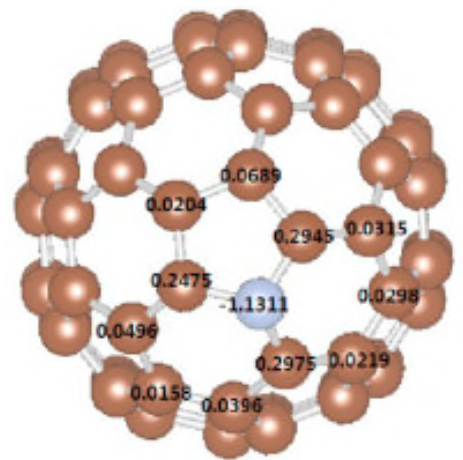

(a)

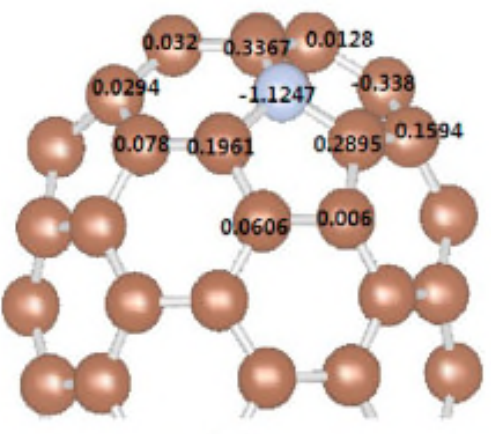

(b)

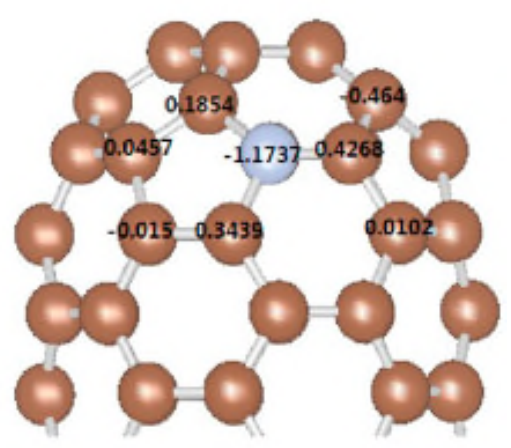

(c)

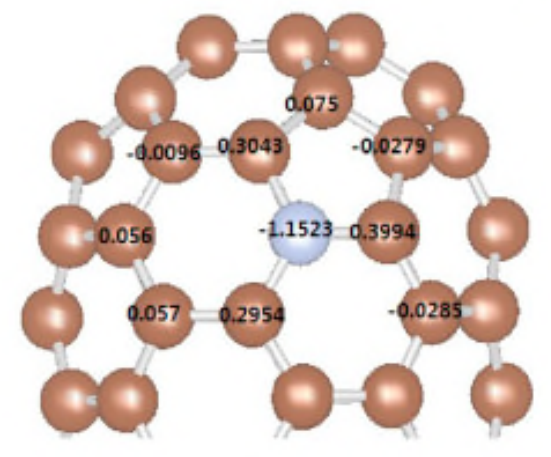

(d)

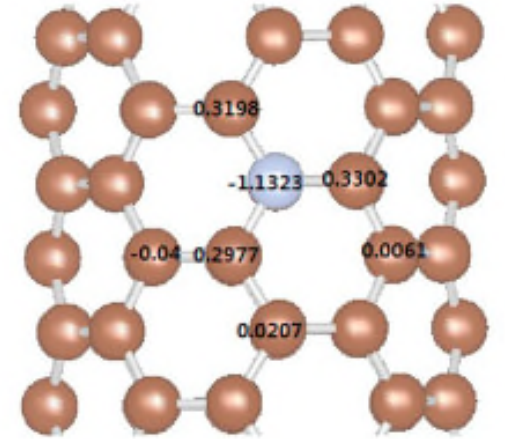

(e)

Figure 1. Bond structures of single $\mathrm{N}$ atom doping on different sites of $(5,5)$ SWNTs. (a-e) Represent N doping at the first, second, third, fourth layers, and the tube, respectively [58]. Reprinted with permission. [58] Copyright 2016 Elsevier. 


\section{FIGURE 2}

a

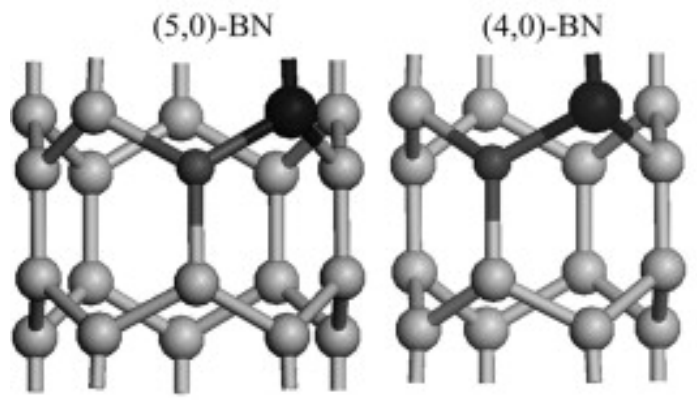

b

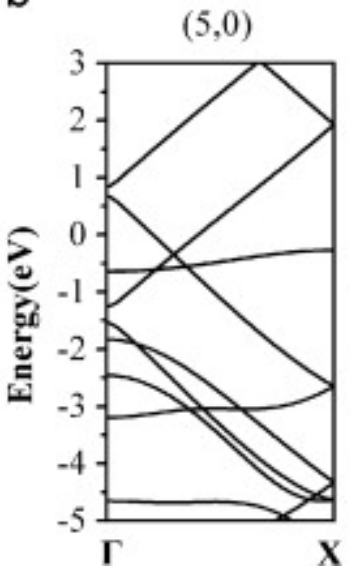

$(4,0)$

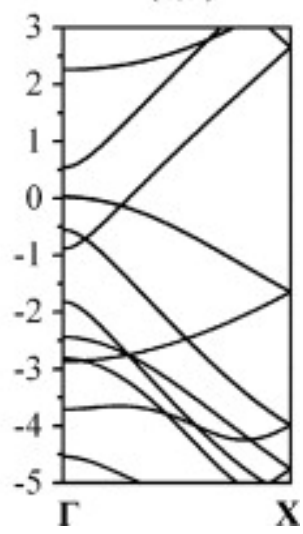

Figure 2. (a) Schematic diagram of $B-N$ co-doping $(5,0)$ and $(4,0)$ SWCNTs after optimization. The light gray ball represents $\mathrm{C}$ atom, the dark gray ball represents $\mathrm{N}$ atom and the black ball represents B atom. (b) Band structures of pristine $(5,0)$ and $(4,0)$ SWCNTs [60]. Reprinted with permission. [60]. Copyright 2014 Elsevier. 


\section{FIGURE 3}
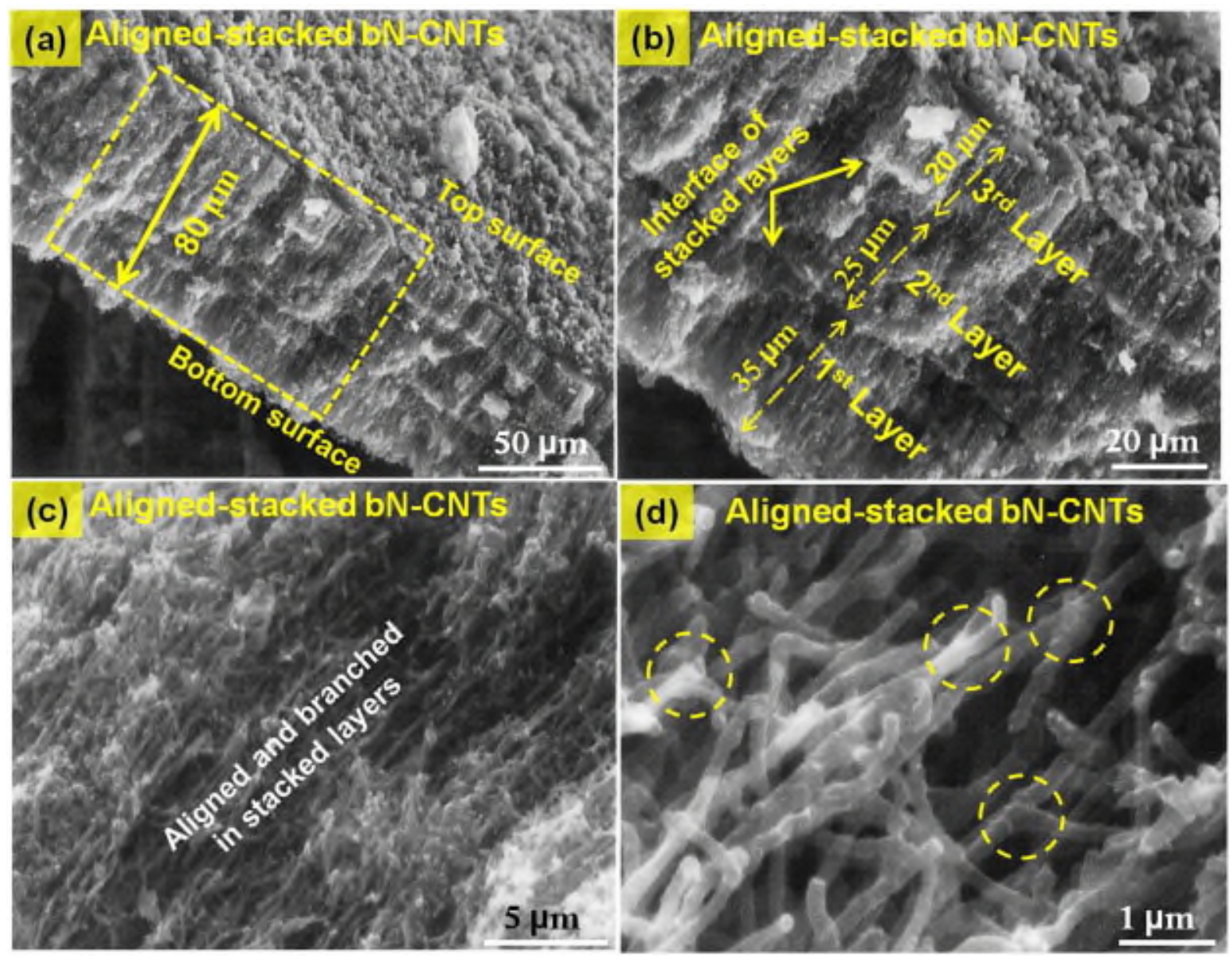

Figure 3. SEM images of aligned-stacked $b N-C N T s$ layers at different magnification. (a) Cross-sectional view of aligned-stacked layers. (b) SEM magnification side view of three aligned-stacked layer with interface between bN-CNT. (c) SEM image of aligned-stacked bNCNTs surface. (d) High magnification SEM image with Y-type junctions. Reprinted with permission. [64]. Copyright 2016 Elsevier. 


\section{FIGURE 4}

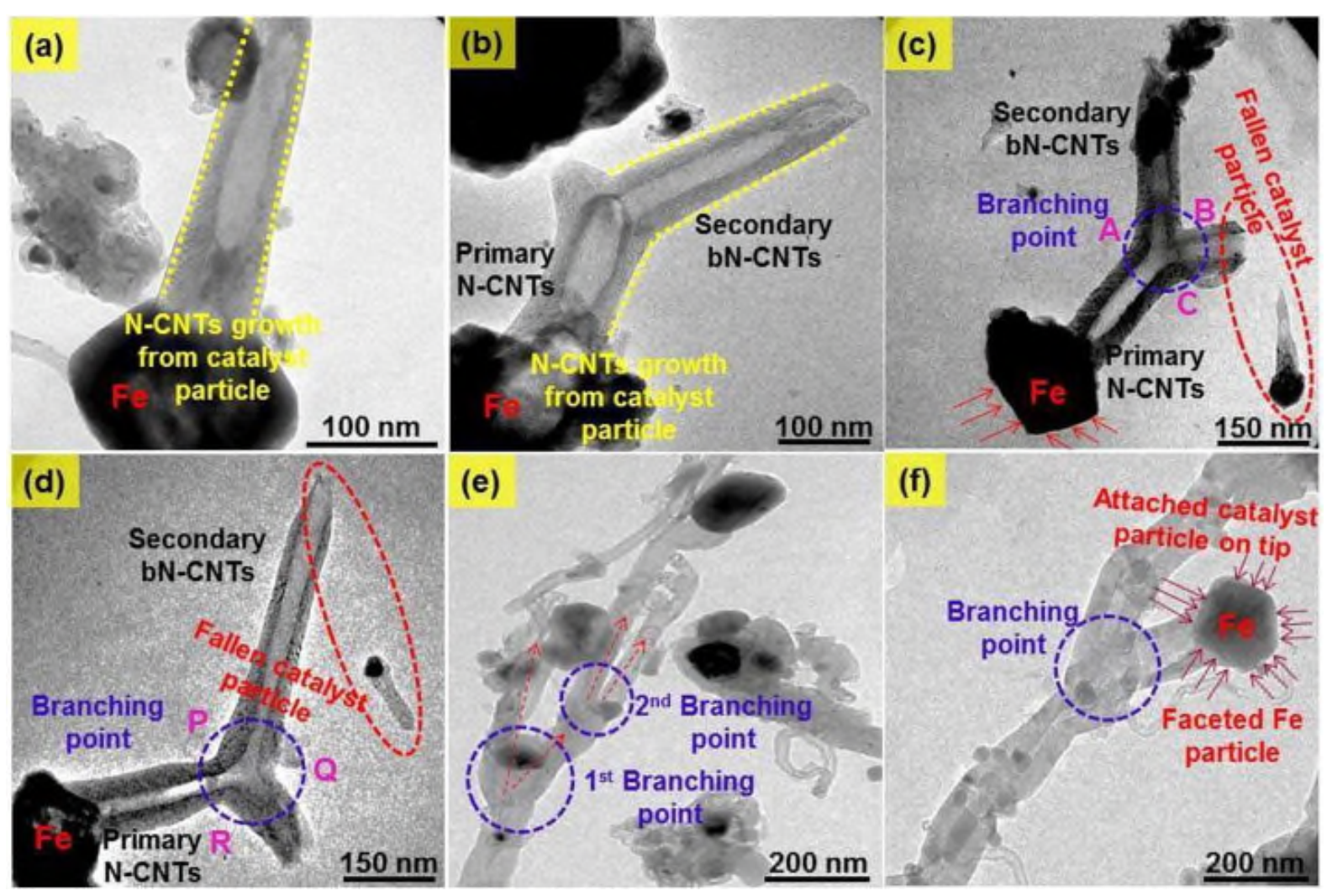

Figure 4. HR-TEM images of aligned-stacked bN-CNTs for growth mechanism detailed analysis. Primary N-CNTs (main branch) shows base growth however secondary bN-CNTs (sub-branched) shows tip growth mechanism. (a) Primary N-CNTs shows base growth from Fe catalyst particle, (b) two secondary bN-CNTs (two sub branching) from primary N-CNTs, (c and d) the growth of primary N-CNTs of faceted Fe catalyst and detachment of Fe particle (tip) from secondary bN-CNTs, (e) multi branching from primary and secondary bN-CNTs (1st branching from primary N-CNTs and 2nd branching from secondary bN-CNTs) and (f) one of the secondary bN-CNTs shows faceted Fe catalyst with tip growth mechanism. Reprinted with permission. [64]. Copyright 2016 Elsevier. 


\section{FIGURE 5}
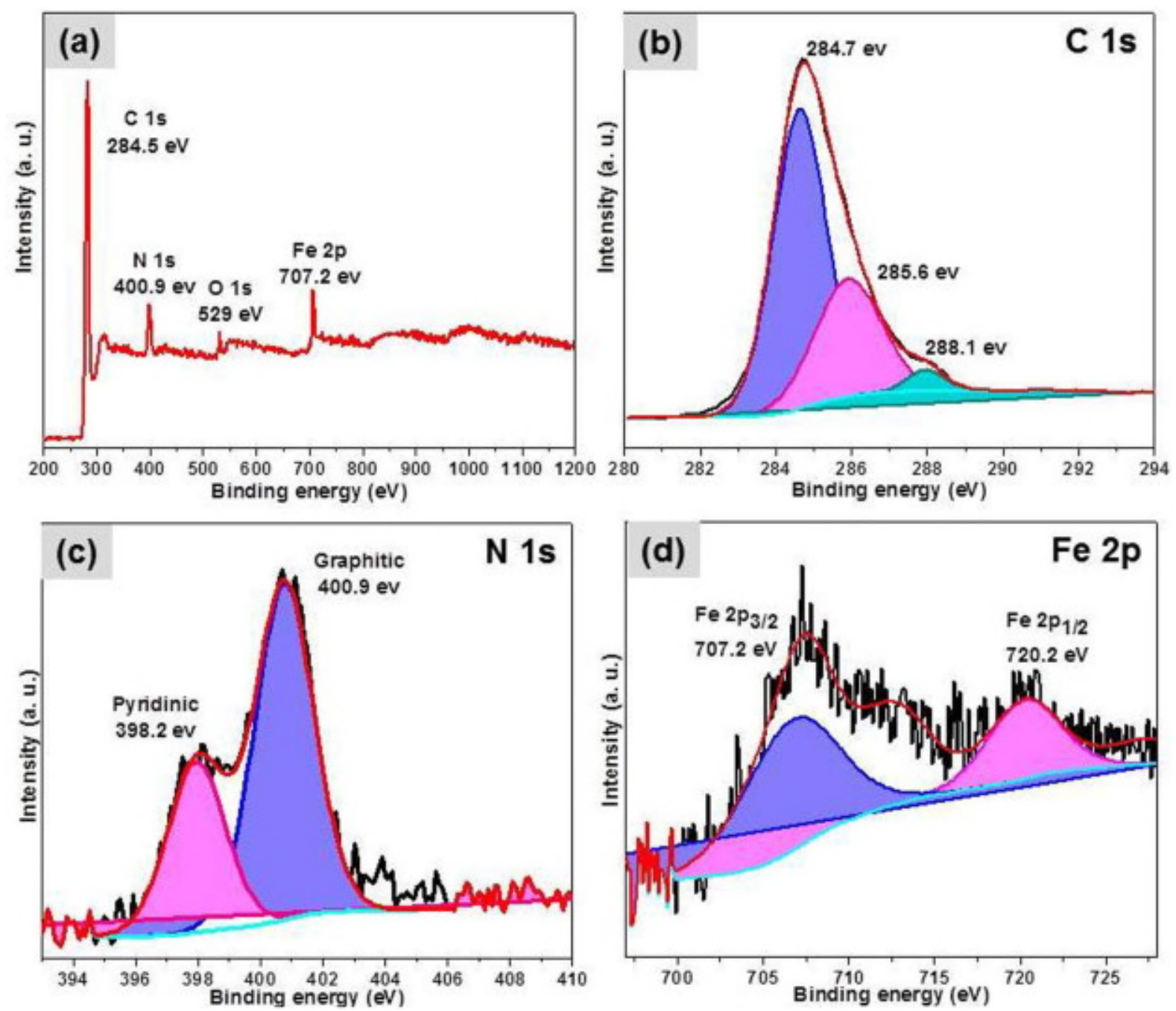

Figure 5. X-ray photoelectron spectra of aligned-stacked bN-CNTs. (a) XPS survey spectrum. Core level deconvoluted spectra of (b) C 1s, (b) N 1s and (c) Fe 2p spectrum. Reprinted with permission. [64]. Copyright 2016 Elsevier. 


\section{FIGURE 6}

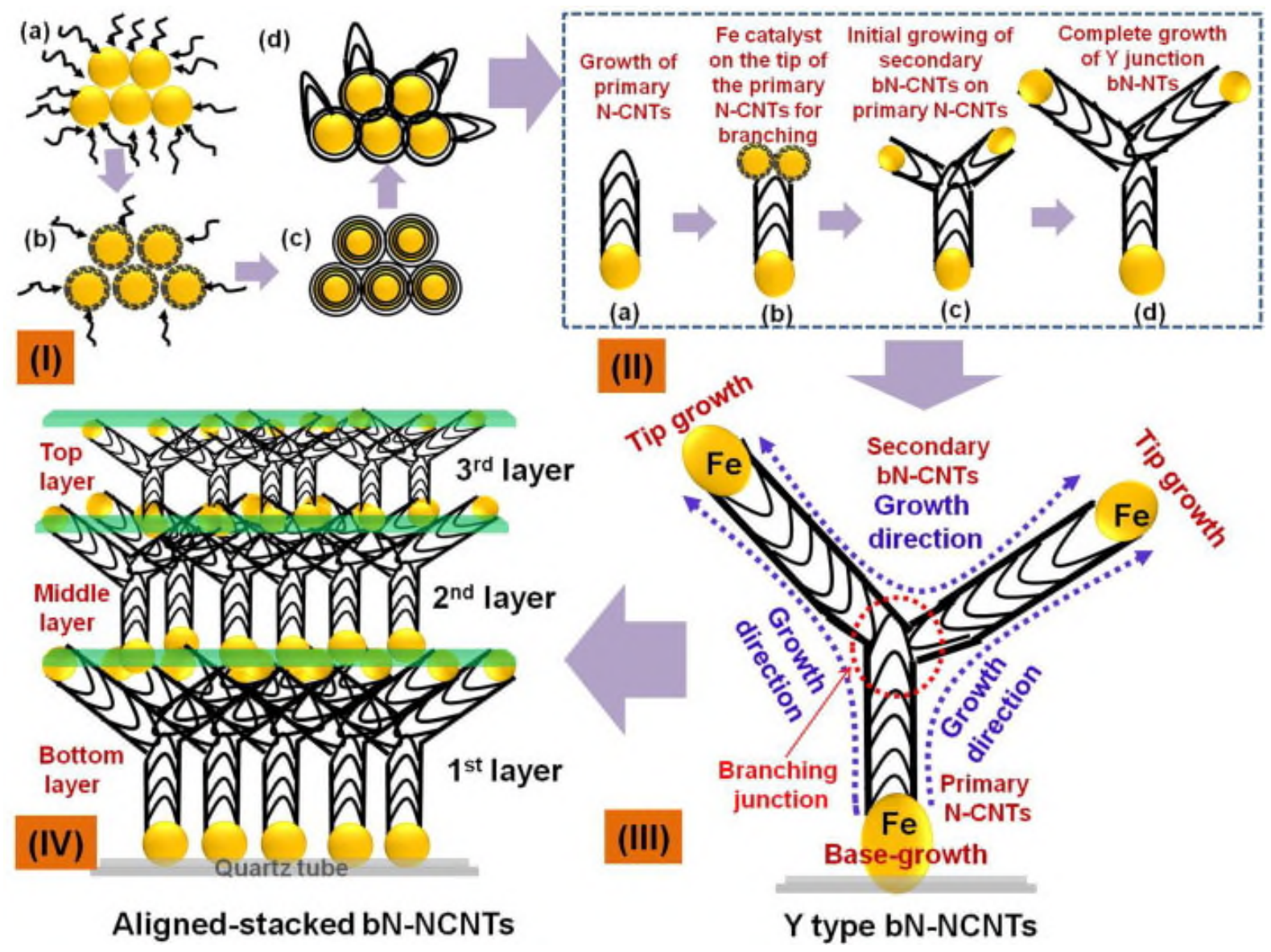

Figure 6. Schematic representation of growth mechanism of aligned-stacked bN-CNTs. (I) VLS growth for N-CNTs: (a) adsorption of hydrocarbon molecules from sesame oil and $\mathrm{CH} 3 \mathrm{CN}$ on $\mathrm{Fe}$ catalyst surface, (b) diffusion of the $\mathrm{C}$ and $\mathrm{N}$ species into catalyst, (c) supersaturation and precipitation of hexagonal carbon containing $\mathrm{N}$-doped sheets and (d) stretching the Fe catalyst into conical shape and initial growth of N-CNTs. (II) Formation of Y-type branched N-CNTs: (a) Growth of primary N-CNTs, (b) Fe catalyst on the tip of the primary N-CNTs for branching, (c) initial growing of secondary bN-CNTs on primary N-CNTs and (d) the final growth of Y-type bN-CNTs. (III) Complete formation of Y-type bN-CNTs with branching growth direction and (IV) final formation of aligned-stacked bN-CNTs. Reprinted with permission. [64]. Copyright 2016 Elsevier. 
FIGURE 7

a

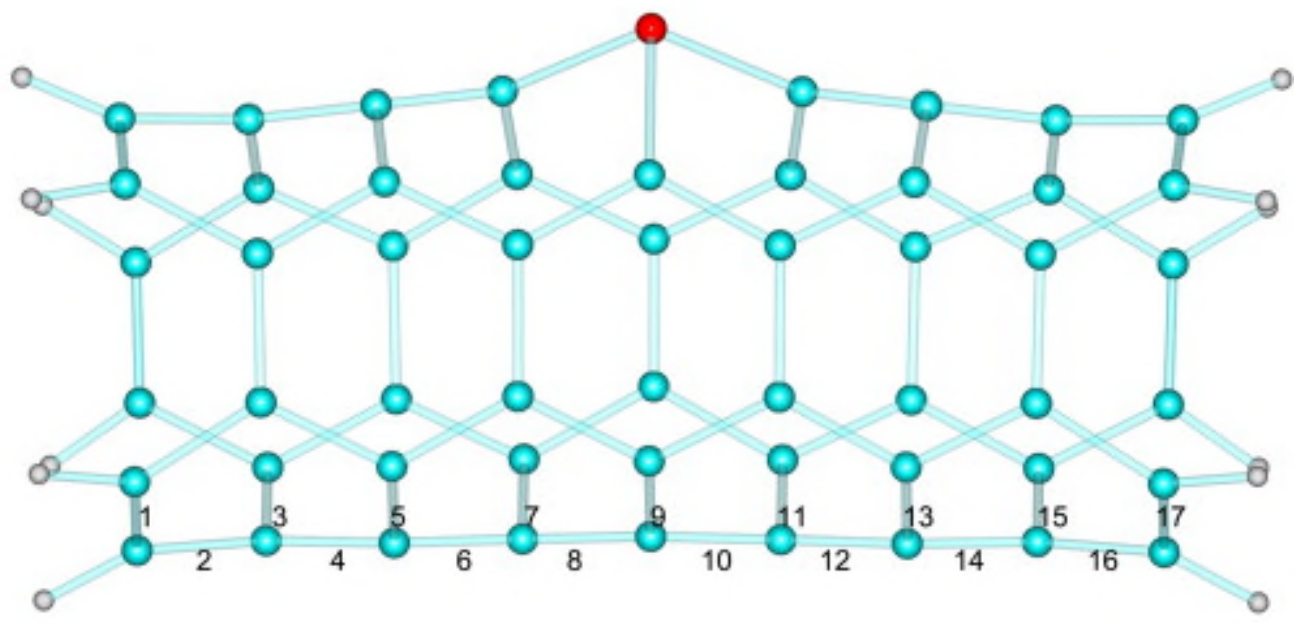

b
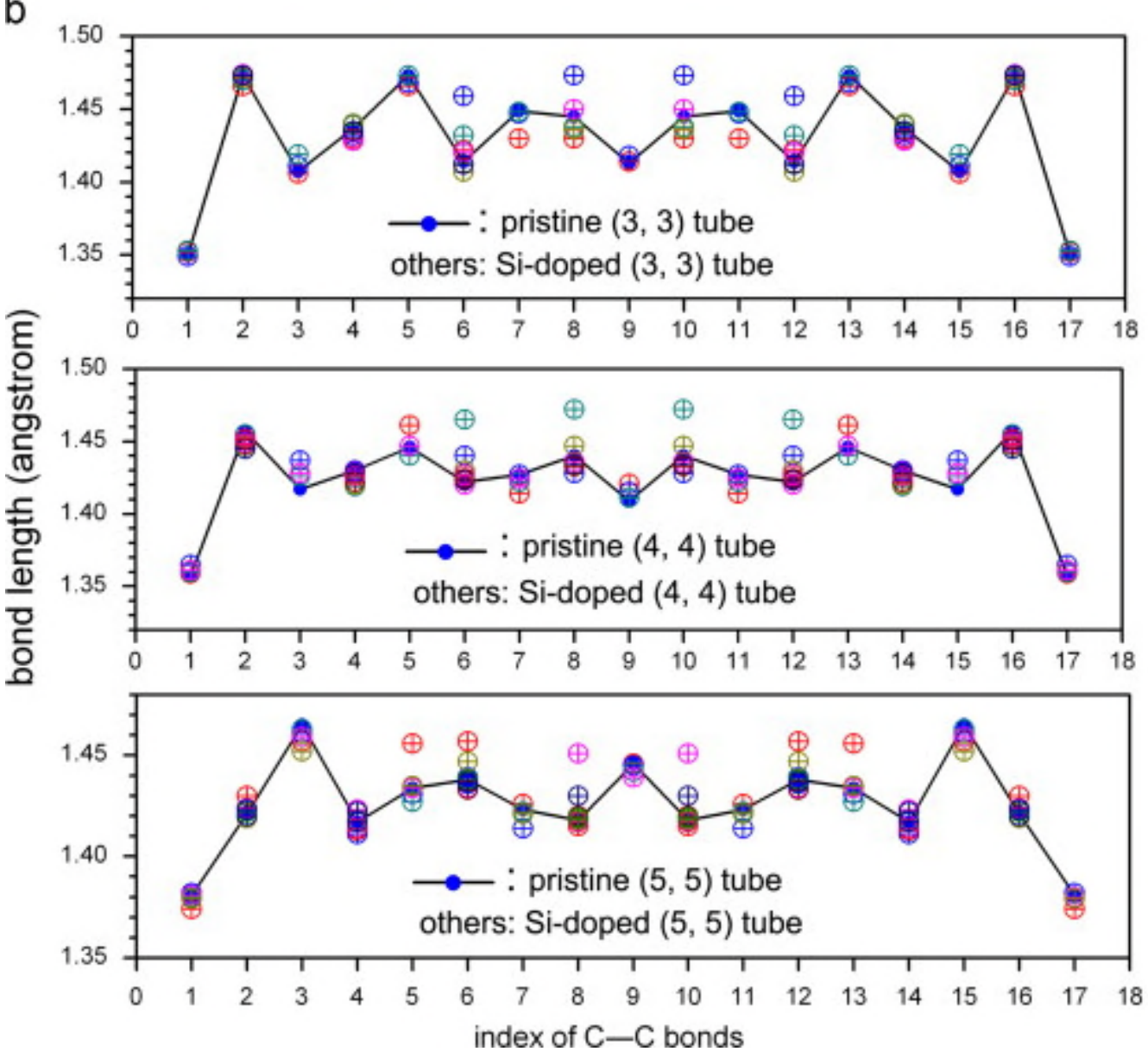

Figure 7. Structure (a) and bond lengths (b) of Si-doped tubes. The number in figure (a) is the index of $\mathrm{C}-\mathrm{C}$ bonds. Reprinted with permission [68]. Copyright 2014 Elsevier. 


\section{FIGURE 8}
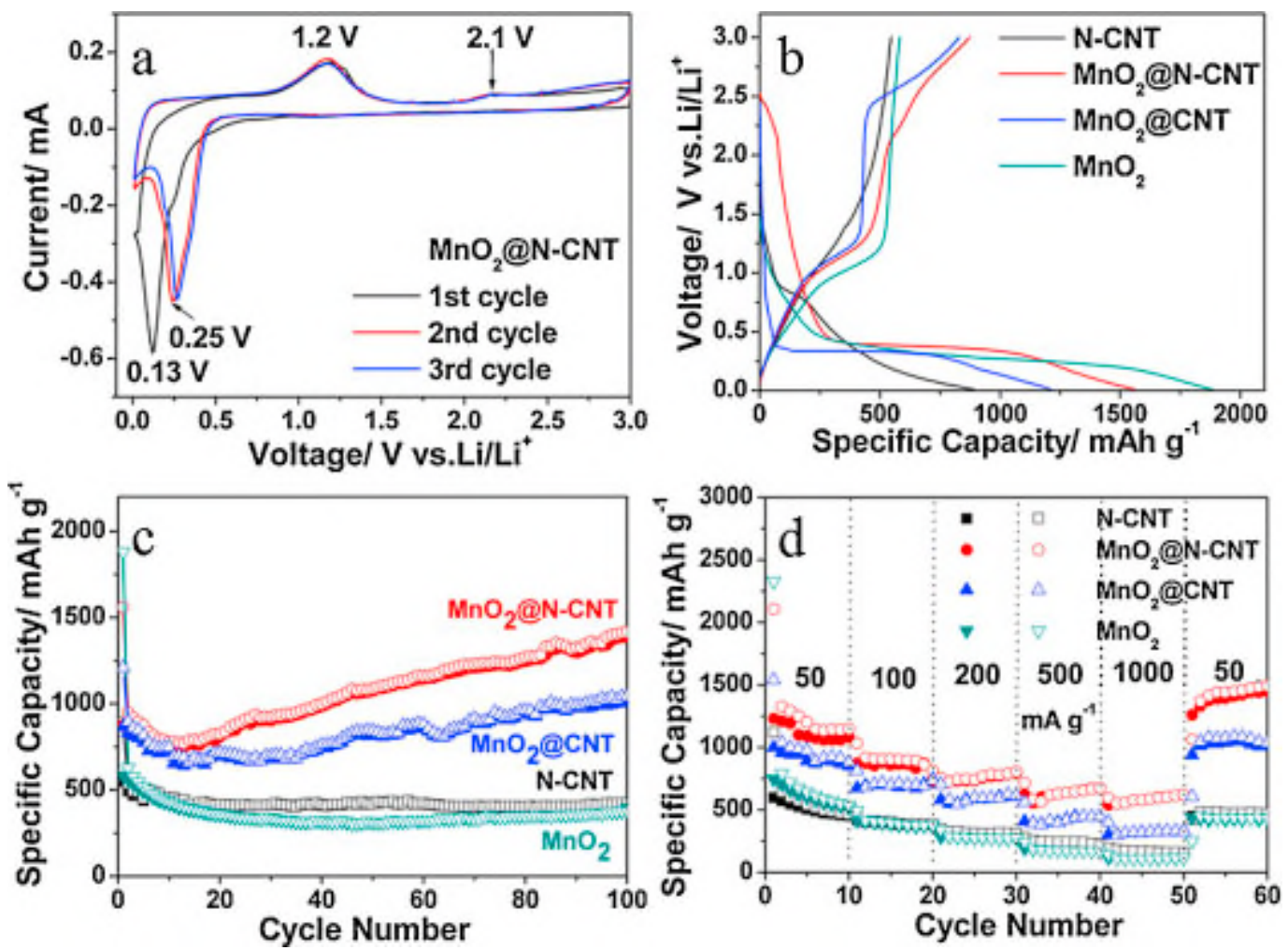

Figure 8. (a) Cyclic-voltammograms of $\mathrm{MnO}_{2} @ \mathrm{~N}-\mathrm{CNT}$ at a scanning rate of $0.1 \mathrm{mV} \mathrm{s}^{-1}$. (b) First discharge-charge curves and (c) cycling performances of N-CNT, MnO $@$ @N-CNT, $\mathrm{MnO}_{2} @ \mathrm{CNT}$ and $\mathrm{MnO}_{2}$ nanomaterials at a current density of $100 \mathrm{mAg} \mathrm{g}^{-1}$. (d) Rate performances of N-CNT, $\mathrm{MnO}_{2} @ \mathrm{~N}-\mathrm{CNT}, \mathrm{MnO}_{2} @ \mathrm{CNT}$ and $\mathrm{MnO}_{2}$ nanomaterials. Reprinted with permission [74]. Copyright 2015 Elsevier. 


\section{FIGURE 9}

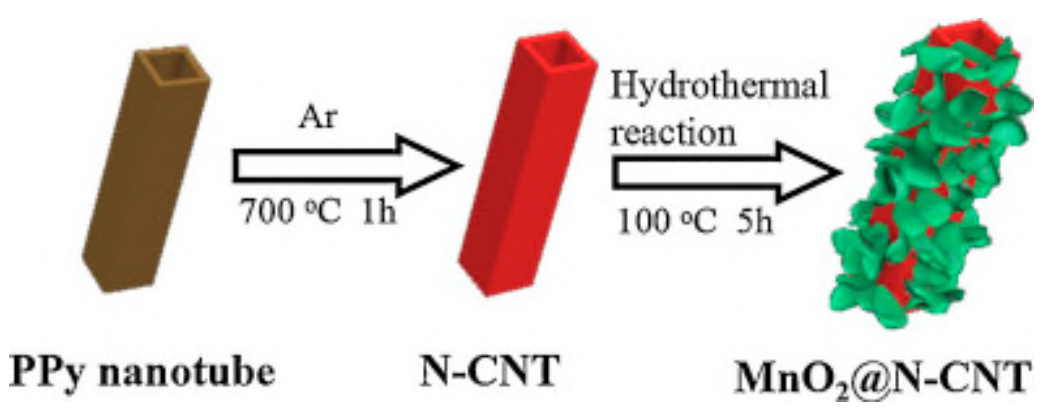

Figure 9. A schematic synthetic route for $\mathrm{MnO}_{2} @ \mathrm{~N}$-doped carbon nanotubes. Reprinted with permission [74]. Copyright 2015 Elsevier. 
FIGURE 10
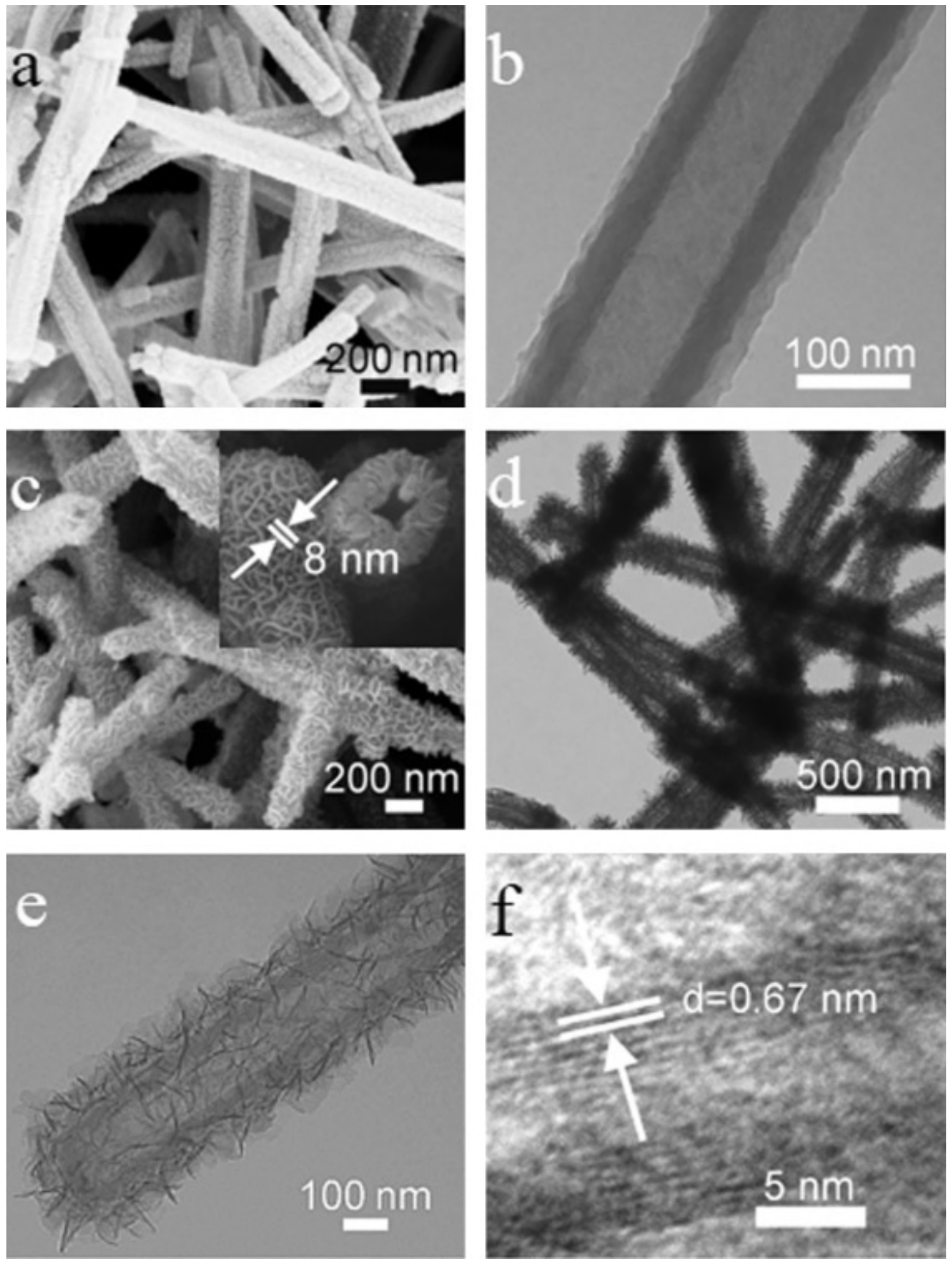

Figure 10. SEM images and TEM images of (a, b) N-CNT and (c-e) $\mathrm{MnO}_{2} @ \mathrm{~N}-\mathrm{CNT}$. (f) HRTEM image of $\mathrm{MnO}_{2}$ on $\mathrm{MnO}_{2} @ \mathrm{~N}-\mathrm{CNT}$. Reprinted with permission [74]. Copyright 2015 Elsevier. 
FIGURE 11
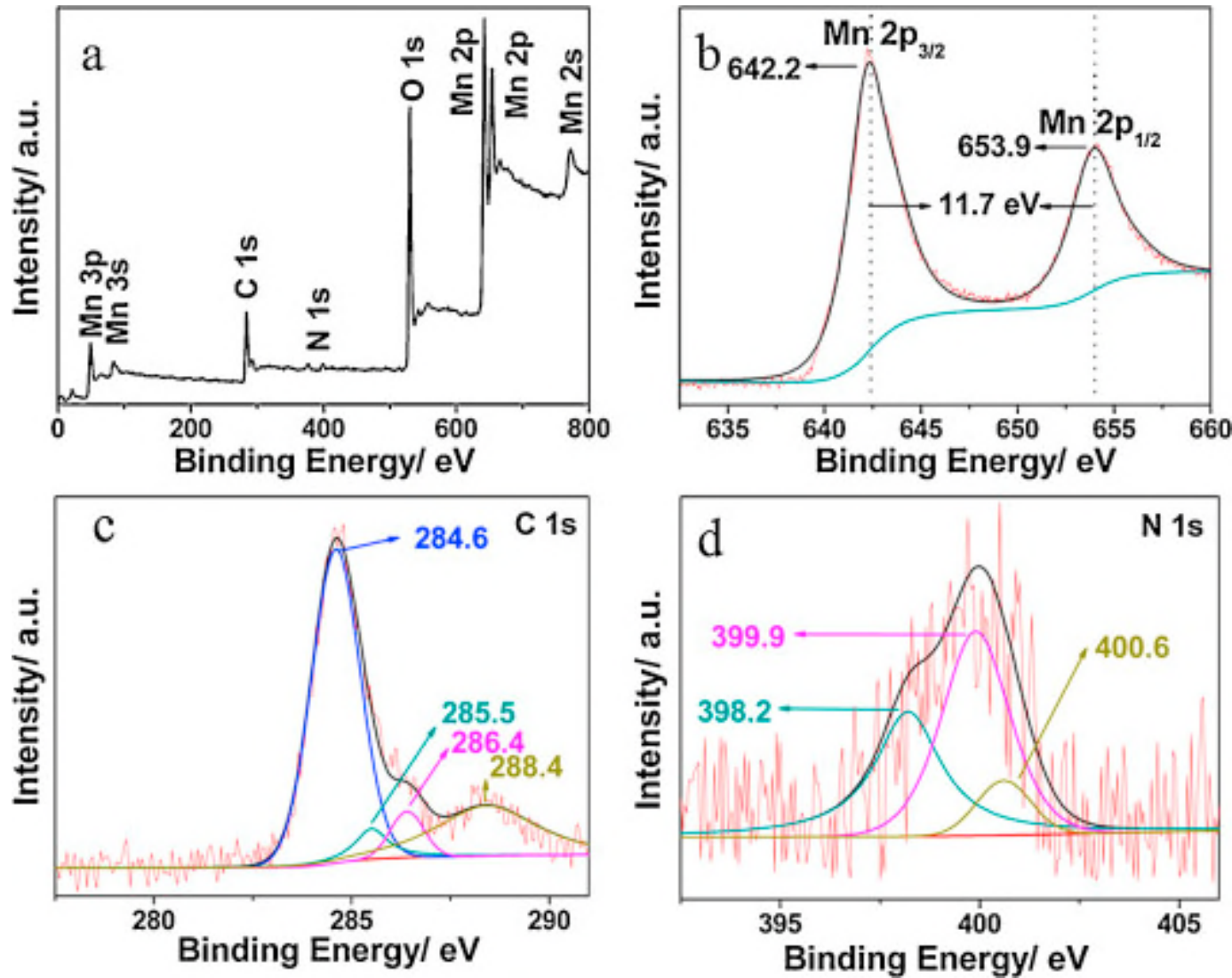

Figure 11. XPS spectra for the $\mathrm{MnO}_{2} @ \mathrm{~N}-\mathrm{CNT}$ : (a) The survey spectrum and the high resolution spectra for (b) Mn 2p, (c) C 1s and (d) N 1s. Reprinted with permission [74]. Copyright 2015 Elsevier. 
FIGURE 12

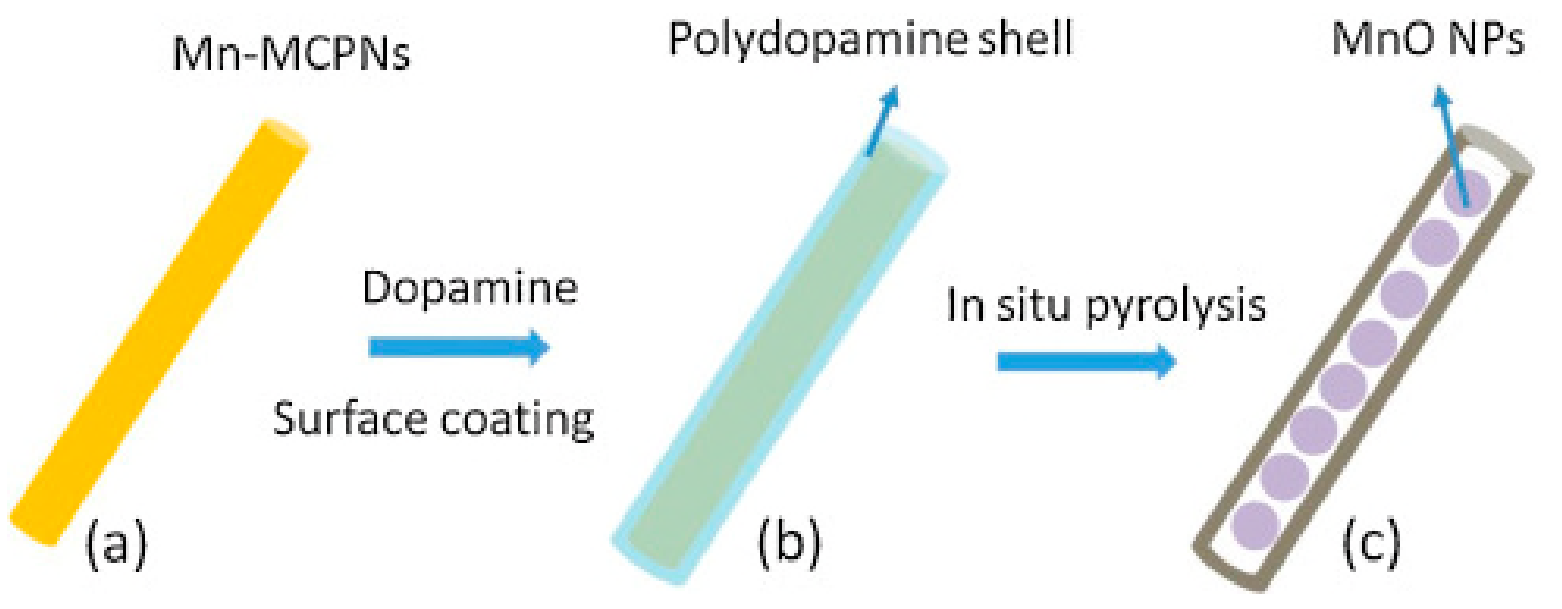

Figure 12. Schematic representation of the synthesis of $\mathrm{MnO} / \mathrm{N}-\mathrm{C}$ nanotubes. Reprinted with permission [75]. Copyright 2016 Elsevier. 
FIGURE 13
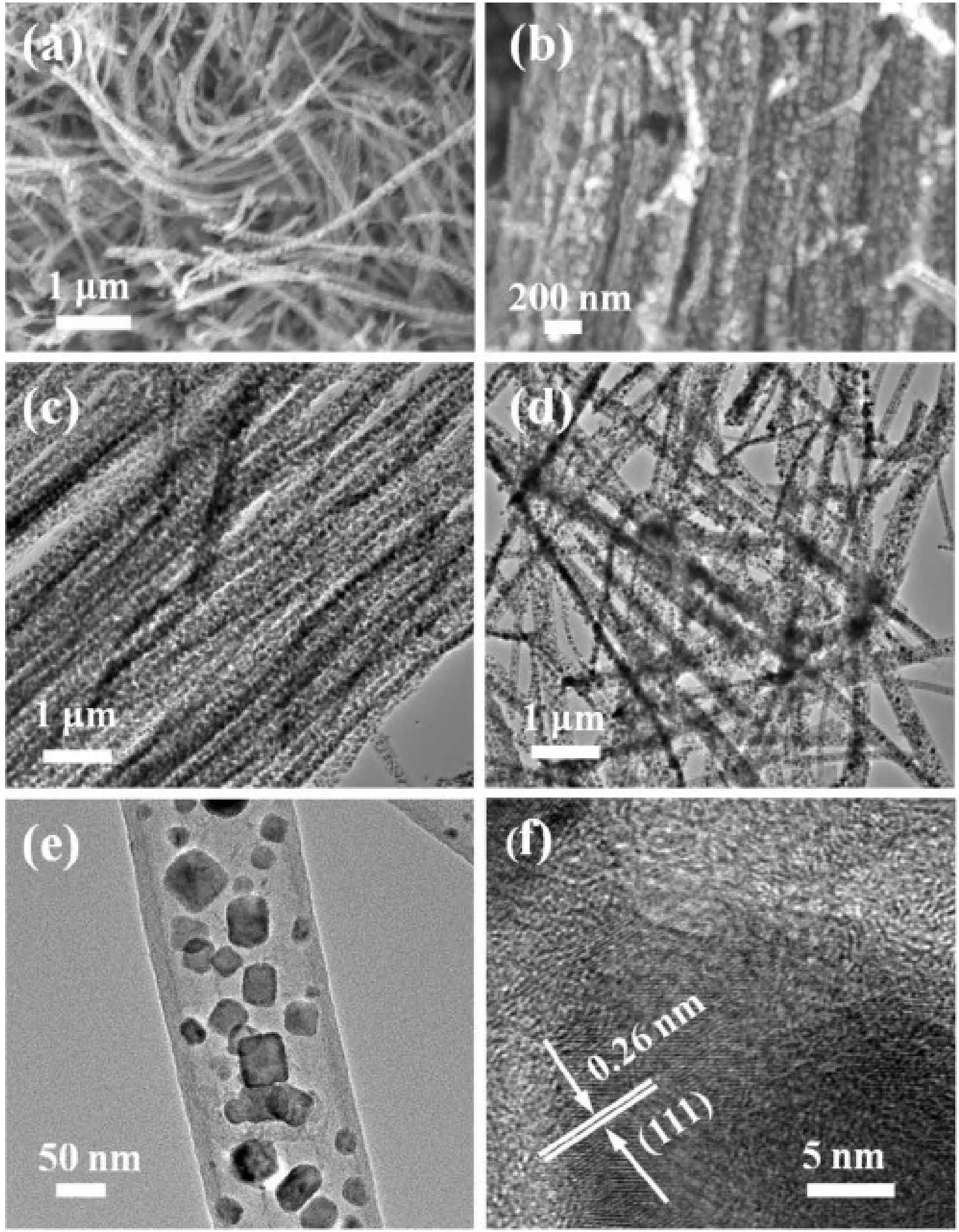

Figure 13. ( $a, b)$ Typical SEM images of $\mathrm{MnO} / \mathrm{N}-\mathrm{C}$ nanotubes. (c,d) TEM images of $\mathrm{MnO} / \mathrm{C}$ $\mathrm{MnO} / \mathrm{N}-\mathrm{C}$ nanotubes. (e) Typical TEM image of an individual $\mathrm{MnO} / \mathrm{N}-\mathrm{C}$ nanotube. (f) Highmagnification TEM image taken from the $\mathrm{MnO}$ nanoparticles inside the $\mathrm{N}$-doped carbon tube. Reprinted with permission [75]. Copyright 2016 Elsevier. 
FIGURE 14
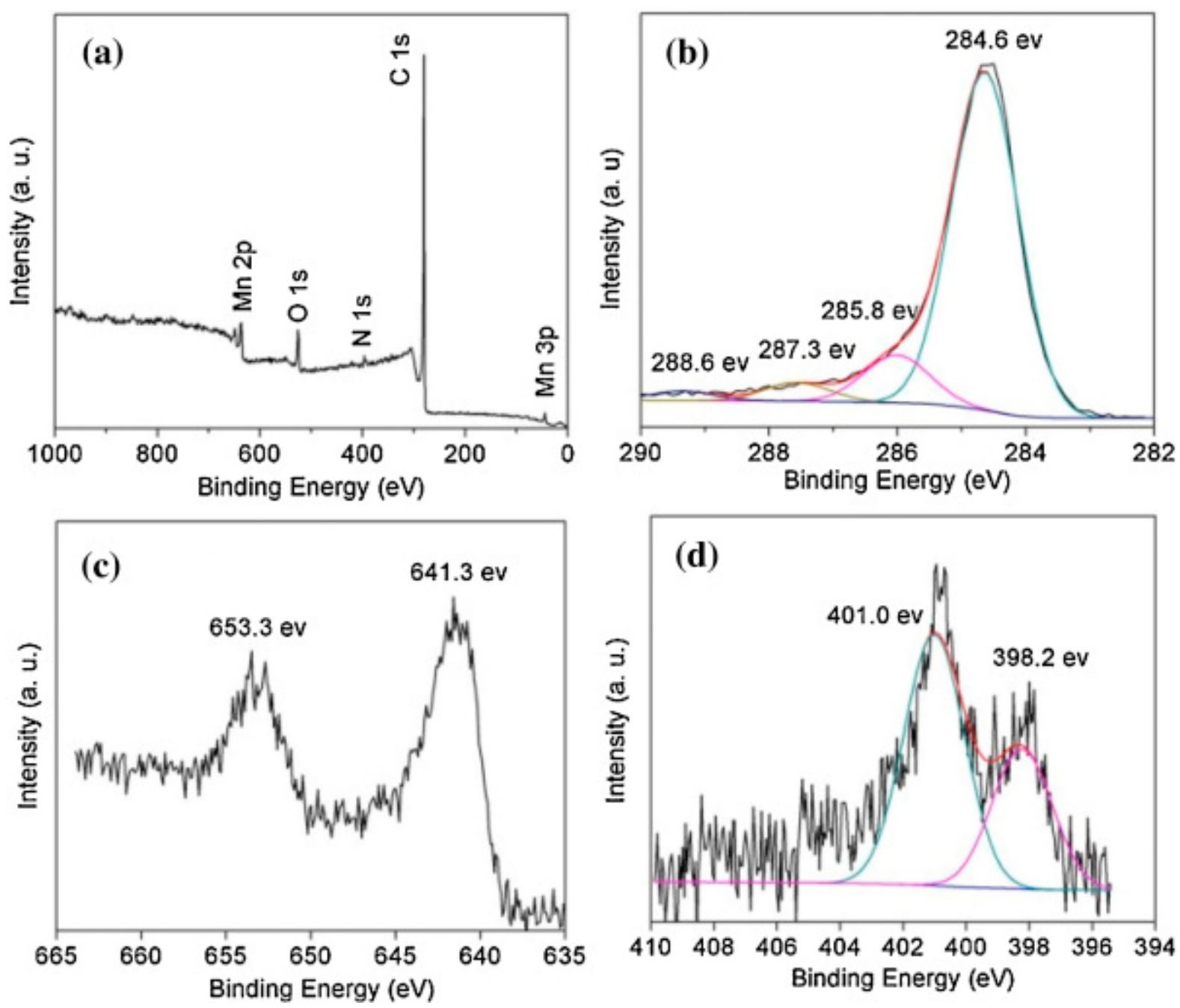

Figure 14. XPS spectra for the $\mathrm{MnO} / \mathrm{N}-\mathrm{C}$ nanotubes: (a) the survey spectrum and the high resolution spectra for (b) C 1s, (c) Mn 2p and (d) N 1s. Reprinted with permission [75]. Copyright 2016 Elsevier. 
FIGURE 15
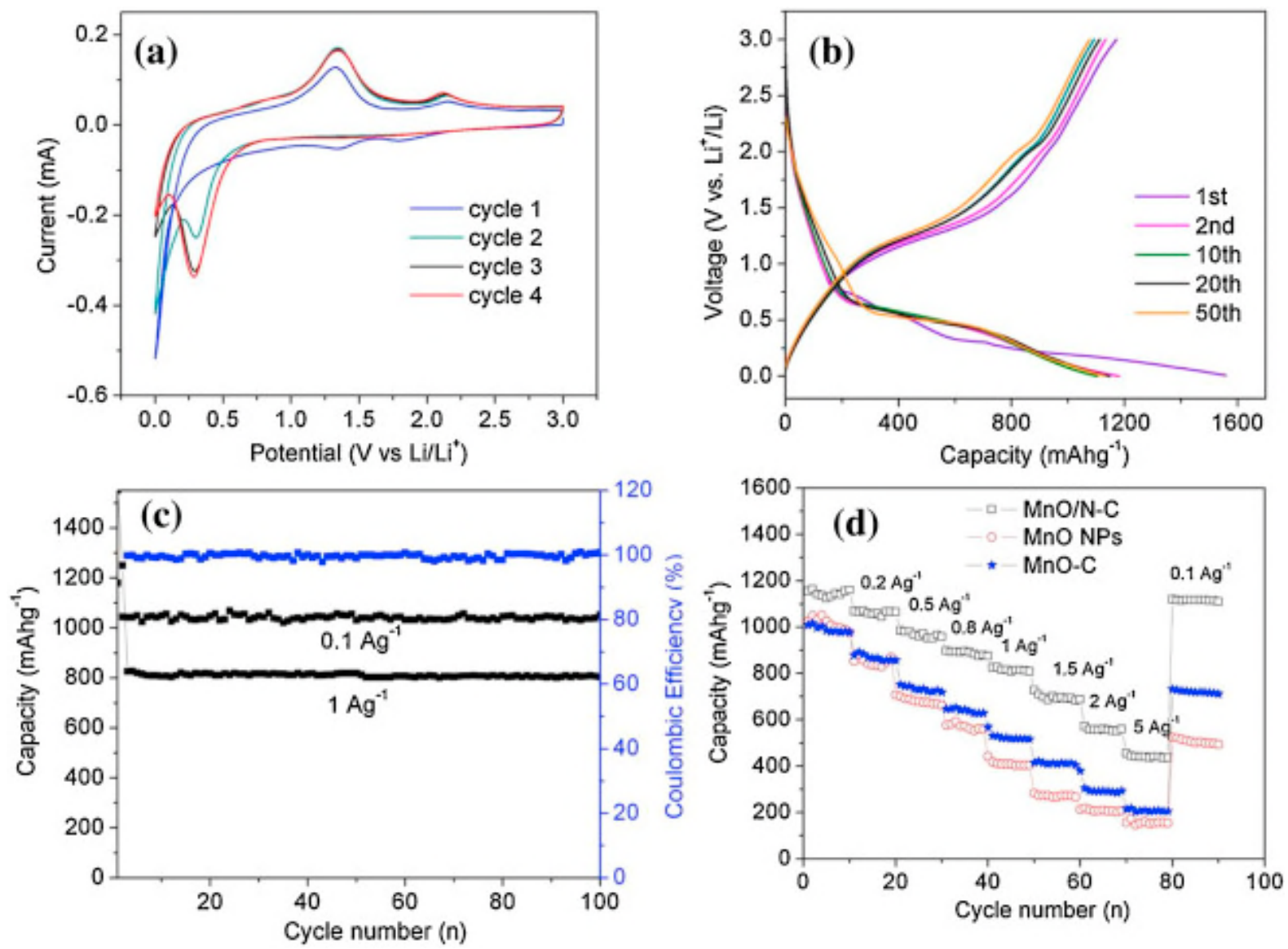

Figure 15. (a) $\mathrm{CV}$ curves of the $\mathrm{MnO} / \mathrm{N}-\mathrm{C}$ nanotubes for the first four cycles at a scan rate of $0.1 \mathrm{mV} \mathrm{s}^{-1}$. (b) The galvanostatic charge/discharge profiles of the $\mathrm{MnO} / \mathrm{N}-\mathrm{C}$ nanotubes at $0.1 \mathrm{~A} \mathrm{~g}^{-1}$ at a voltage window of 0.01 to $3.0 \mathrm{~V}$ for different cycles. (c) Cycle performance and Columbic efficiency of $\mathrm{MnO} / \mathrm{N}-\mathrm{C}$ nanotubes at a current density of 0.1 and $1 \mathrm{~A} \mathrm{~g}^{-1}$. (d) Rate performance of the $\mathrm{MnO} / \mathrm{N}-\mathrm{C}$ nanotube, $\mathrm{MnO}-\mathrm{C}$, and pure $\mathrm{MnO}$ NPs electrodes at a current density from 0.1 to $5 \mathrm{~A} \mathrm{~g}^{-1}$. Reprinted with permission [75]. Copyright 2016 Elsevier. 


\section{FIGURE 16}

a) Carbon paper (CP) as starting material b) Deposition of $\mathrm{Ti}$ and Fe layers over carbon paper

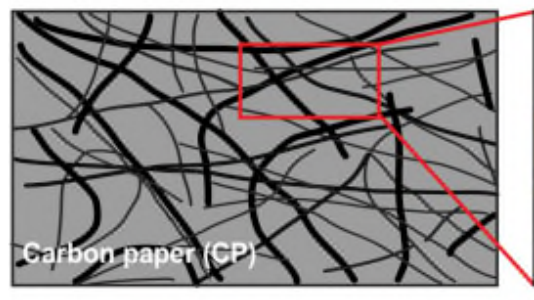

f) Hematite nanorods formation by thermal treatment (HR/NCNTs/CP)

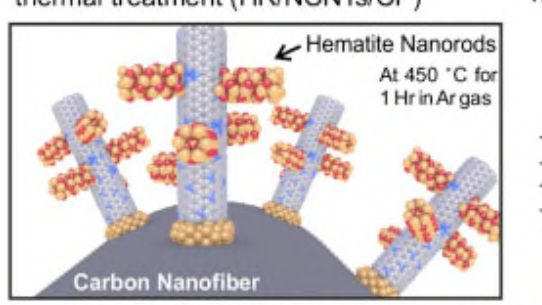

nanorods

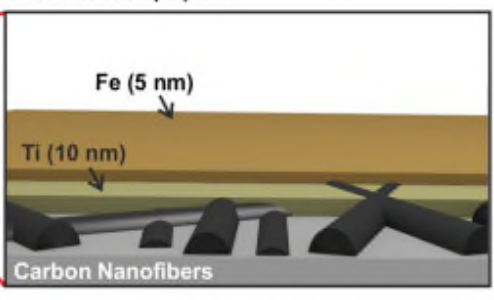

e) Hydrothermal synthesis of iron hydroxide d)

Autociave

$\mathrm{FeC1}$

- Water/Methanol

- NaNO,

- $\mathrm{N}$-doped CNT on

carbon paper (NCNTs/CP)

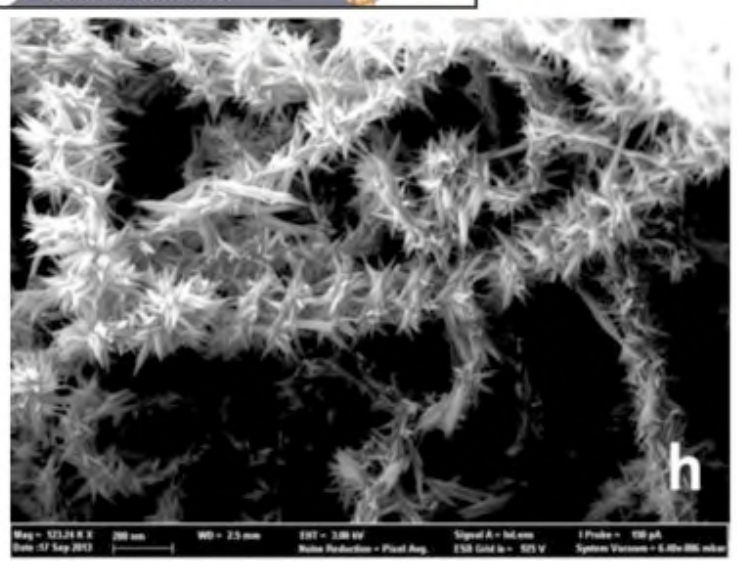

c) Fe nanoparticles formation by high temperature Ammonia pretreatment

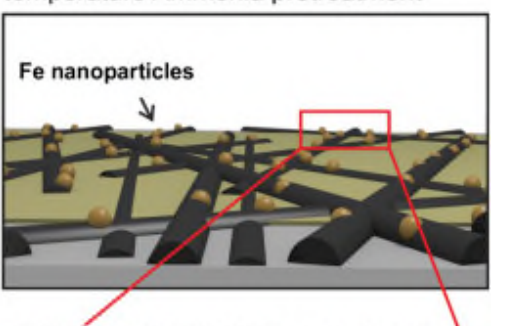

d) CVD synthesis of nitrogen-doped nanotubes
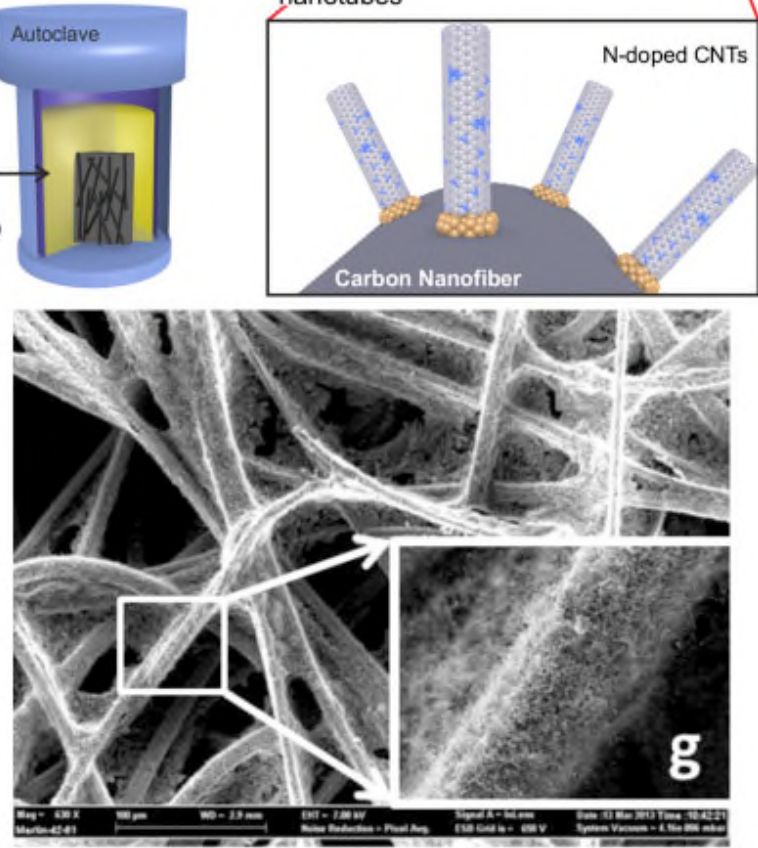

Figure 16. Schematic picture of the synthesis route to prepare the hierarchical HR/NCNTs/CP structures (a-f) and SEM images of the resulting NCNTs/CP (g) and HR/NCNTs/CP (h) electrodes. Reprinted with permission [76]. Copyright 2015 Elsevier. 
FIGURE 17

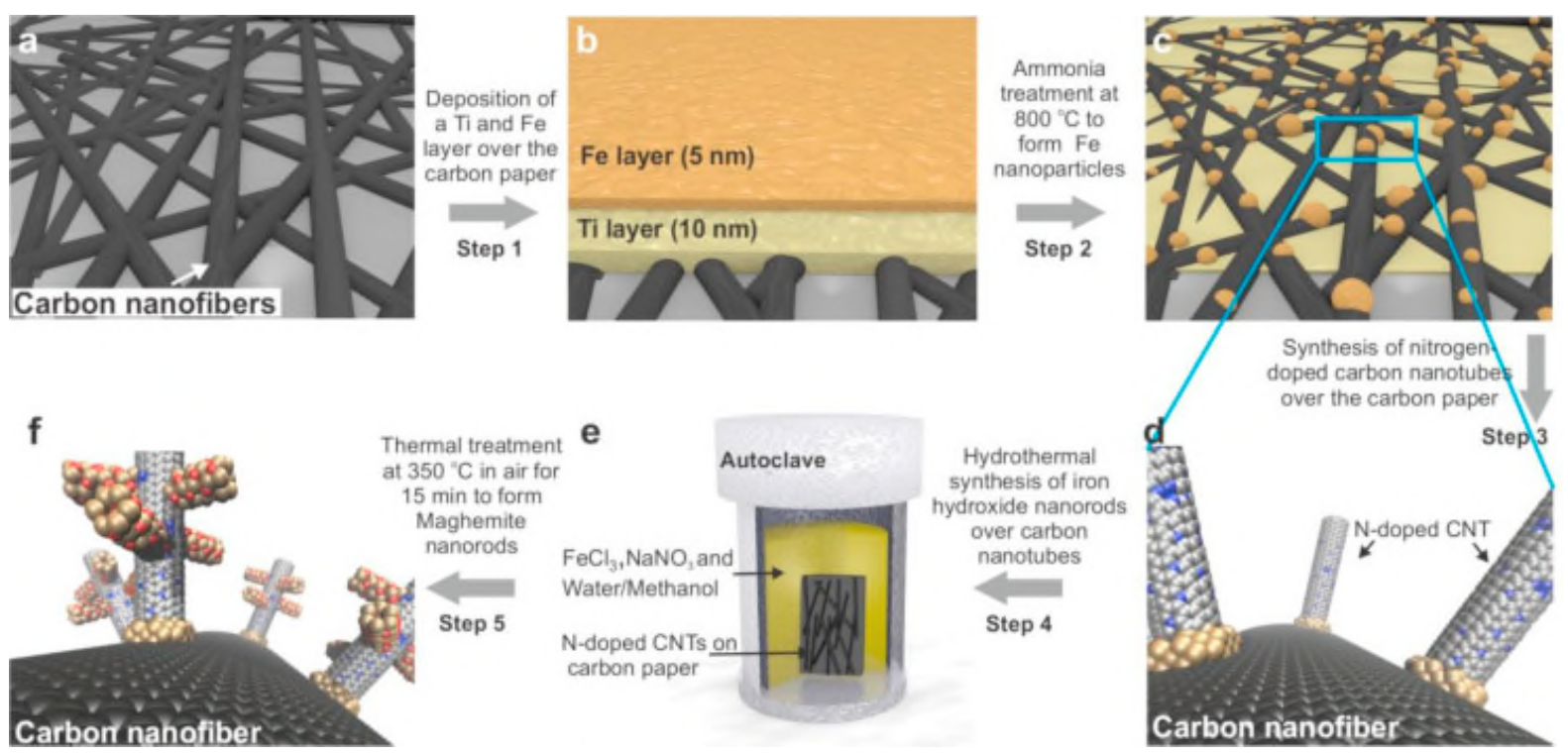

Figure 17. Schematic picture of the synthesis route to prepare the hierarchical MR@NCNTs/CP structures (a-f). Reprinted with permission [100]. Copyright 2016 Elsevier. 
FIGURE 18
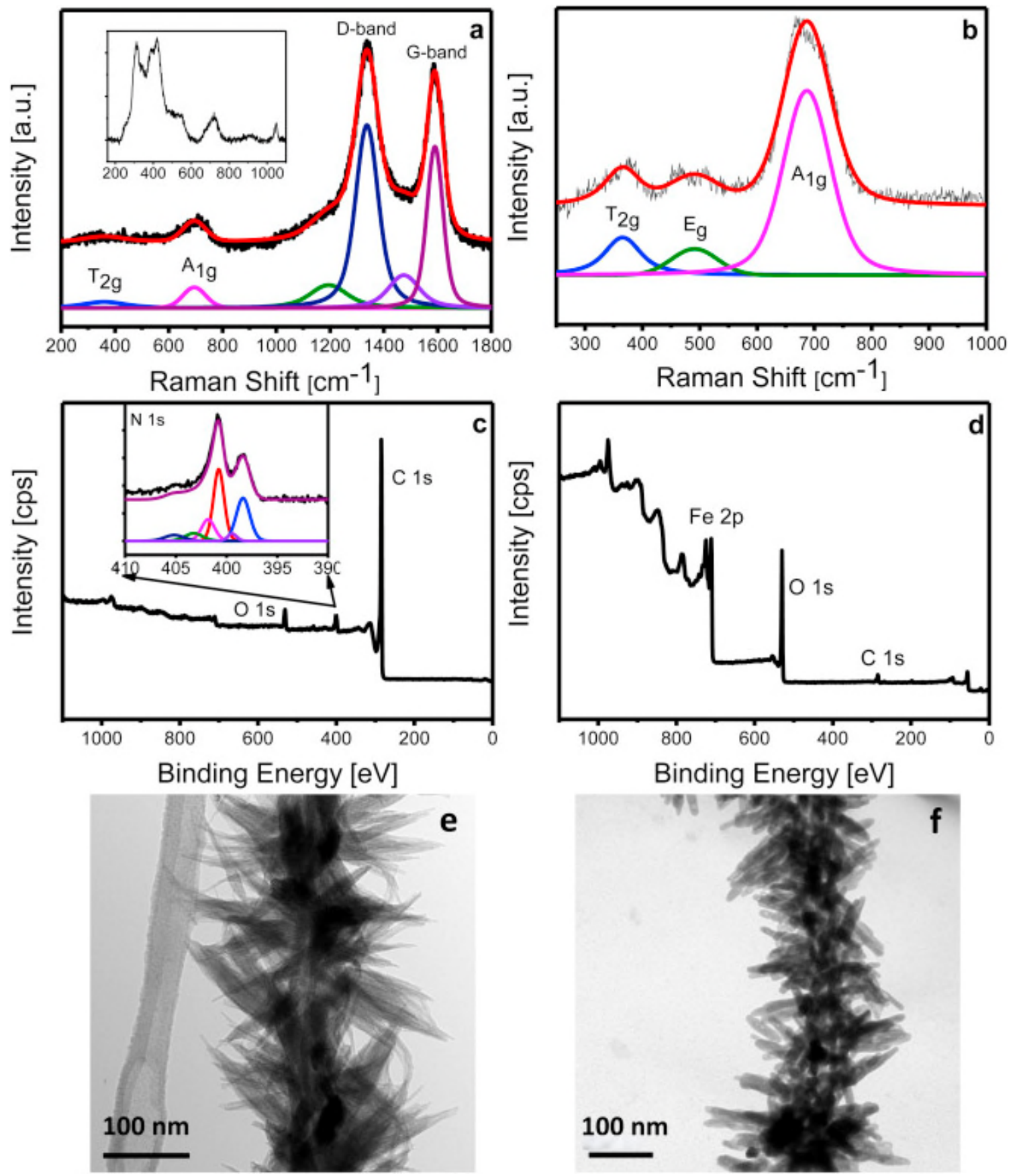

Figure 18. a) Raman spectrum of MR@NCNTs/CP. The inset shows the spectrum of the same material before heat treatment (iron hydroxide@NCNTs/CP), b) Raman spectrum of MR@FTO with the assigned peaks, c) XPS spectrum of NCNTs/CP. The inset shows the N 1s peak at high resolution deconvoluted into distinct peaks with different binding energies d) XPS spectrum of MR@NCNTs/CP with assigned peaks, e) TEM image of iron hydroxide@NCNTs and f) TEM image of the same material as (e), but after heat treatment in air at $350{ }^{\circ} \mathrm{C}$ for 15 min (MR@NCNTs). Reprinted with permission [100]. Copyright 2016 Elsevier. 
FIGURE 19
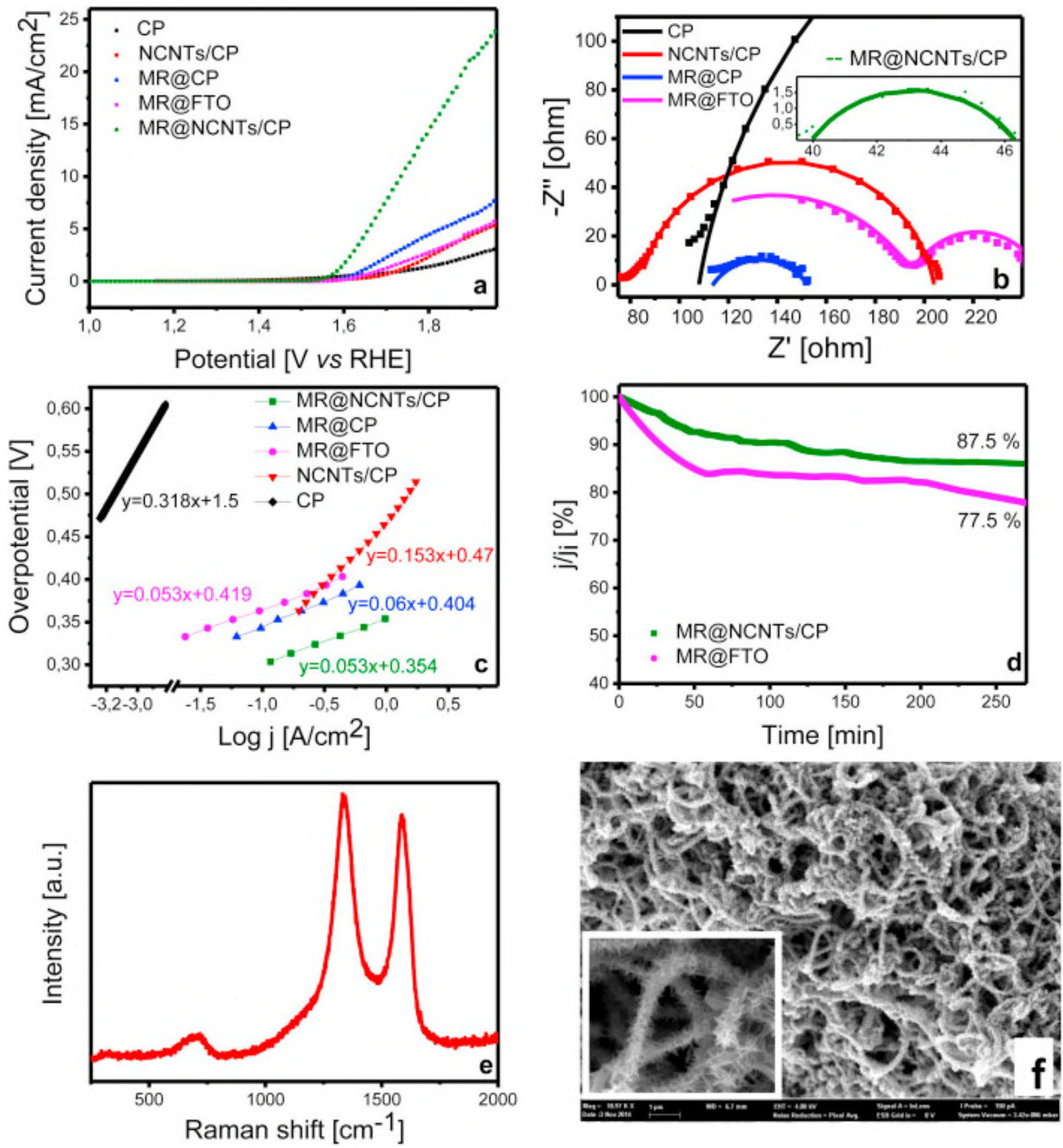

Figure 19. a) Polarization curves of bare CP, NCNT/CP, MR@CP, MR@NCNTs/CP and MR@FTO electrodes scanned at $2 \mathrm{mV} / \mathrm{s}$ in $0.1 \mathrm{M} \mathrm{KOH}$ solution, b) Electrochemical impedance spectroscopy (EIS) of CP and FTO supported electrode materials recorded at a dc potential of $1.789 \mathrm{~V}$, with the EIS of MR@NCNTs/CP shown in the inset c) Tafel plots of the electrodes, d) Chronoamperometric measurement of MR@NCNTs/CP and MR@FTO at $1.71 \mathrm{~V}$ in $0.1 \mathrm{M} \mathrm{KOH}$, e) Raman spectrum of MR@NCNTs/CP electrode after being used in the stability test for 16,000 s, and f) SEM image of MR@NCNTs/CP after electrochemical testing. Reprinted with permission [100]. Copyright 2016 Elsevier. 
FIGURE 20

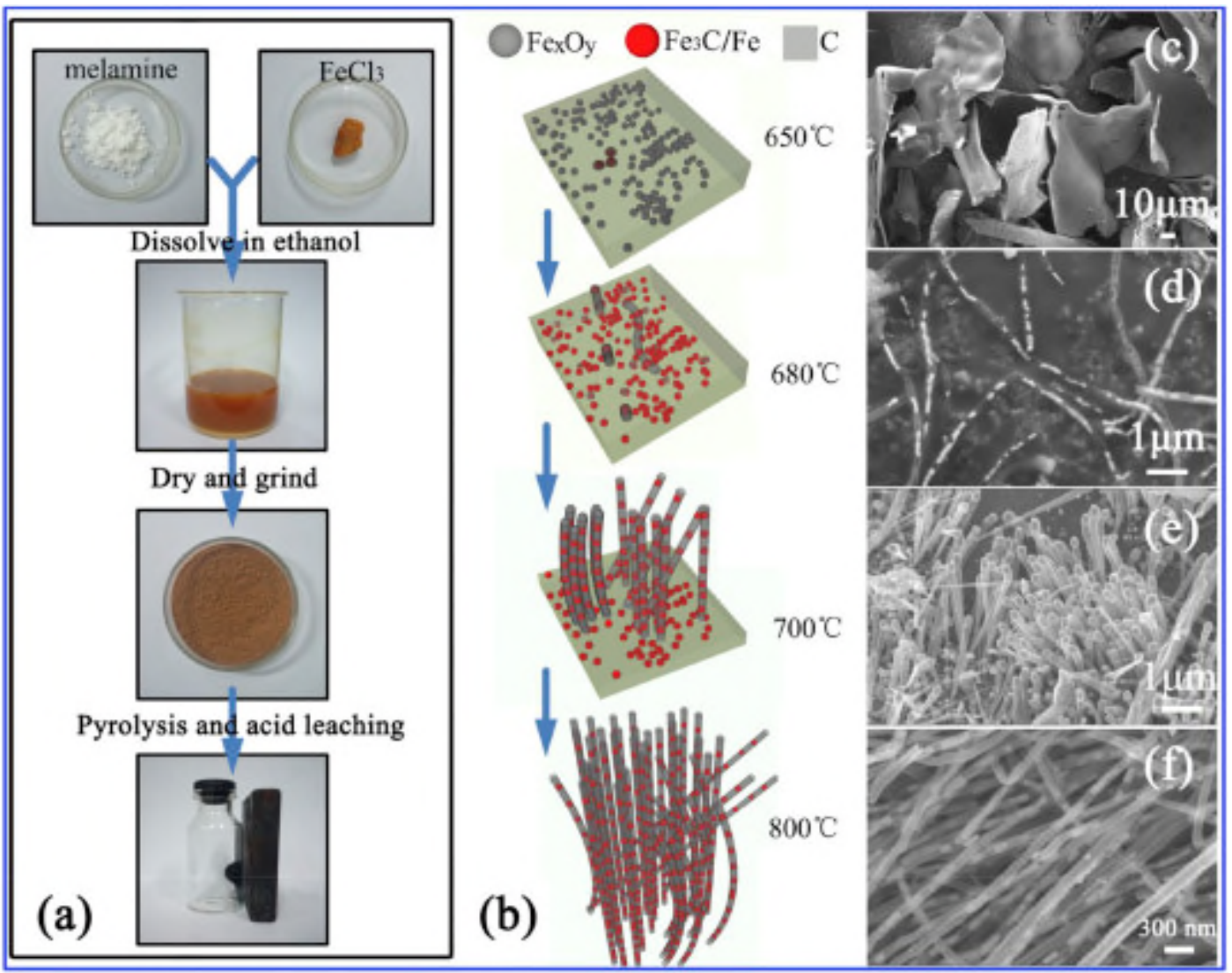

Figure 20. Schematic of (a) the synthesis route and (b) growth mechanism of $\mathrm{Fe}_{3} \mathrm{C} @ \mathrm{NCNTs}$. SEM images of the samples prepared at (c) $600{ }^{\circ} \mathrm{C}$, (d) $680{ }^{\circ} \mathrm{C}$, (e) $700{ }^{\circ} \mathrm{C}$ and (f) $800{ }^{\circ} \mathrm{C}$. Reprinted with permission [103]. Copyright 2015 Elsevier. 
FIGURE 21
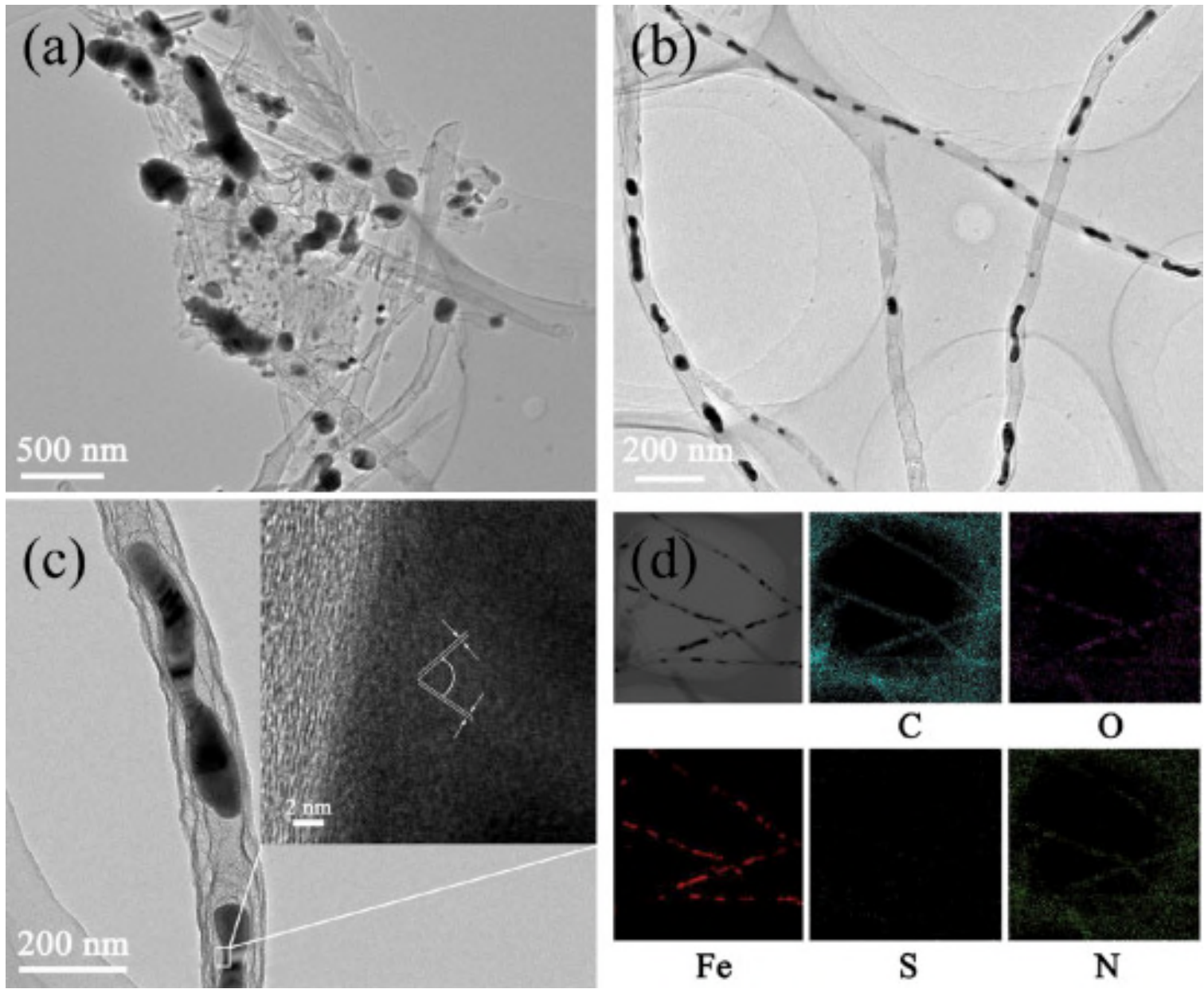

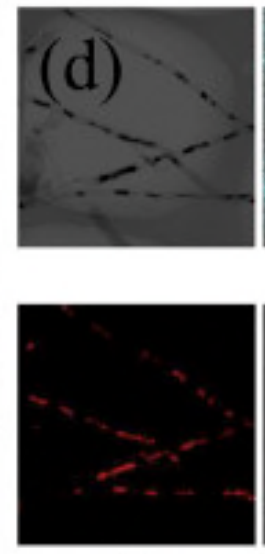

$\mathrm{Fe}$

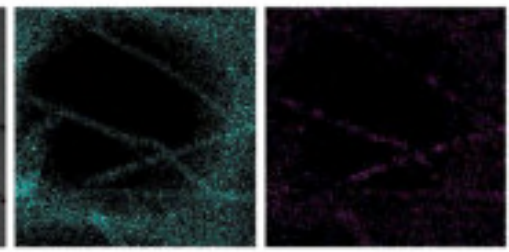

$\mathrm{C}$

$\mathrm{O}$

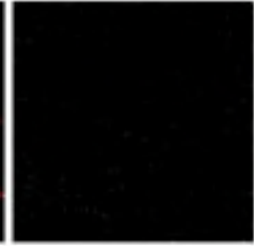

S

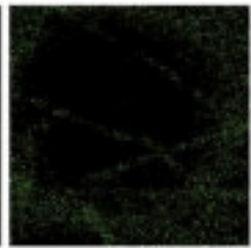

$\mathrm{N}$

Figure 21. TEM images of (a) Fe 3 C@NCNTs-700 and (b) Fe 3 C@NCNTs-800. (c) HRTEM image of $\mathrm{Fe}_{3} \mathrm{C} @$ NCNTs-800. (d) Elemental-mapping images of $\mathrm{Fe}_{3} \mathrm{C} @$ NCNTs-800. Reprinted with permission [103]. Copyright 2015 Elsevier. 
FIGURE 22
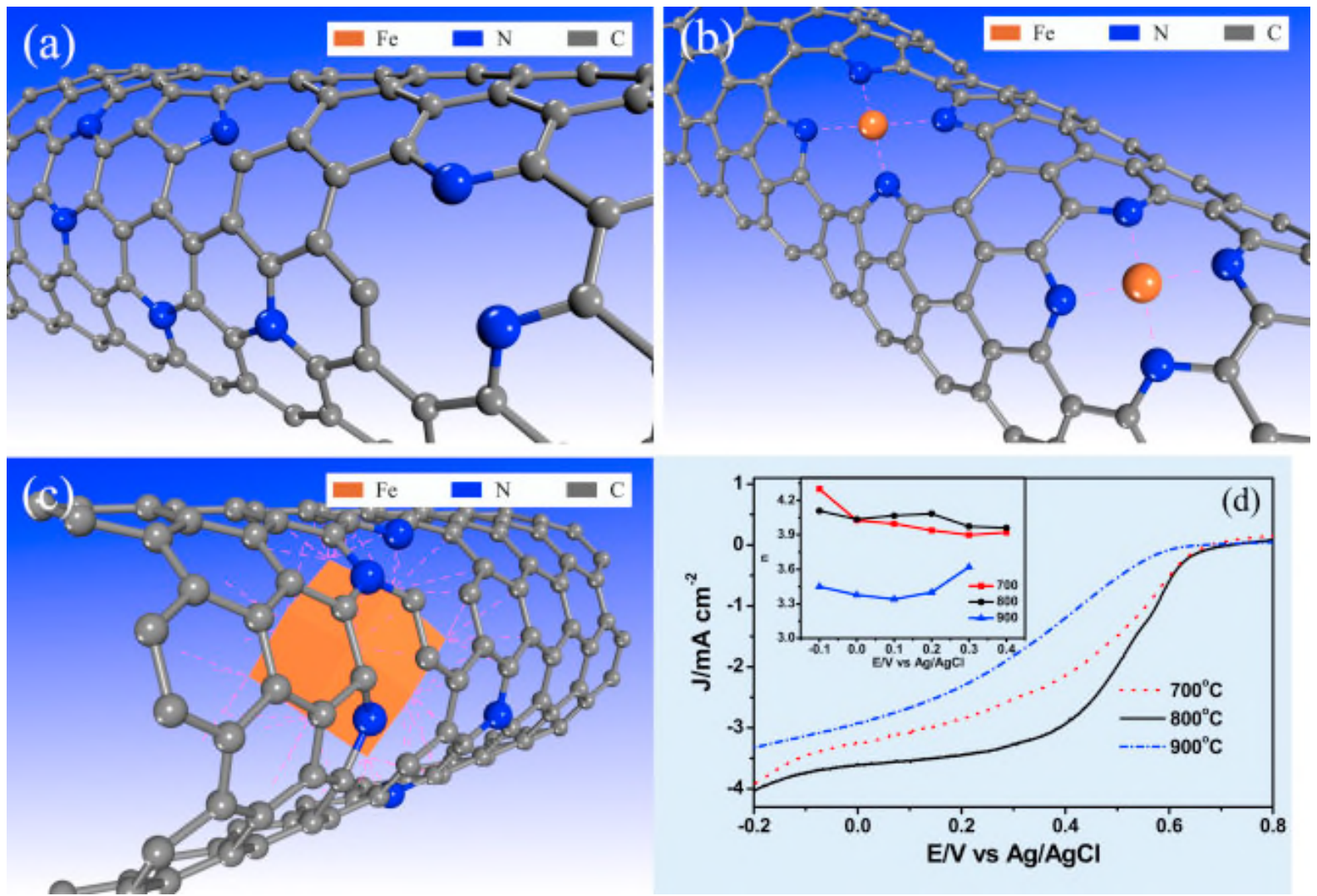

Figure 22. Possible catalytic active sites in carbon-based ORR catalysts: (a) N-doped carbon, (b) Fe coordination compounds, and (c) $\mathrm{N}$ doped carbon with encapsulated Fe species, (d) LSV curves and electron transfer value $n$ (inset) of $\mathrm{Fe}_{3} \mathrm{C} @$ NCNTs-700, 800 and $900{ }^{\circ} \mathrm{C}$. The LSV results were obtained in $\mathrm{O}_{2}$-saturated $1 \mathrm{M} \mathrm{HClO}_{4}$ at a rotation speed of $1600 \mathrm{rpm}$ and a scan rate of $10 \mathrm{mVs}^{-1}$. Reprinted with permission [103]. Copyright 2015 Elsevier. 
FIGURE 23

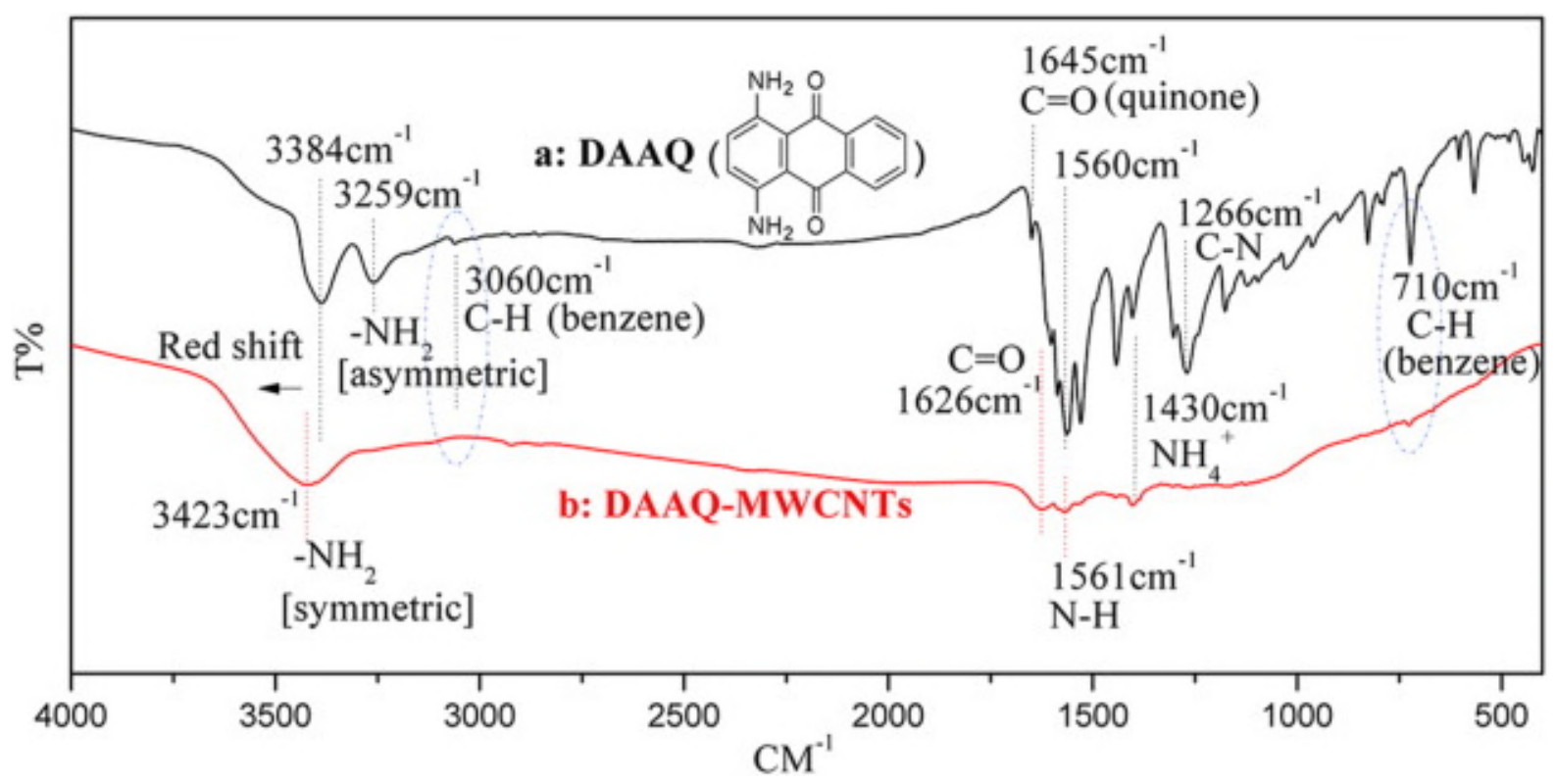

Figure 22. FT-IR spectra of (a) DAAQ and (b) DAAQ-MWCNTs. Reprinted with permission [112]. Copyright 2016 Elsevier. 
FIGURE 24
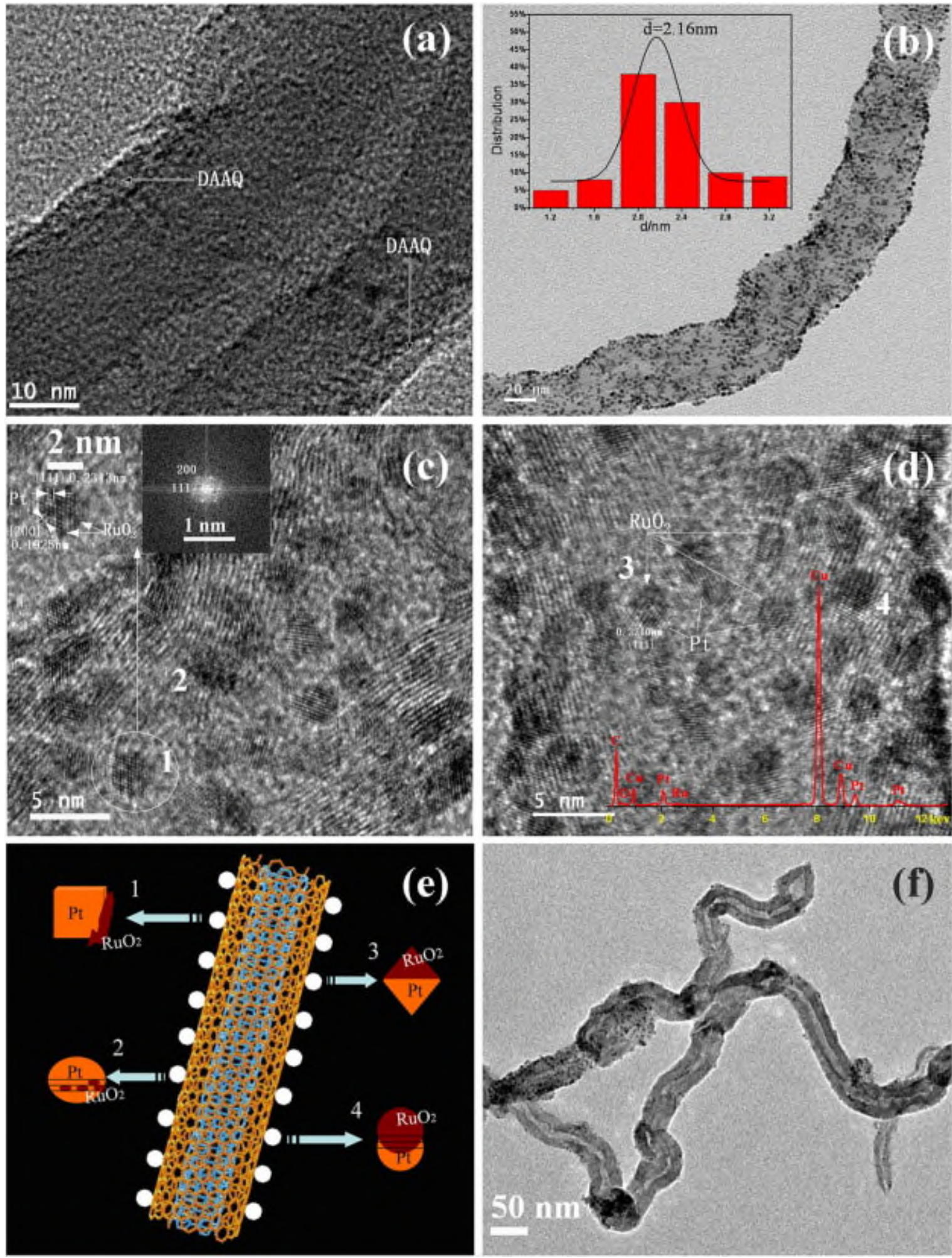

Figure 24. (a) TEM image of DAAQ-MWCNTs, (b) TEM image of Pt-RuO $/ \mathrm{DAAQ}$ MWCNTs, (c) and (d) HRTEM images of Pt-RuO $2 /$ DAAQ-MWCNTs, (e) schematic illustration of the Pt-RuO 2 structure shown in (c) and (d), (f) TEM image of Pt-RuO $2 / \mathrm{AO}$ MWCNTs. Reprinted with permission [112]. Copyright 2016 Elsevier. 
FIGURE 25
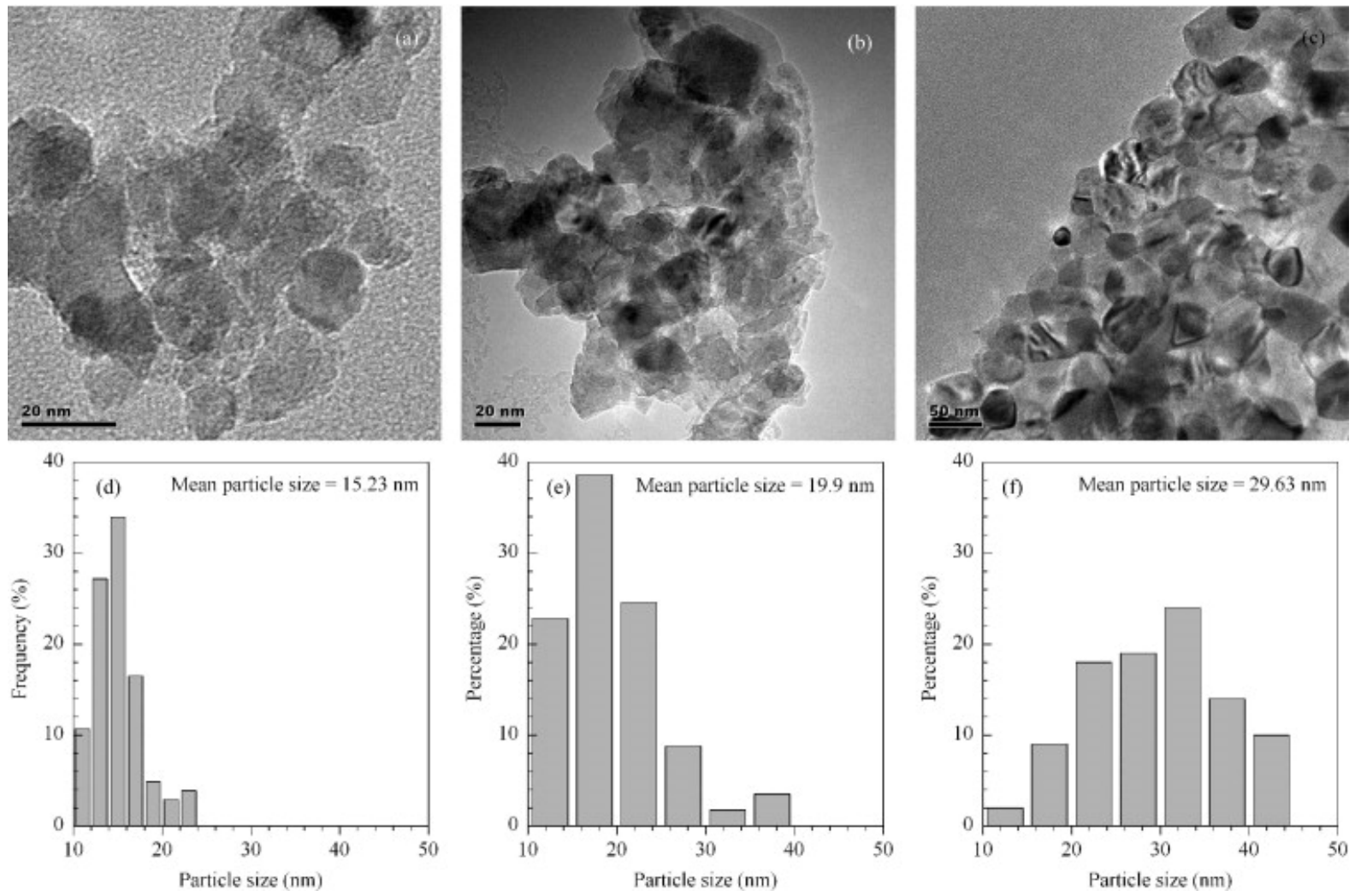

Figure 25. HRTEM images and metal particle size distribution histogram of catalysts after reduction in $\mathrm{H}_{2}$ at $550{ }^{\circ} \mathrm{C}$ for $1 \mathrm{~h}$. (a, d) NiO-MgO, (b, e) $20 \% \mathrm{MnO}_{2}-\mathrm{NiO}-\mathrm{MgO}$, (c, f) $30 \%$ $\mathrm{MnO}_{2}-\mathrm{NiO}-\mathrm{MgO}$. Reprinted with permission [113]. Copyright 2014 Elsevier. 
FIGURE 26
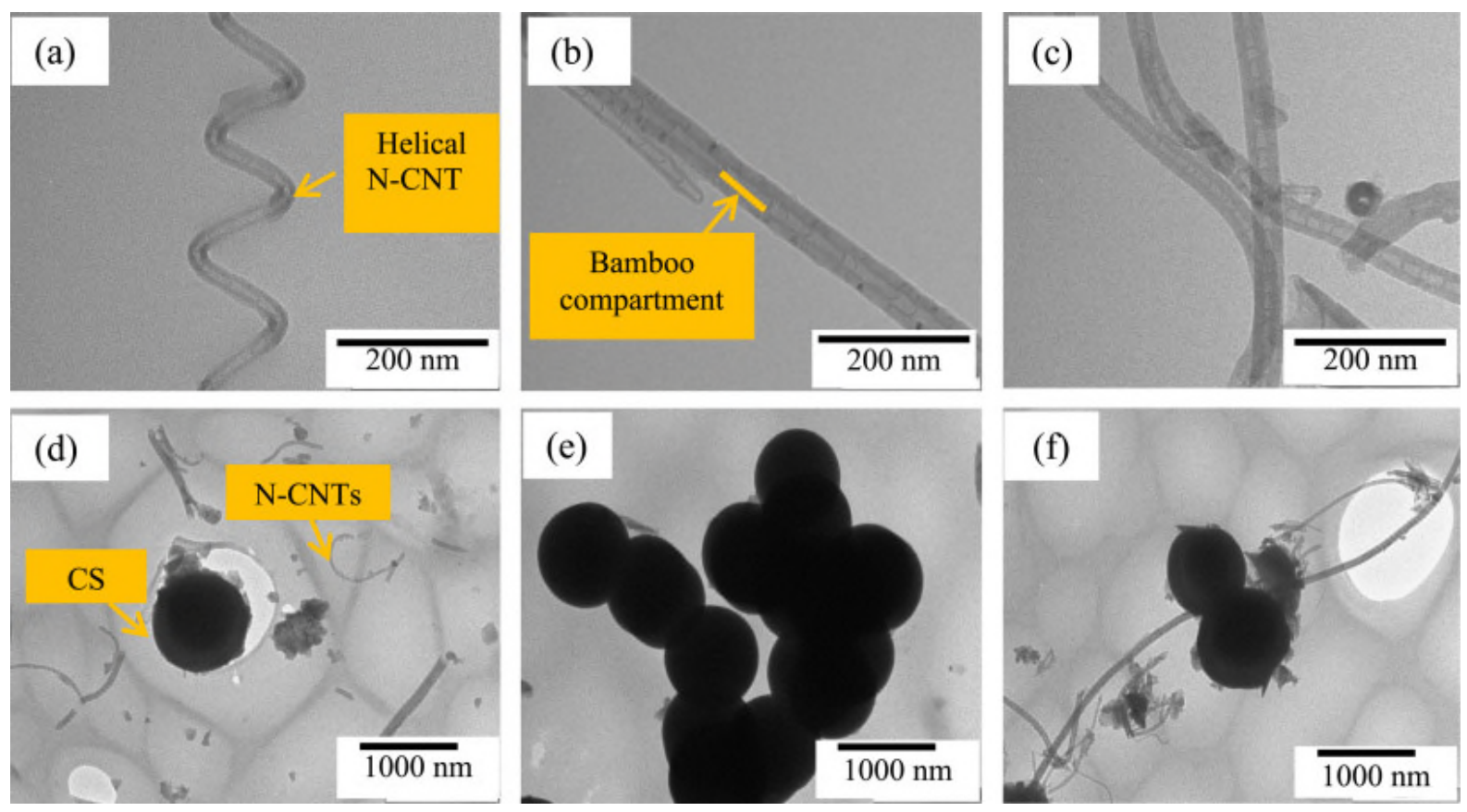

Figure 26. TEM images of pristine $\mathrm{N}-\mathrm{CNTs}$ synthesized by use of (a) para- $\mathrm{CF}_{3}$, (b) para-Cl and (c) para-CN catalysts, and TEM images of N-CNTs and CS synthesized by using (d) para$\mathrm{CF}_{3}$, (e) para- $\mathrm{Cl}$ and (f) para-CN catalysts in pyridine. Reprinted with permission [113]. Copyright 2016 Elsevier. 
FIGURE 27
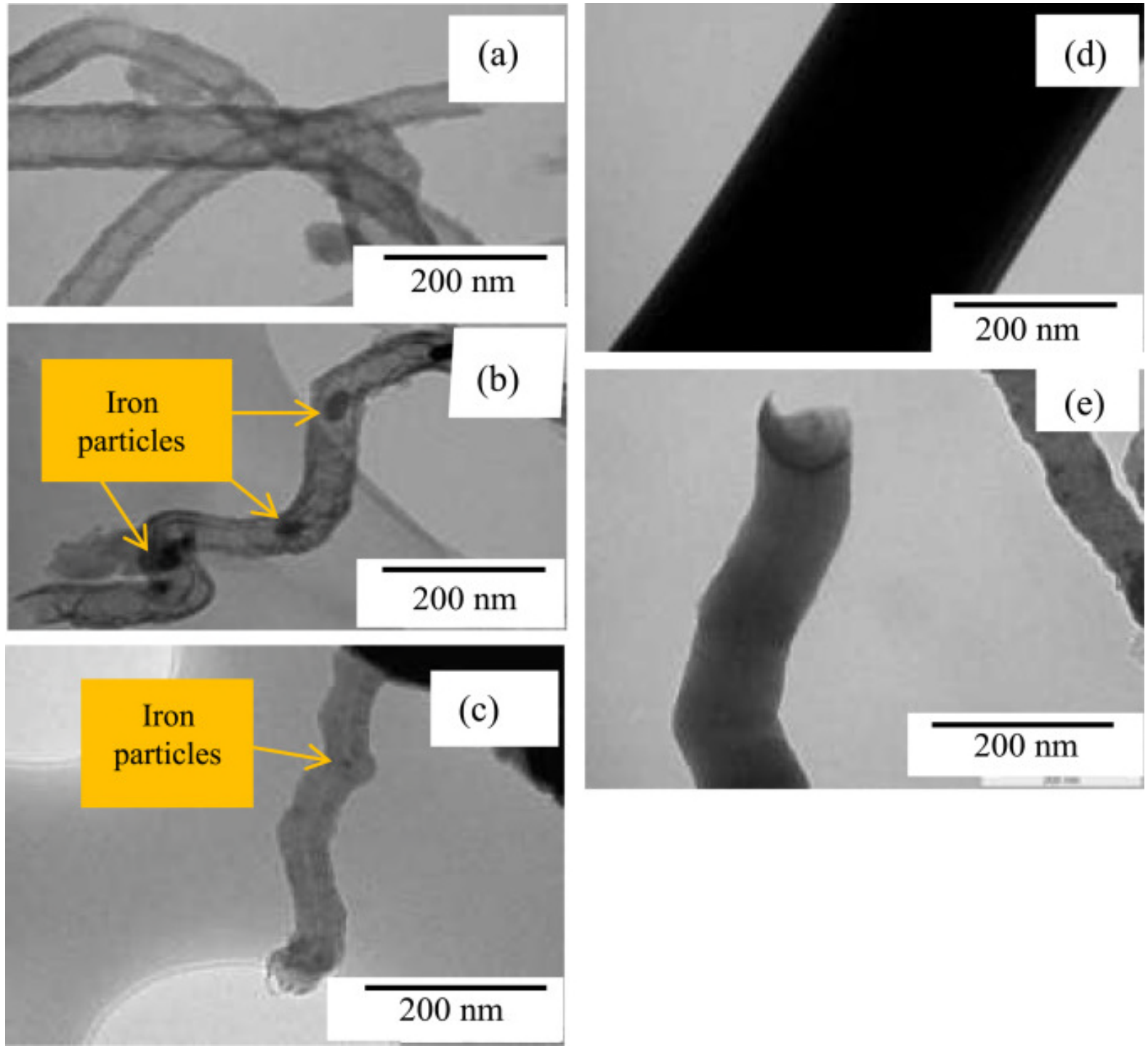

Figure 27. TEM images of pristine N-CNTs synthesized by using (a) para-CN, (b) para$\mathrm{CF}_{3}$ and (c) para-Cl catalyst in acetonitrile. TEM images of CNFs synthesized by use of (d) para-CN and (e) para-Cl catalyst in acetonitrile. Reprinted with permission [113]. Copyright 2016 Elsevier. 
FIGURE 28

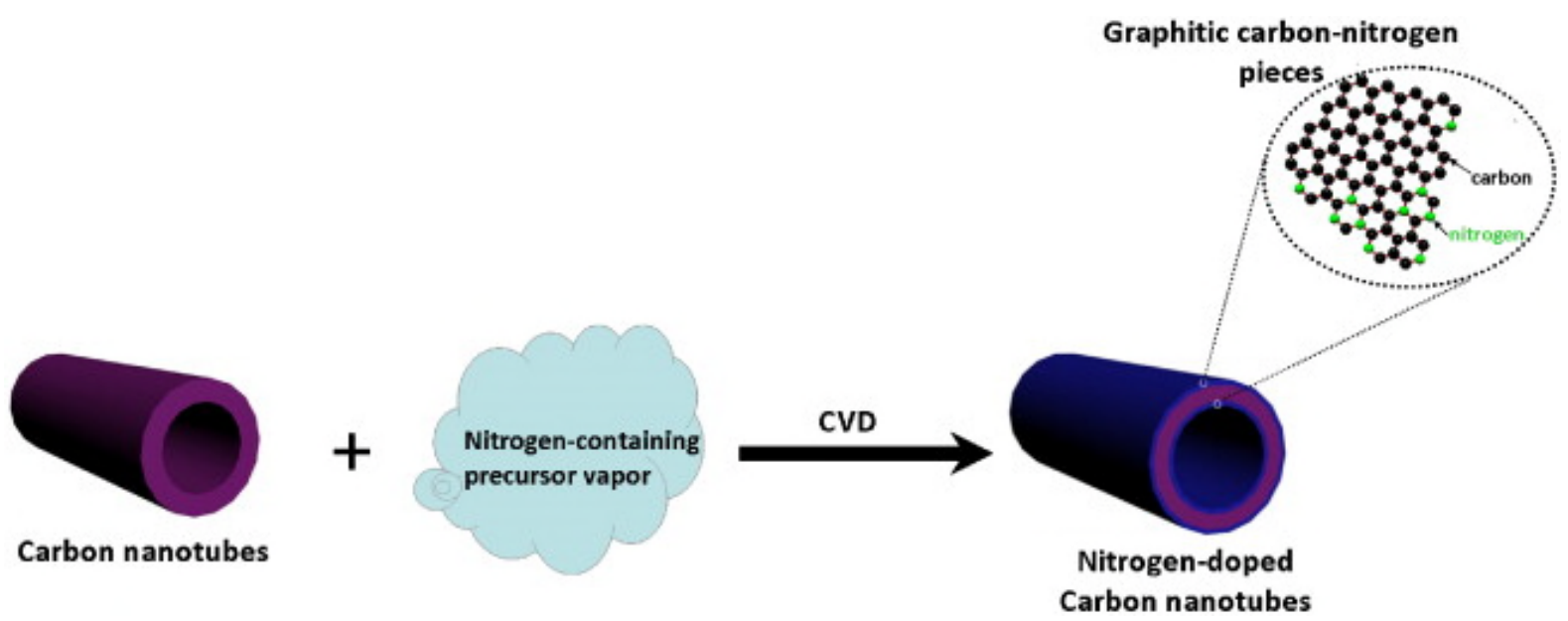

Figure 28. Illustration for the preparation of nitrogen-doped carbon nanotubes by a post-doping method. Reprinted with permission [115]. Copyright 2014 Elsevier. 


\section{FIGURE 29}

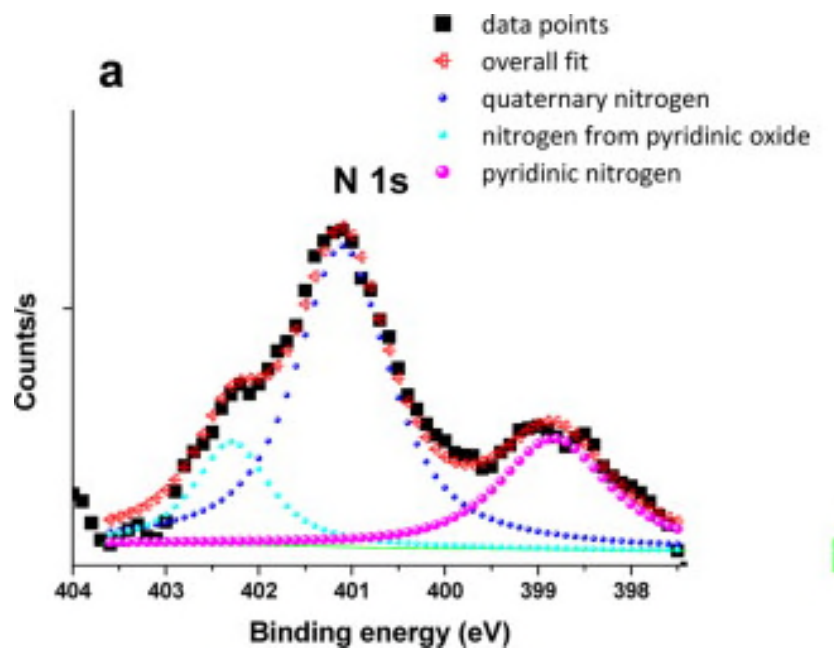

b

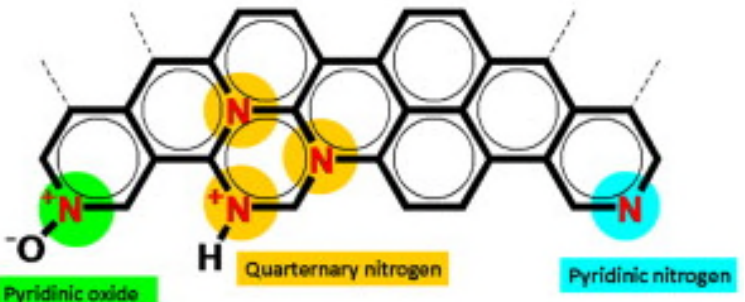

Figure 29. N1s XPS spectra of (a) N-CNT-750 and (b) the types of nitrogen species on the nitrogen-doped carbon nanotubes prepared by post-doping method. Reprinted with permission [115]. Copyright 2014 Elsevier. 
FIGURE 30
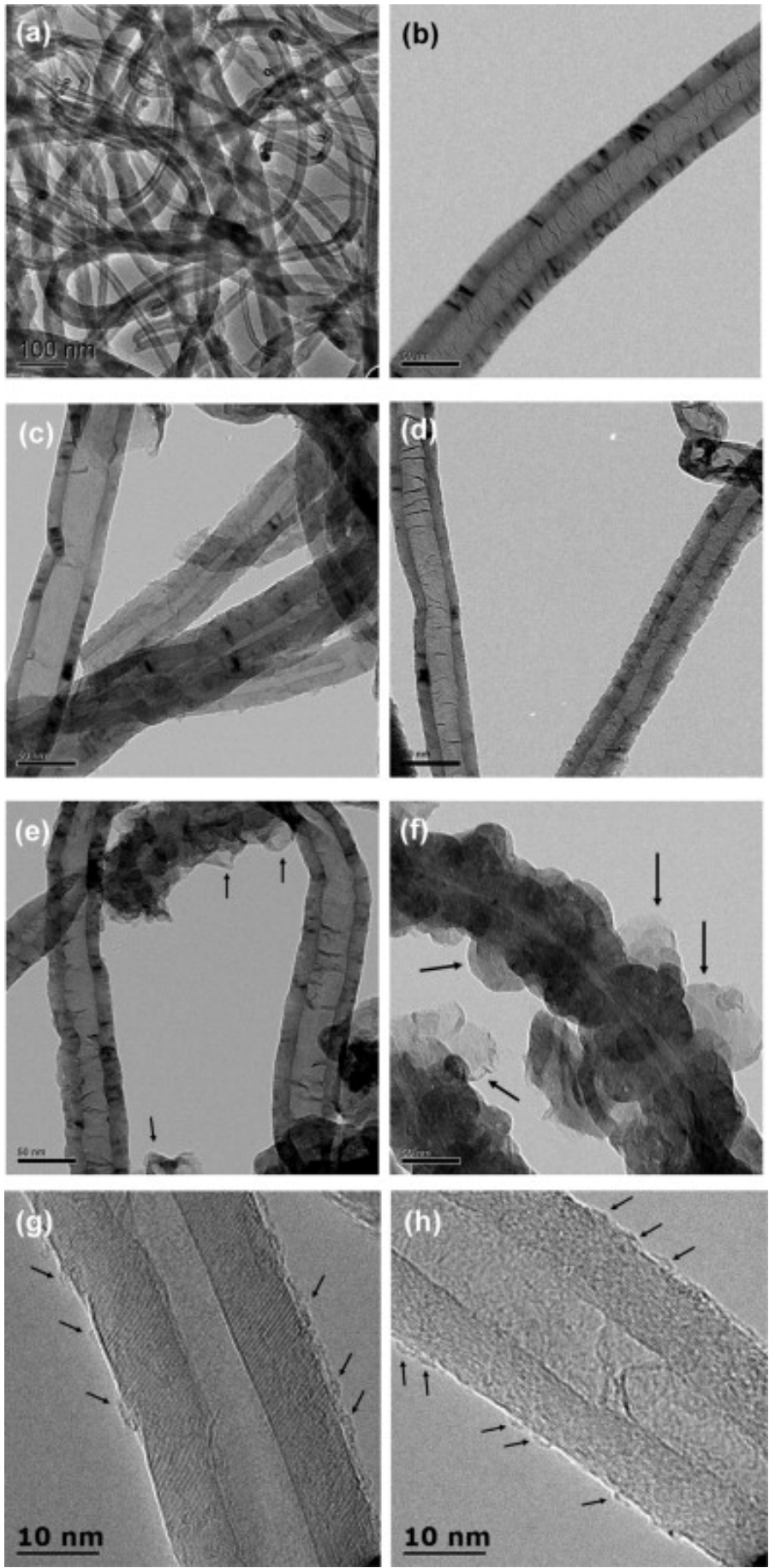

Figure 30. TEM images of CNTs and N-CNTs prepared by post-doping at different temperatures: (a) purified CNT; (b) N-CNT-700; (c) N-CNT-750; (d) N-CNT-800; (e) N-CNT850; (f) N-CNT-900; (g) and (h) HRTEM images of N-CNT-750 showing the formation of carbon-nitrogen fragments (arrows). Reprinted with permission [115]. Copyright 2014 Elsevier. 
FIGURE 31

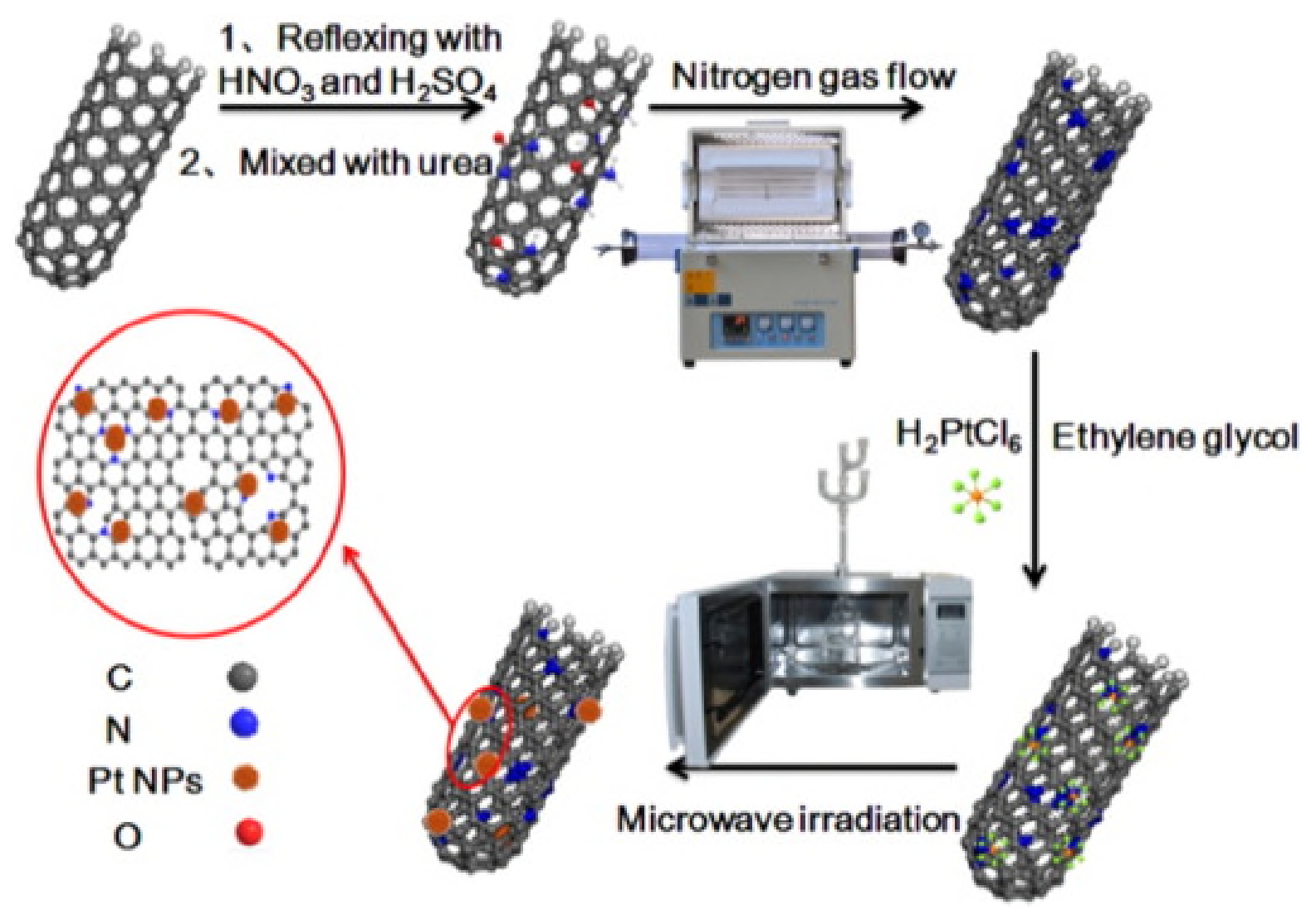

Figure 31. Preparation routine of Pt/N-MWCNTs. Reprinted with permission [117]. Copyright 2015 Elsevier. 
FIGURE 32
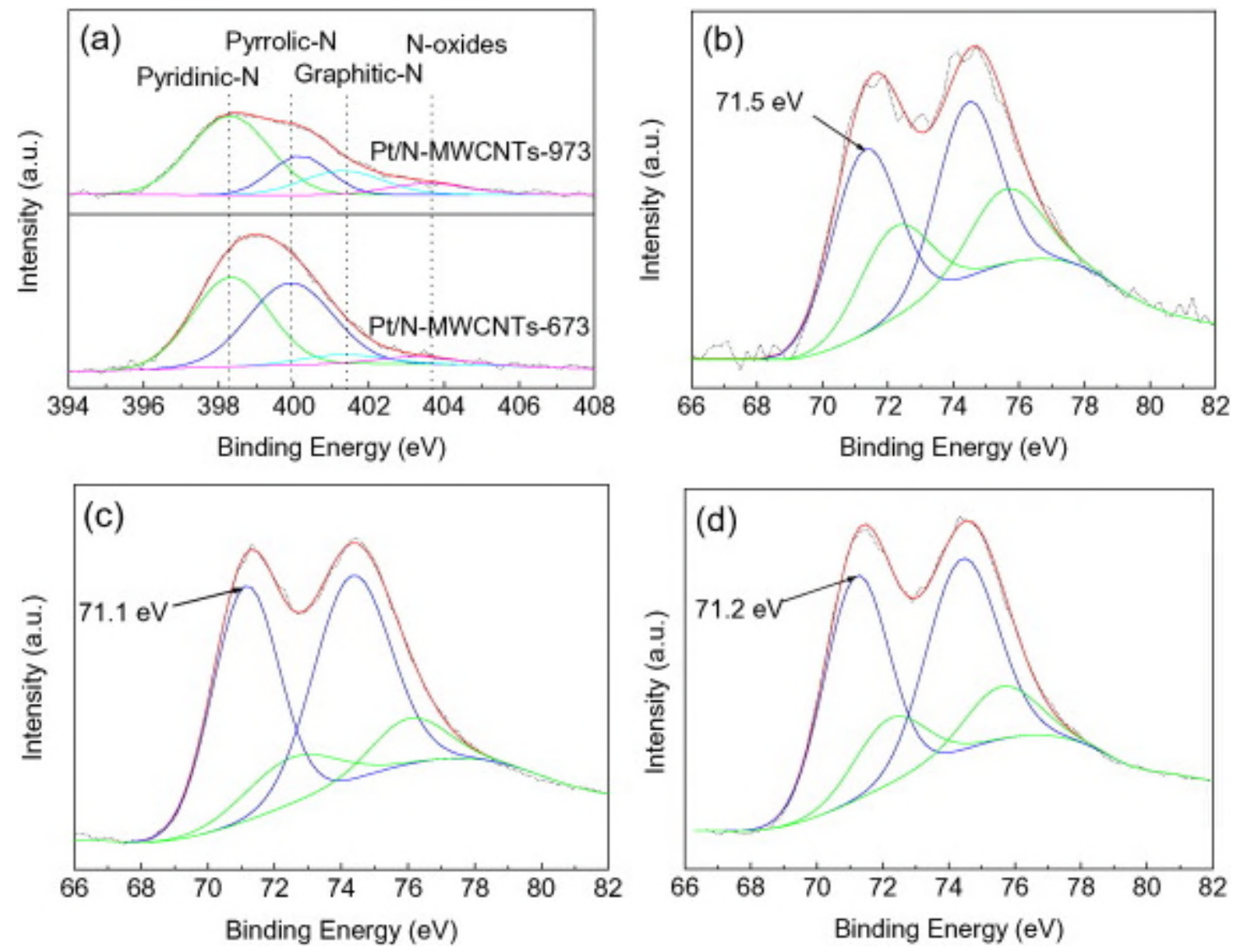

Figure 32. High resolution XPS analysis of $\mathrm{N} 1 \mathrm{~s}$ signals (a), Pt $4 \mathrm{f}$ spectra in Pt/MWCNTs (b), Pt/N-MWCNTs-673 (c) and Pt/N-MWCNTs-973 (d). Reprinted with permission [117]. Copyright 2015 Elsevier. 
FIGURE 33
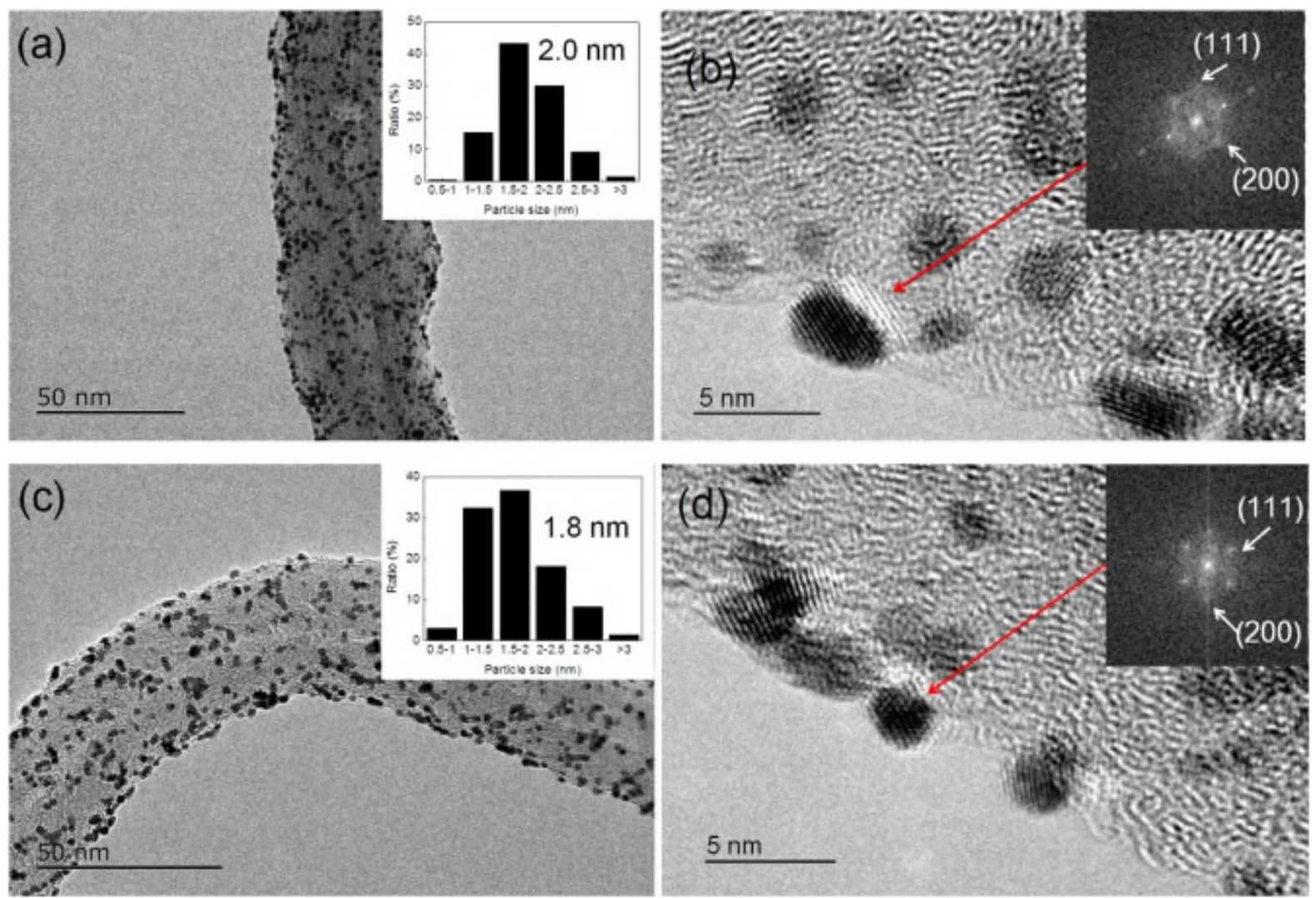

(e)

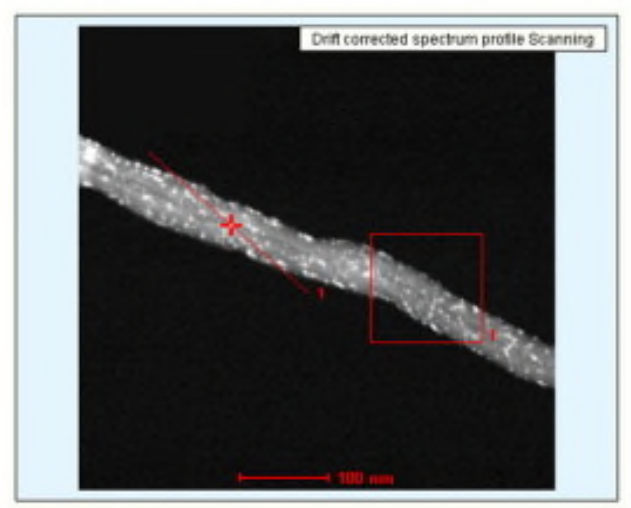

(f)

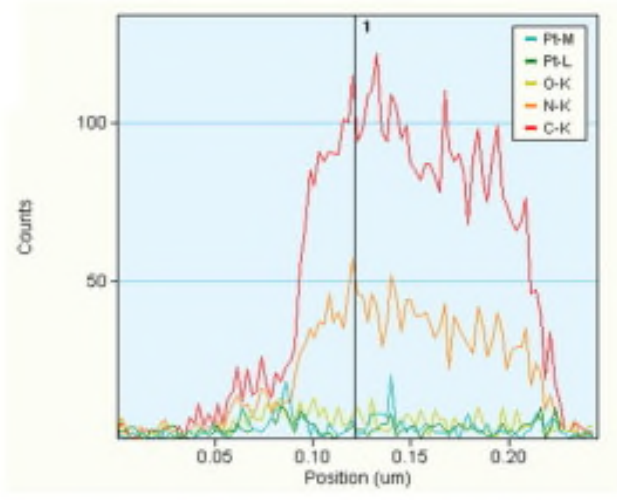

Figure 33. TEM images and corresponding FFT of Pt/N-MWCNTs-673 (a, b), Pt/NMWCNTs-973 (c, d) with particle size distributions, STEM (e) and elemental line scans (f) of Pt/N-MWCNTs-973. Reprinted with permission [117]. Copyright 2015 Elsevier. 
FIGURE 34
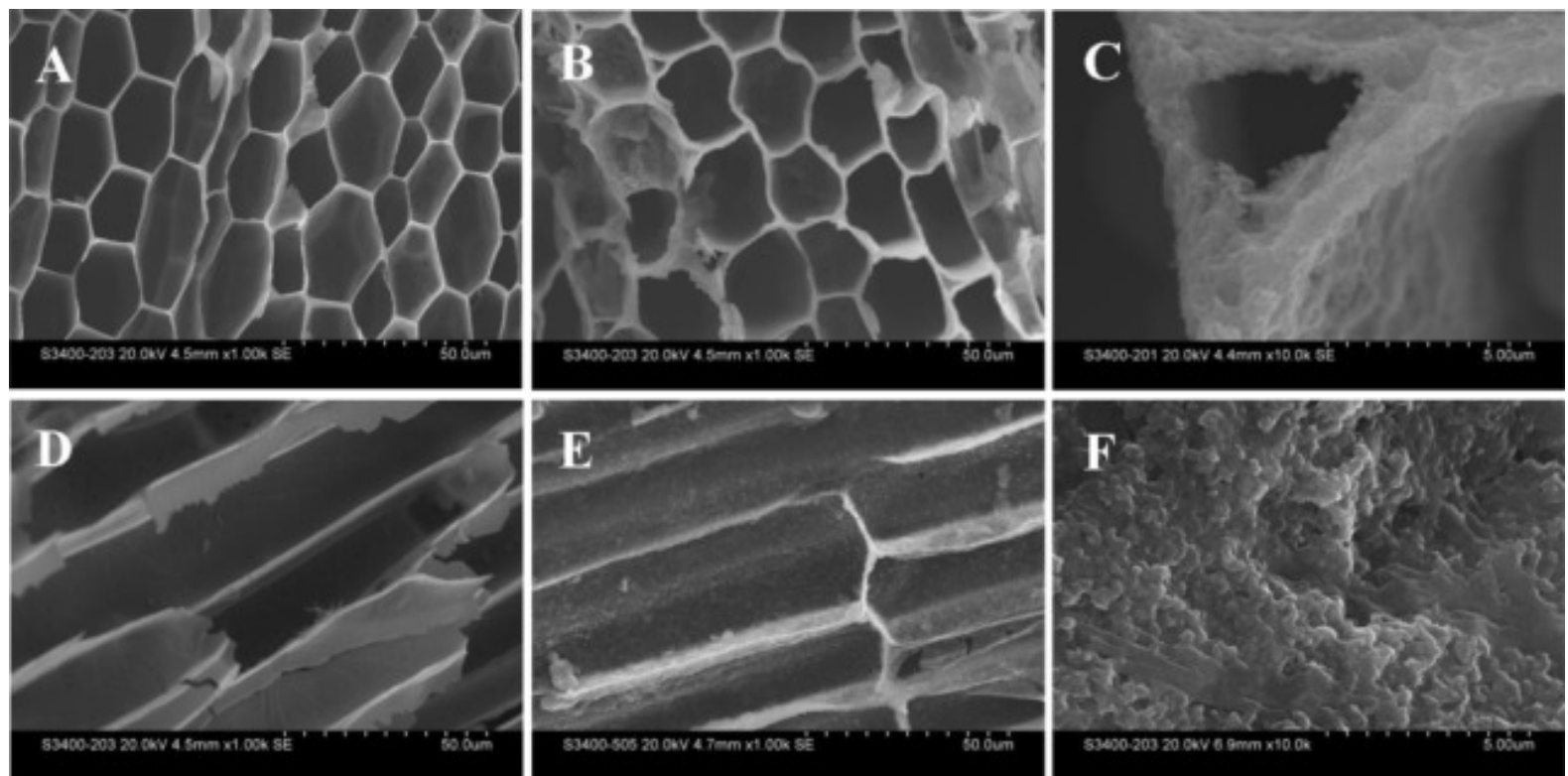

Figure 34. SEM images of KSC: (A) top view and (D) side view. SEM images of KSC/PANI: $(\mathrm{B}, \mathrm{C})$ top view and (E, F) side view. Reprinted with permission [120]. Copyright 2016 Elsevier. 
FIGURE 35
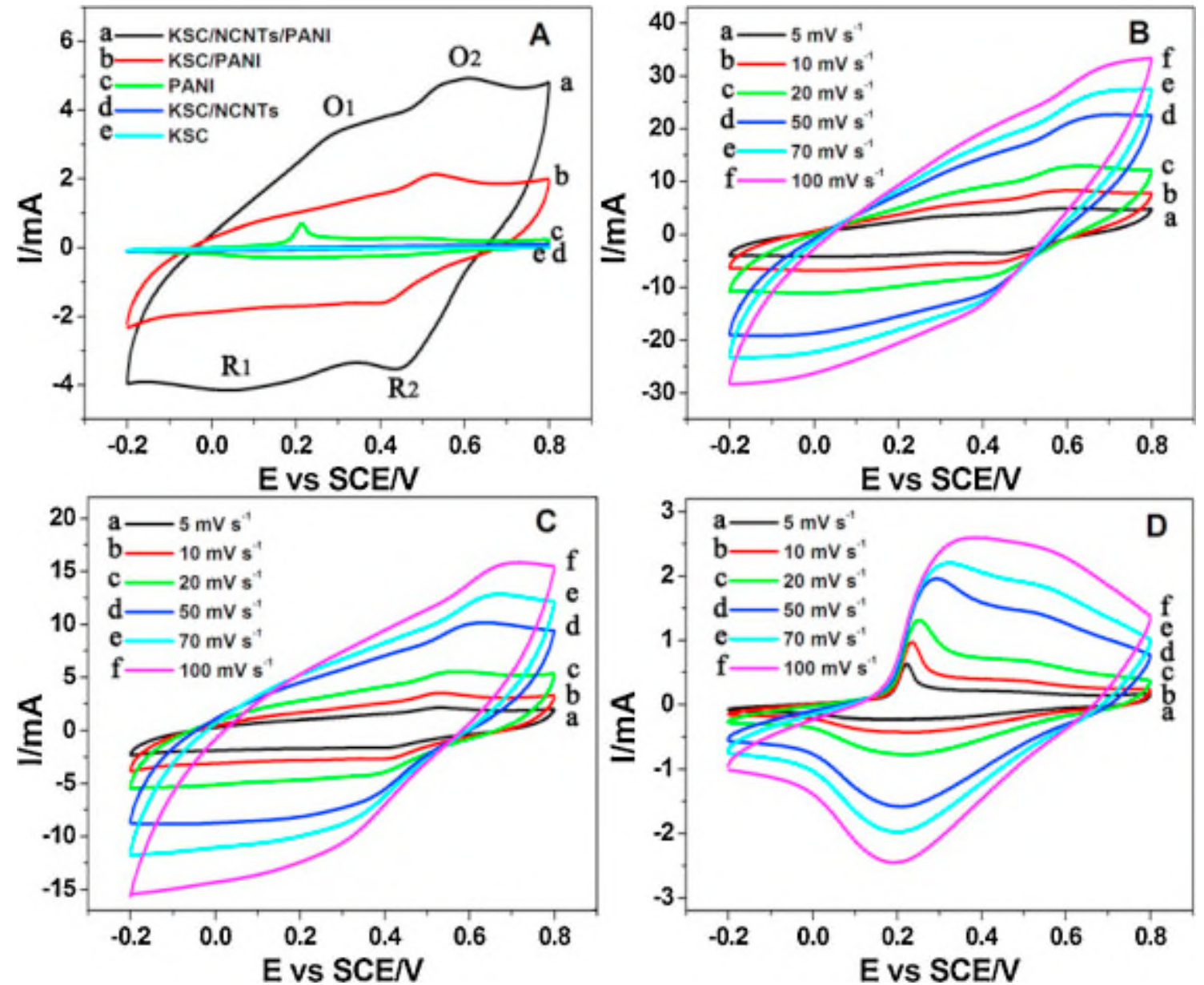

Figure 35. (A) CVs curves of KSC/NCNTs/PANI (curve a), KSC/PANI (curve b), PANI (curve c), $\mathrm{KSC} / \mathrm{NCNT}$ (curve d) and $\mathrm{KSC}$ (curve e) in $2 \mathrm{M} \mathrm{H}_{2} \mathrm{SO}_{4}$ solution at a scan rate of $5 \mathrm{mV} \mathrm{s}^{-1}$. (B-D) CVs curves of (B) KSC/NCNTs/PANI, (C) KSC/PANI, and (D) PANI in $2 \mathrm{M}$ $\mathrm{H}_{2} \mathrm{SO}_{4}$ solution with different scan rates. Reprinted with permission [120]. Copyright 2016 Elsevier. 
FIGURE 36
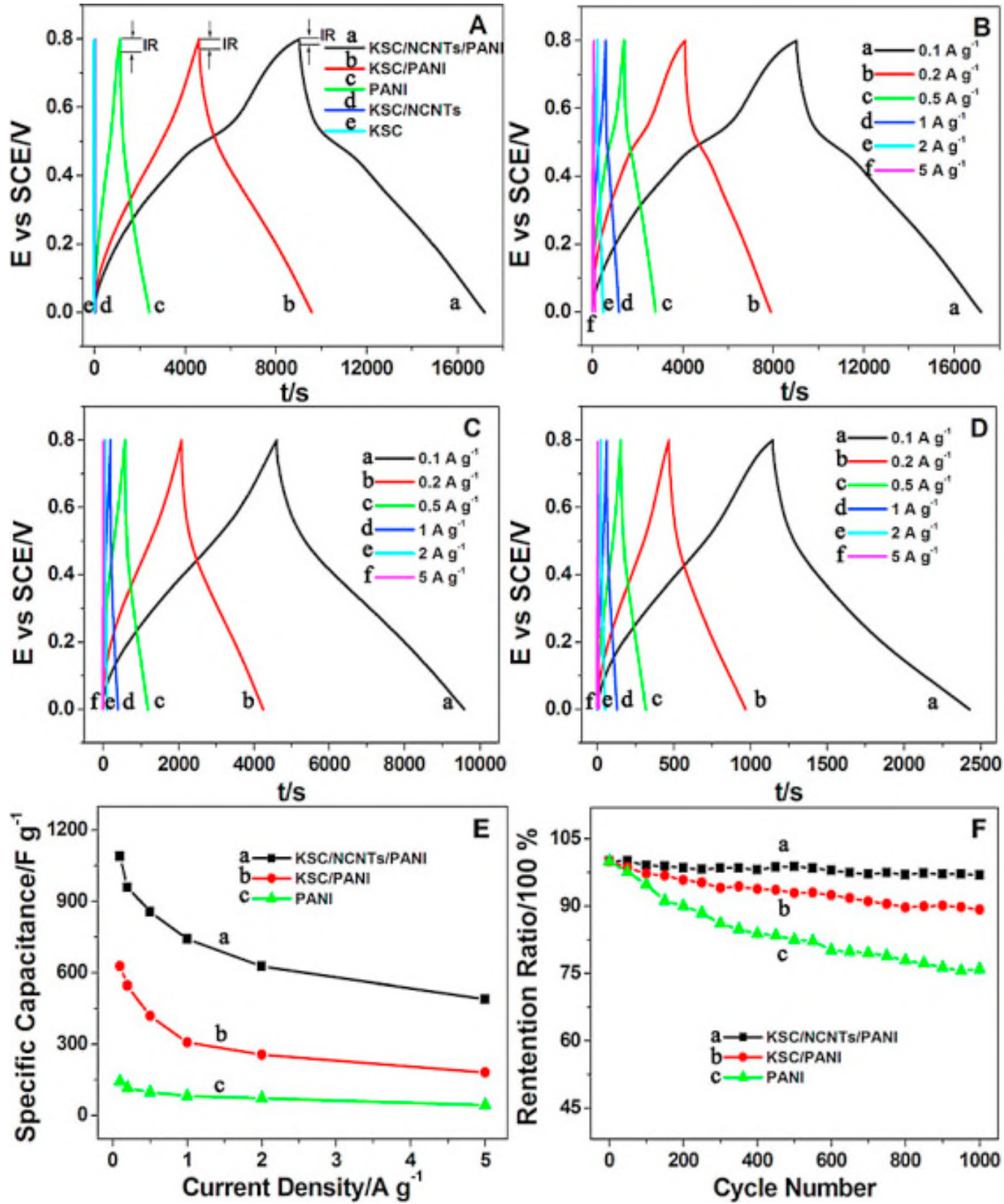

Figure 36. (A) Charge-discharging curves of KSC/NCNTs/PANI (curve a), KSC/PANI (curve b), PANI (curve c), KSC/NCNTs (curve d) and $\mathrm{KSC}$ (curve e) in $2 \mathrm{M} \mathrm{H}_{2} \mathrm{SO}_{4}$ solution at current density of $0.1 \mathrm{~A} \mathrm{~g}^{-1}$. (B-D) Charge-discharging curves of (B) KSC/NCNTs/PANI, (C) $\mathrm{KSC} / \mathrm{PANI}$, and (D) PANI in $2 \mathrm{M} \mathrm{H}_{2} \mathrm{SO}_{4}$ solution at different current densities. (E) Specific capacitance plots at different current densities. (F) Plots of cycle life test of KSC/NCNTs/PANI (curve a), KSC/PANI (curve b), and PANI (curve c). Reprinted with permission [120]. Copyright 2016 Elsevier. 
FIGURE 37
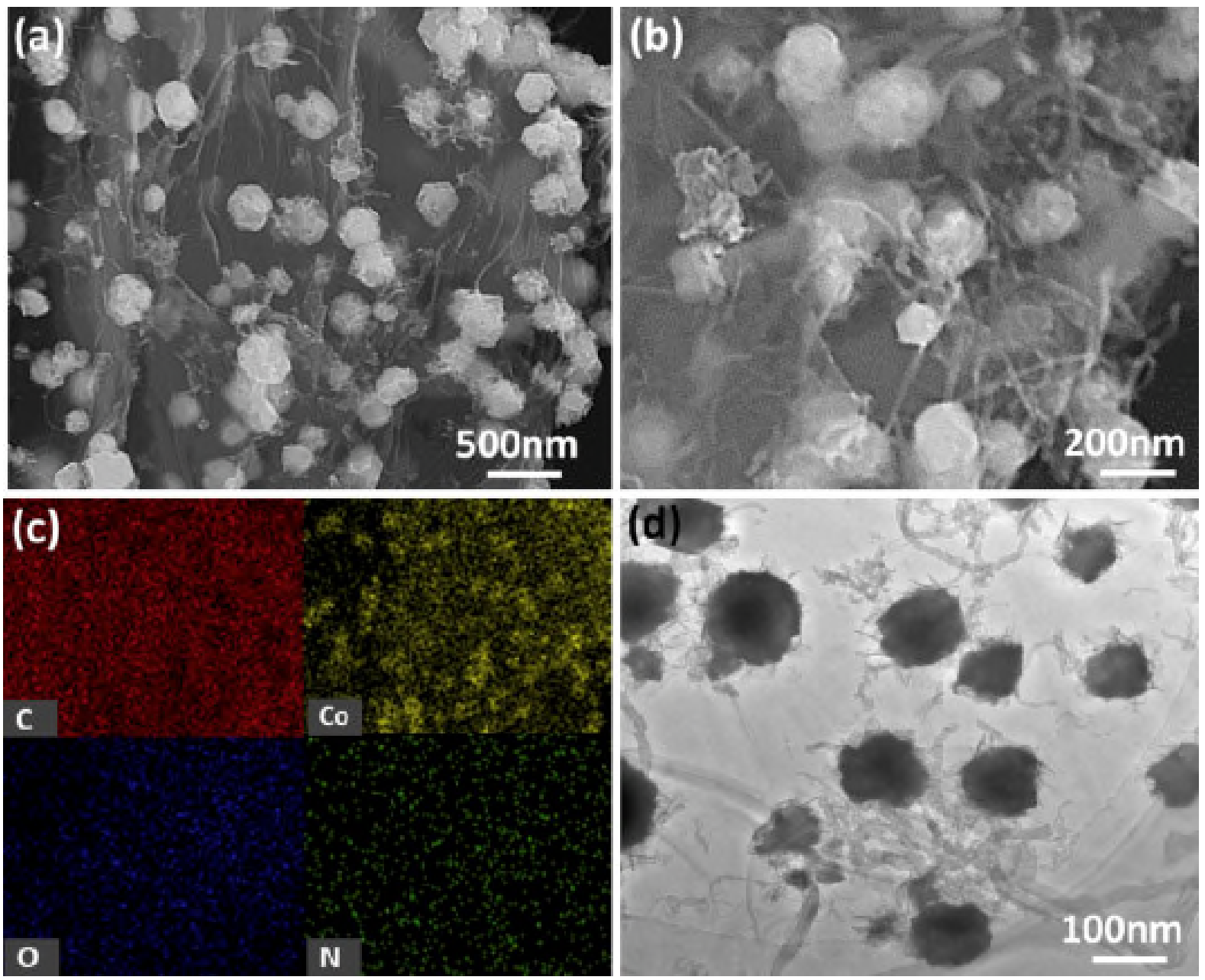

Figure 37. (a) Low- and (b) high-magnification SEM images, (c) EDS mappings and (d) TEM of $\mathrm{Co}_{3} \mathrm{O}_{4} /$ nitrogen-doped graphene/carbon nanotubes. Reprinted with permission [121]. Copyright 2015 Elsevier. 
FIGURE 38
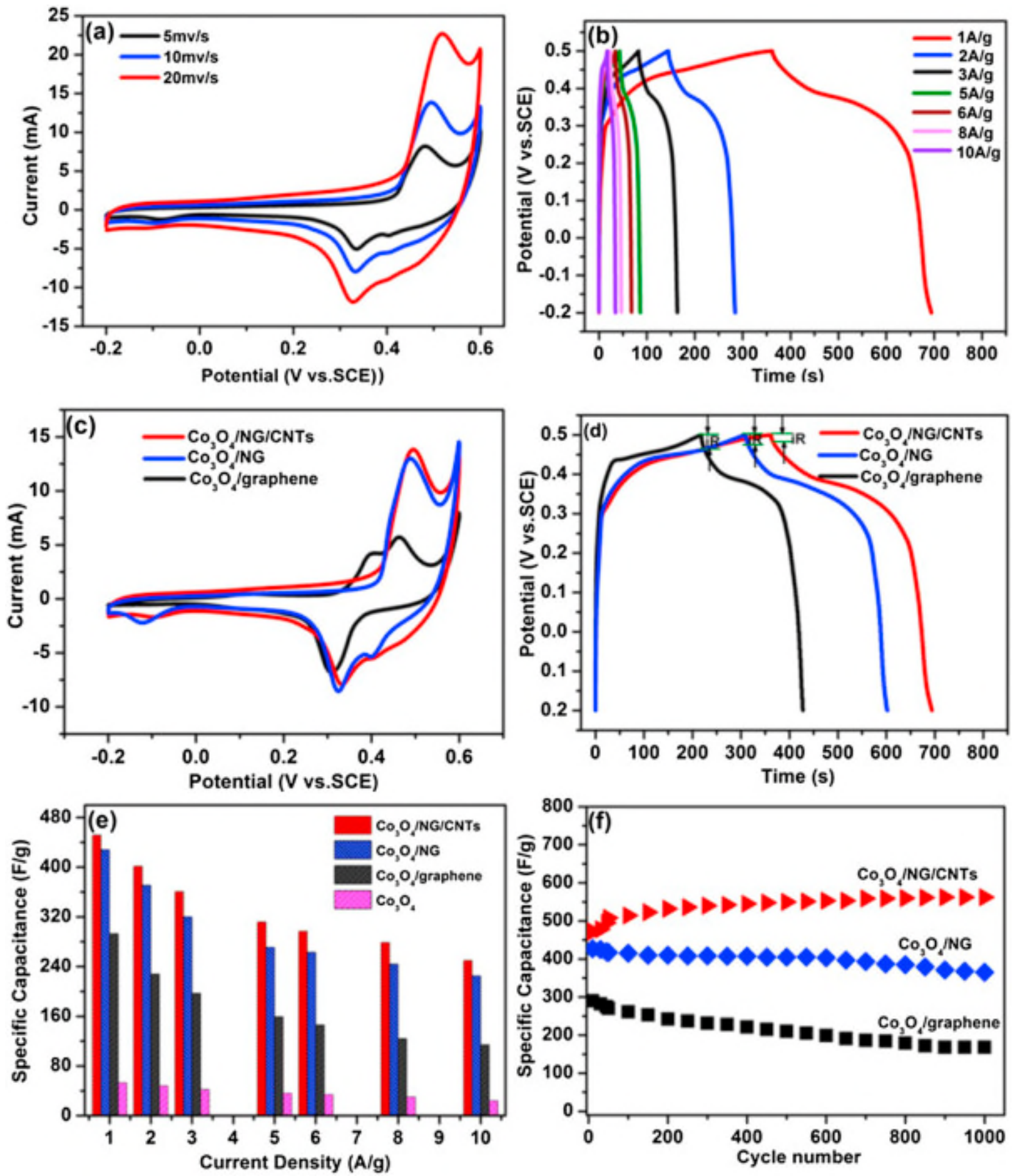

Figure 38. (a) $\mathrm{CV}$ of $\mathrm{Co}_{3} \mathrm{O}_{4} / \mathrm{NG} / \mathrm{CNT}$ s at different scan rates, (b) $\mathrm{GCD}$ of $\mathrm{Co}_{3} \mathrm{O}_{4} / \mathrm{NG} / \mathrm{CNTs}$ at different current densities, (c) $\mathrm{CV}$ curves of $\mathrm{Co}_{3} \mathrm{O}_{4} / \mathrm{NG} / \mathrm{CNTs}, \mathrm{Co}_{3} \mathrm{O}_{4} / \mathrm{NG}$ and $\mathrm{Co}_{3} \mathrm{O}_{4} /$ graphene at $10 \mathrm{mVs}^{-1}$, (d) GCD curves $\mathrm{Co}_{3} \mathrm{O}_{4} / \mathrm{NG} / \mathrm{CNTs}, \mathrm{Co}_{3} \mathrm{O}_{4} / \mathrm{NG}$ and $\mathrm{Co}_{3} \mathrm{O}_{4} /$ graphene at $1 \mathrm{Ag}^{-1}$, (e) the specific capacitance comparison of $\mathrm{Co}_{3} \mathrm{O}_{4} / \mathrm{NG} / \mathrm{CNTs}, \mathrm{Co}_{3} \mathrm{O}_{4} / \mathrm{NG}, \mathrm{Co}_{3} \mathrm{O}_{4} /$ graphene and $\mathrm{Co}_{3} \mathrm{O}_{4}$ at different current densities and (f) cycle life of $\mathrm{Co}_{3} \mathrm{O}_{4} / \mathrm{NG} / \mathrm{CNTs}, \mathrm{Co}_{3} \mathrm{O}_{4} / \mathrm{NG}$ and $\mathrm{Co}_{3} \mathrm{O}_{4} /$ graphene at $1 \mathrm{Ag}^{-1}$ in $6 \mathrm{M} \mathrm{KOH}$ aqueous solution. Reprinted with permission [121]. Copyright 2015 Elsevier. 
FIGURE 39

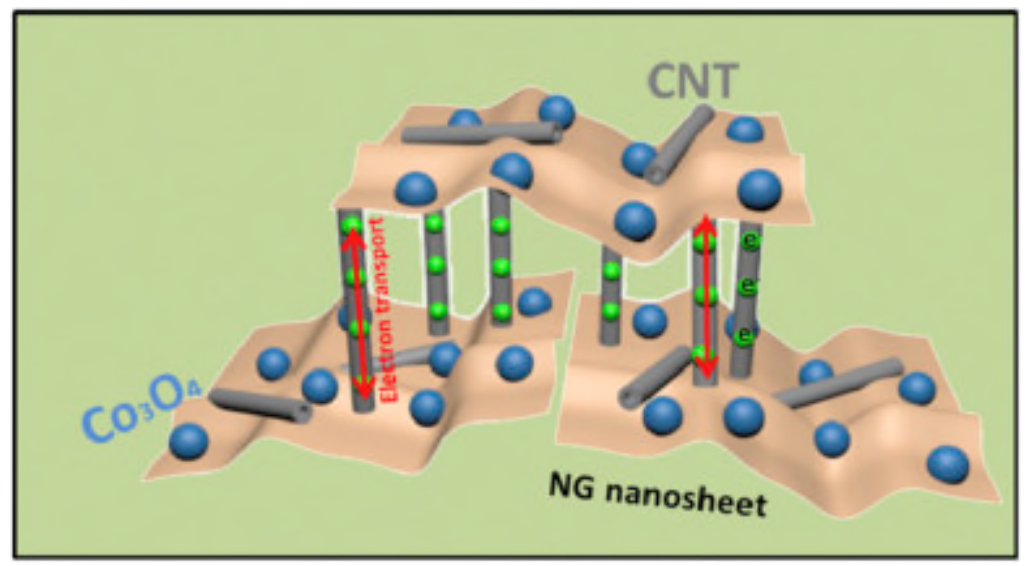

Figure 39. Schematic representation of structure and energy storage characteristics of the $\mathrm{Co}_{3} \mathrm{O}_{4} / \mathrm{NG} / \mathrm{CNTs}$ composite. Reprinted with permission [121]. Copyright 2015 Elsevier. 
FIGURE 40

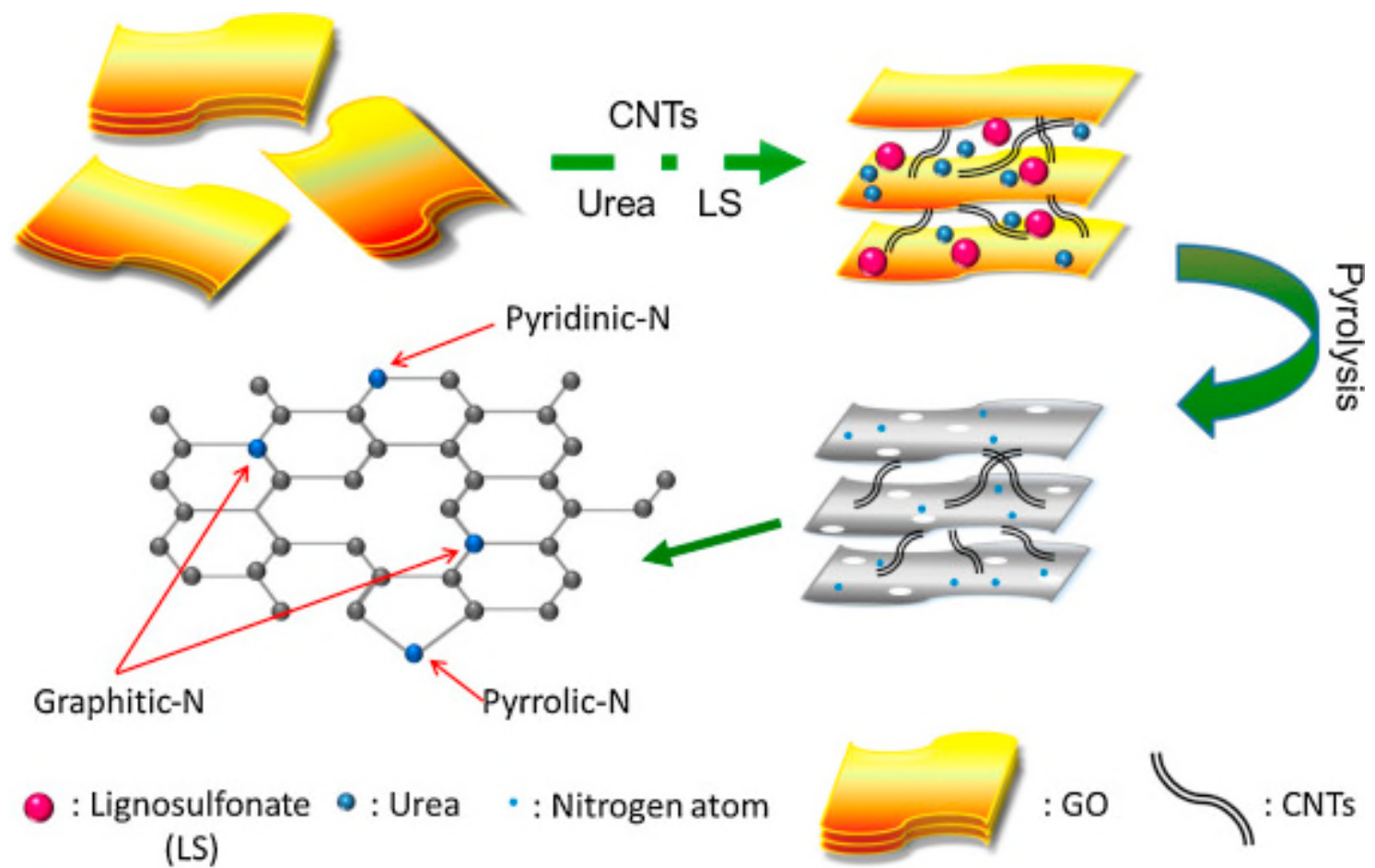

Figure 40. Schematic representation of preparation procedure of PNGC. Reprinted with permission [122]. Copyright 2015 Elsevier. 
FIGURE 41
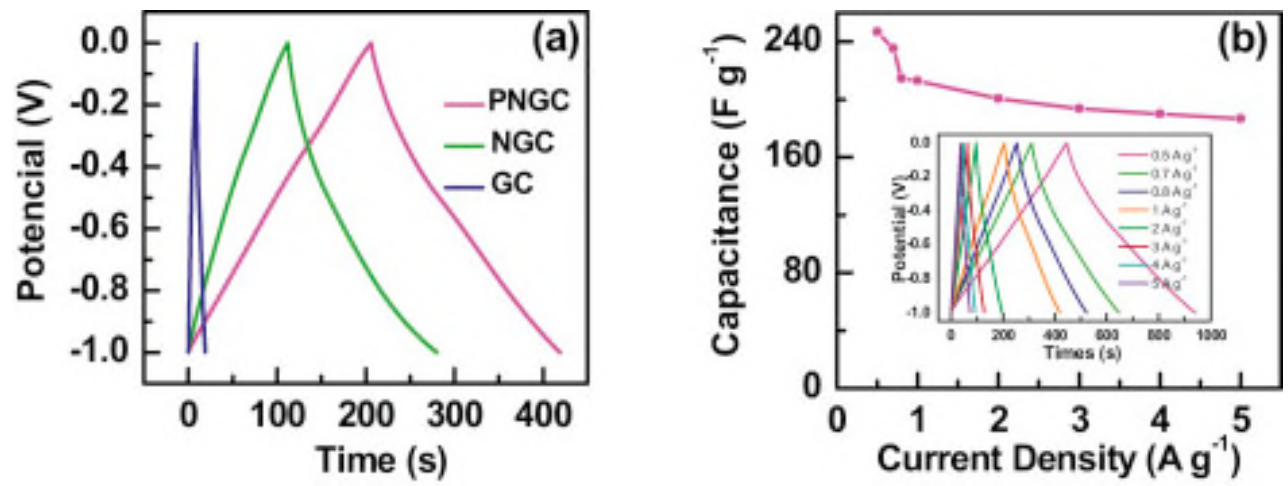

Figure 41. (a) GCD curves of GC, NGC and PNGC at a current density of $1 \mathrm{~A} \mathrm{~g}^{-1}$, and (b) Specific capacitance of PNGC at different current densities from 0.5 to $5.0 \mathrm{~A} \mathrm{~g}^{-1}$ (inset shows GCD curves of PNGC at different densities). Reprinted with permission [122]. Copyright 2015 Elsevier. 
FIGURE 42

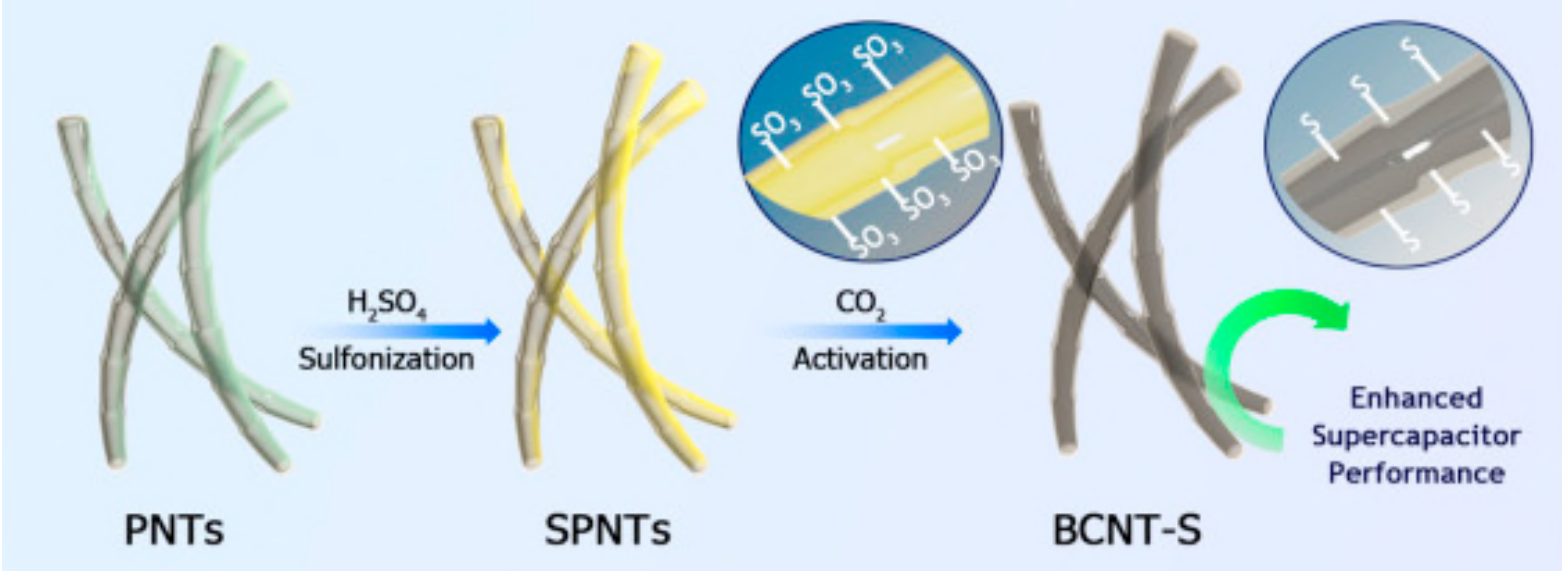

Figure 42. Schematic diagram for preparation of BCNT-S. Reprinted with permission [124]. Copyright 2016 Elsevier. 
FIGURE 43

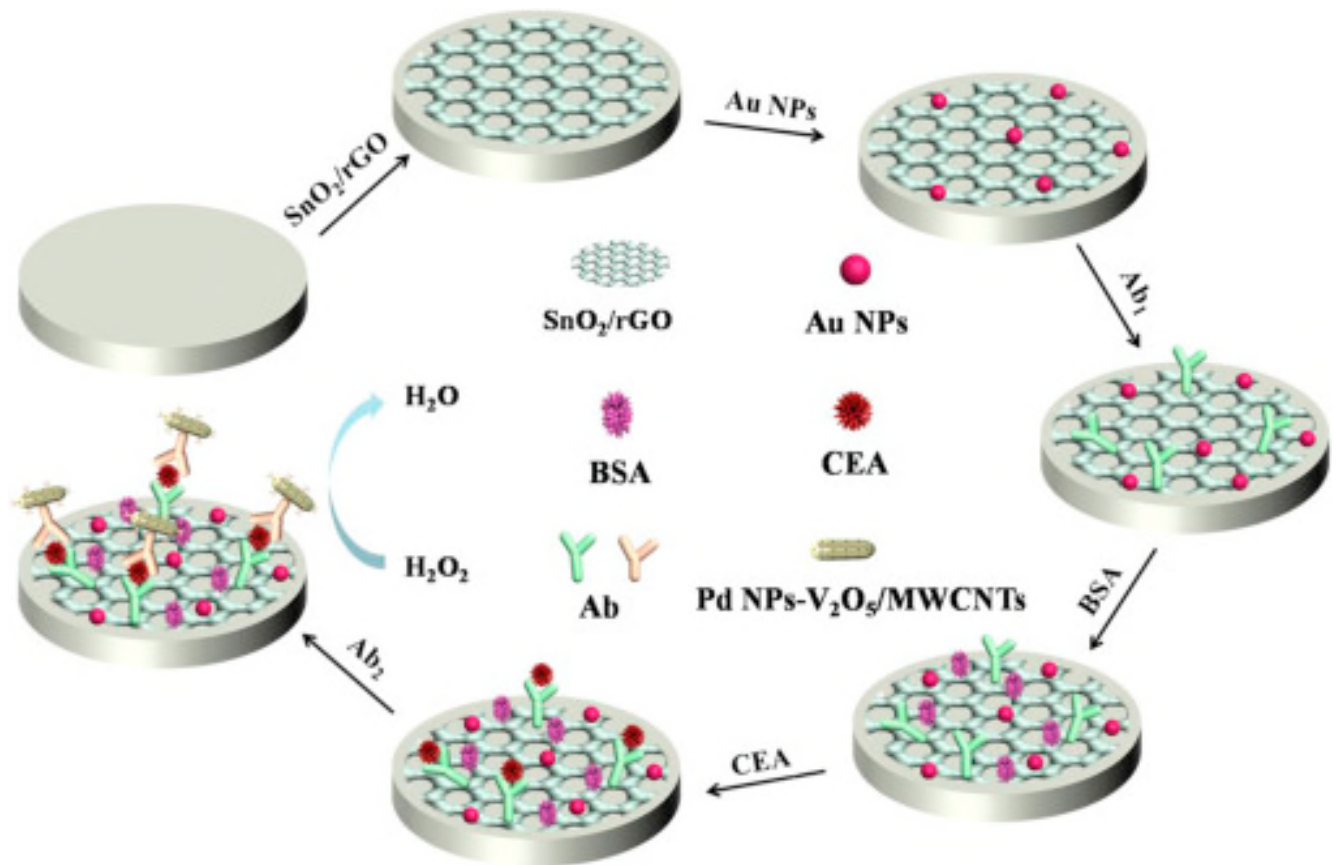

Figure 43. The fabrication steps of a typical immunosensor. Reprinted with permission [128]. Copyright 2016 Elsevier. 


\section{FIGURE 44}
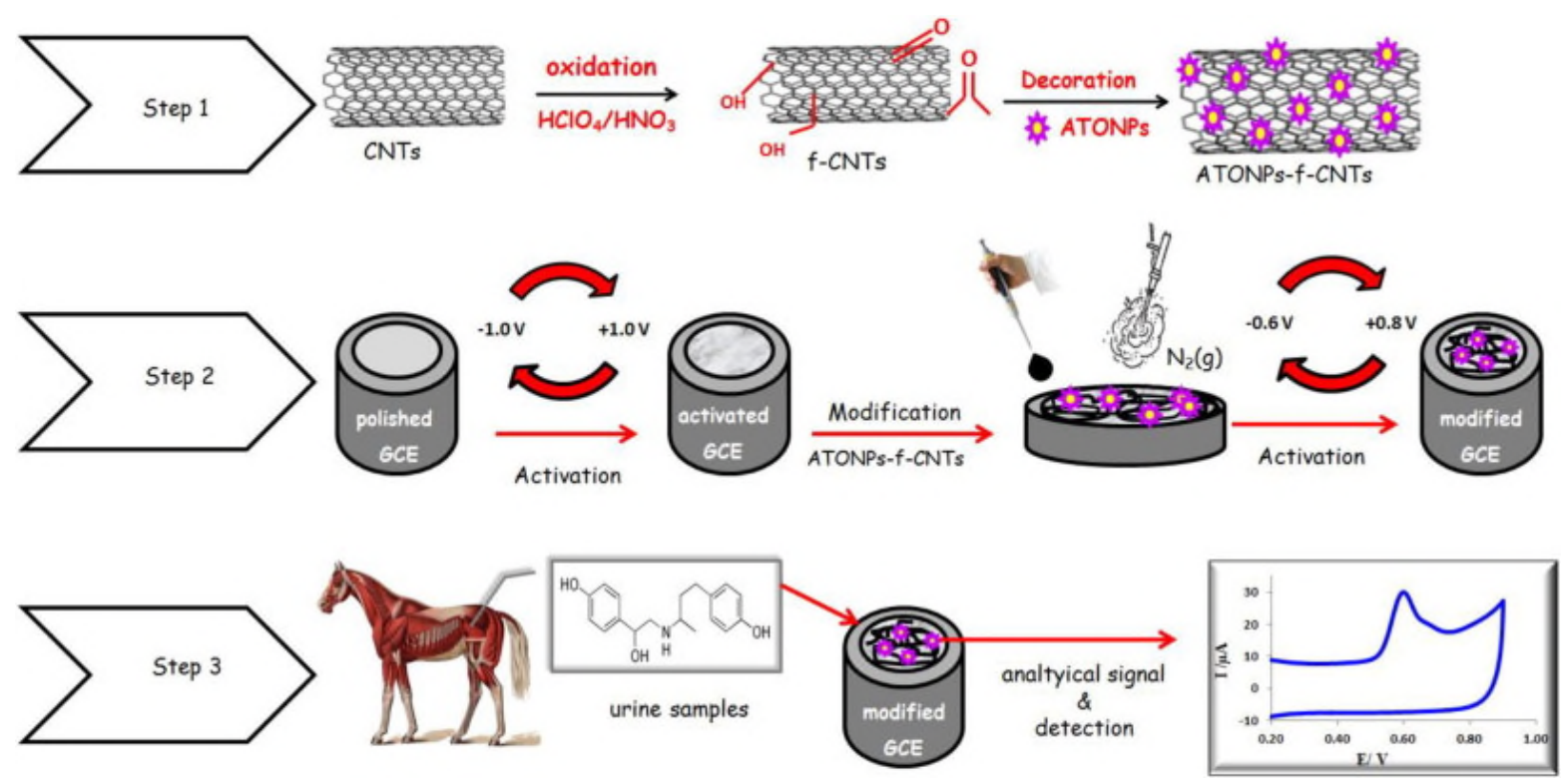

Figure 44. A schematic illustration of the proposed electrode. 
2018-05-22

Fundamentals and scopes of doped carbon nanotubes towards energy and biosensing applications

\author{
Muhulet, Alexandru
}

Elsevier

Muhulet A, Miculescu F, Voicu SI, et al., (2018) Fundamentals and scopes of doped carbon nanotubes towards energy and biosensing applications. Materials Today Energy, Volume 9, September 2018, pp.154-186

https://doi.org/10.1016/j.mtener.2018.05.002

Downloaded from Cranfield Library Services E-Repository 